Craig Addison Rohe, BA, Brock University, 2009

\author{
A Major Research Paper \\ Presented to Ryerson University
}

In partial fulfillment of the requirements for the degree of

\author{
Master of Planning \\ In \\ Urban Development
}

Toronto, Ontario, Canada, 2011

(C) Craig Rohe, 2011 
I hereby declare that I am the sole author of this major research paper.

I authorize Ryerson University to lend this paper to other institutions or individuals for the purpose of scholarly research.

I further authorize Ryerson University to reproduce this paper by photocopying or by other means, in total or in part, at the request of other institutions or individuals for the purpose of scholarly research. 


\title{
HOUSEHOLD SIZE AS A DETERMINANT OF ANNUAL SHELTER AND TRANSPORTATION EXPENDITURES IN CANADA
}

\author{
C Craig Addison Rohe, 2011 \\ Master of Planning \\ in \\ Urban Development \\ Ryerson University
}

\begin{abstract}
In Canada, households spend the most significant portions of their annual income on shelter and transportation. Recent academic literature has suggested that increased investments in shelter can reduce annual transportation costs for household. The rationale behind this trade off has traditionally been density, whereas those households living in high density neighbourhoods have access to additional forms of transportation which invariably lowers annual transportation expenditures. Using data from the 2008 Survey of Household Spending, respondent households within urban communities of 100,000 or more persons in Quebec, Ontario, Alberta and British Columbia were used to test the assumed trade-off curve. The analysis provided shows that increases in shelter expenditures will lead to an increase in transportation expenditures in all cases, and that household size, not density, is the determining variable. The analysis provided is intended to make academics and urban planners reconsider their presumptions about density as they plan for an increasing urban population across the nation.
\end{abstract}

Key words: Household Expenditures; Transportation; Shelter; Household Size; Density. 


\section{Acknowledgements}

I would like express my sincere thanks to Dr. Murtaza Haider for overseeing this paper. He has encouraged me to think critically about urban issues and the importance of fact. I am ever grateful for your time and motivation to create a great paper.

I also would like to thank Dr. Christopher Fullerton, the second reader of this Major Research Project. You have inspired my career aspirations and have undeniably made me the student and professional I am today.

On a personal note I would like to thank my peers for keeping me motivated over the past two years. I wish you well in your future careers and hope we meet again. 


\section{Table of Contents}

Introduction

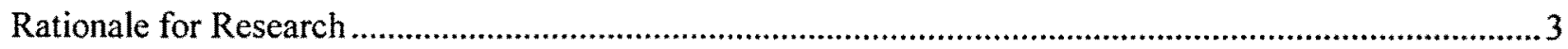

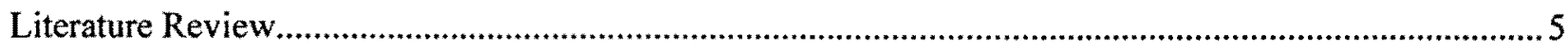

Understanding and Defining Household Transportation Expenditures ....................................................5

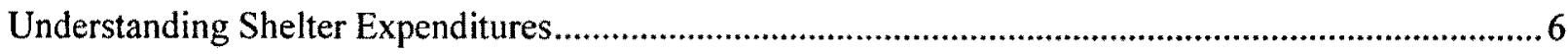

The Link between Geographic Location and Annual Expenditures .......................................................

Linking Household Expenditures and Income .........................................................................................

Determinants of Transportation Choices ......................................................................................

Calculating Household Transportation Expenditures in Canada ............................................................ 13

The Annual Costs of Transportation in Canada ................................................................................. 15

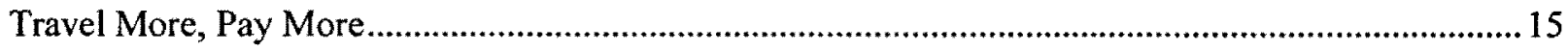

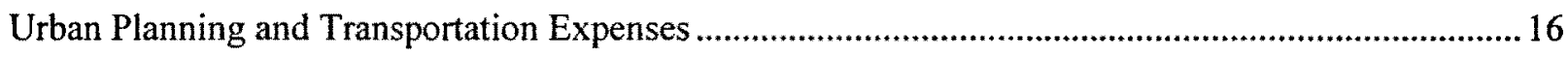

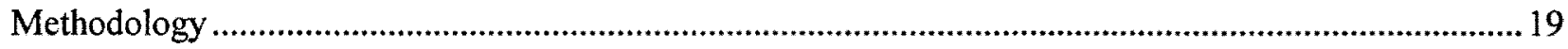

Survey of Household Spending, 2008 ........................................................................................... 19

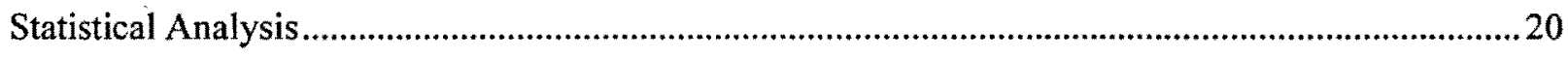

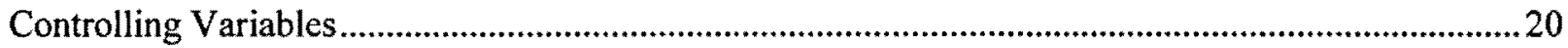

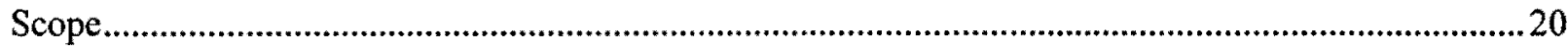

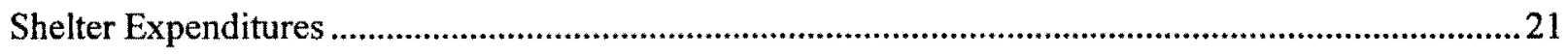

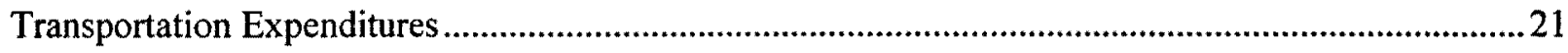

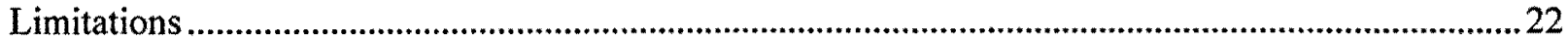

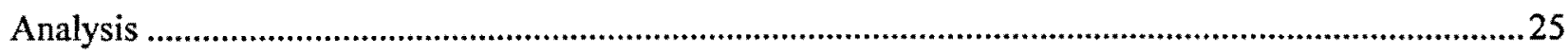

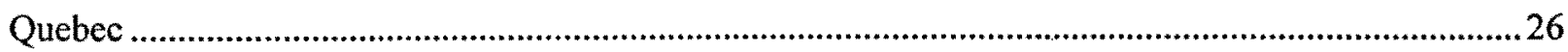

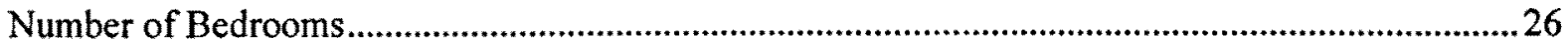

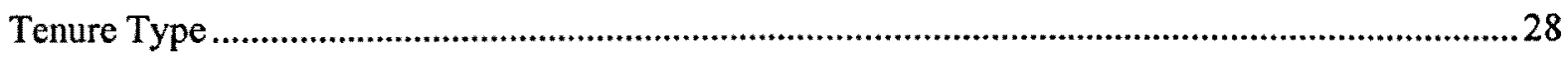

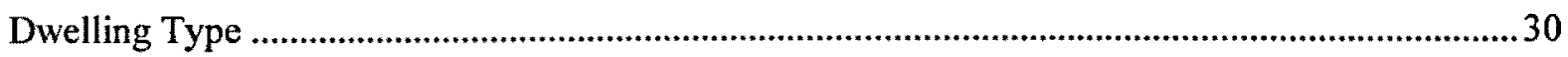

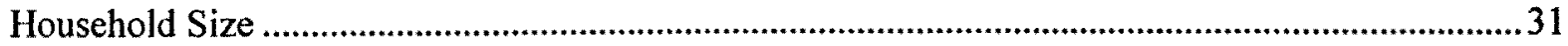

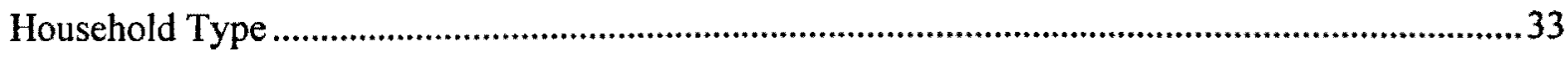

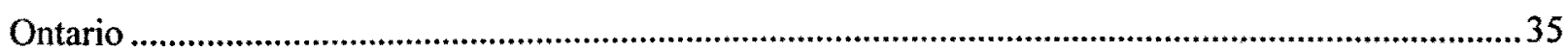

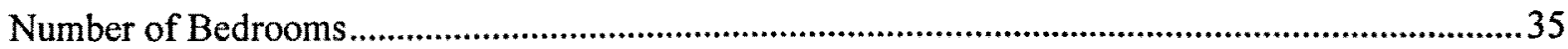

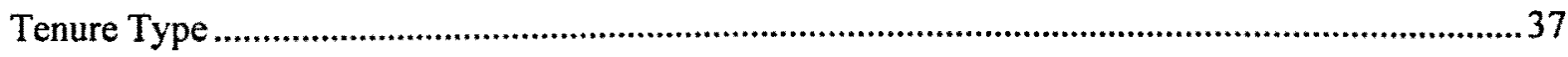

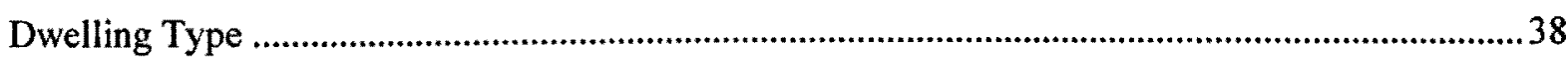

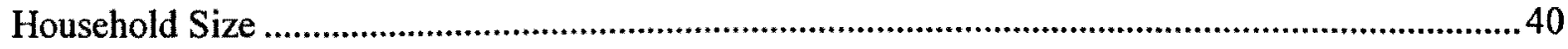


Household Type

Alberta .43

Number of Bedrooms 43

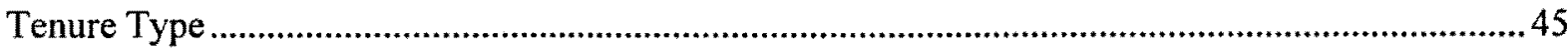

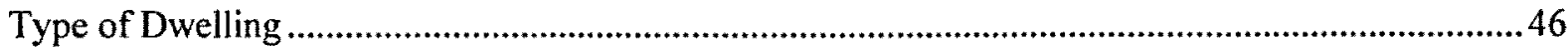

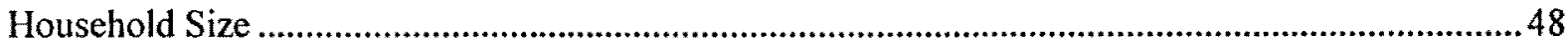

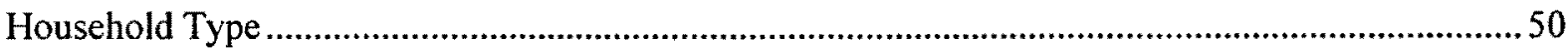

British Columbia

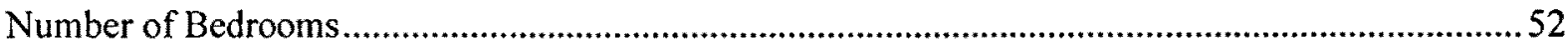

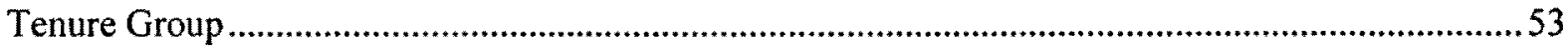

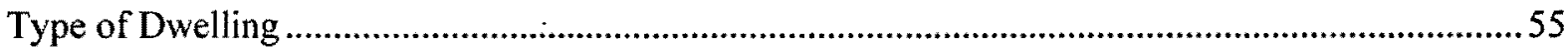

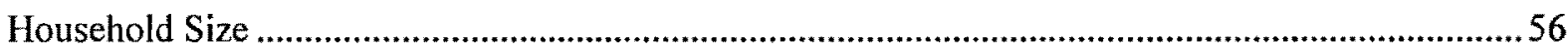

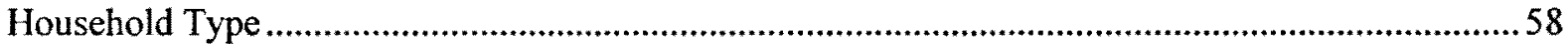

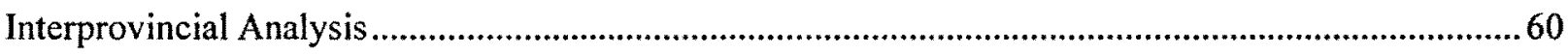

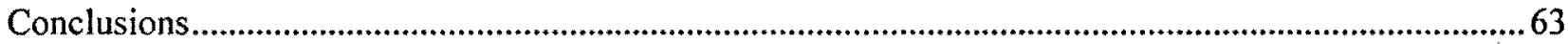

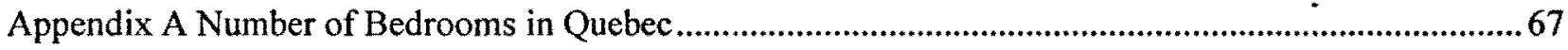

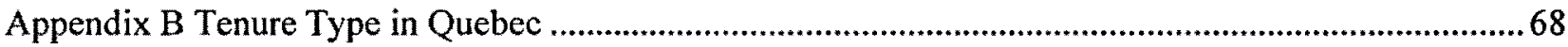

Appendix C Households by Dwelling Type in Quebec .................................................................................69

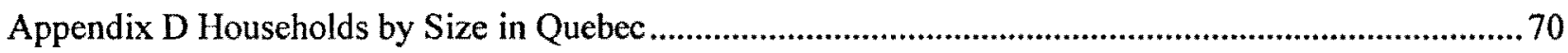

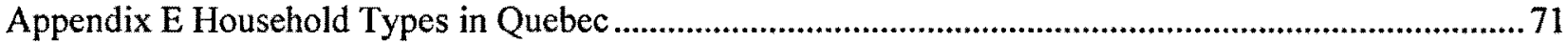

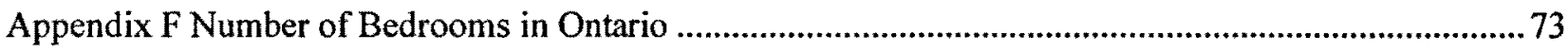

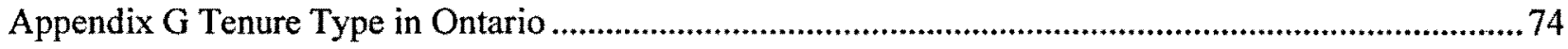

Appendix H Households by Dwelling Type in Ontario ............................................................................. 75

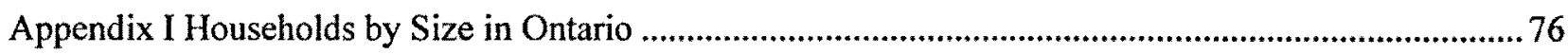

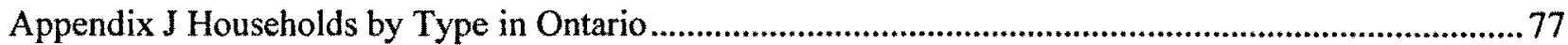

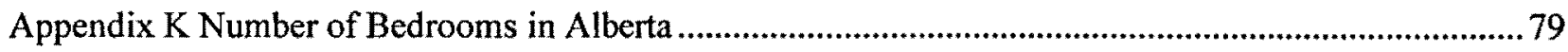

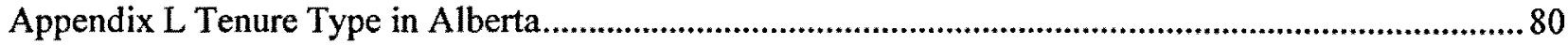

Appendix M Households by Dwelling Type in Alberta ............................................................................... 81

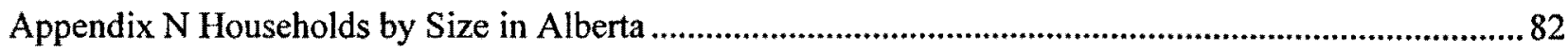

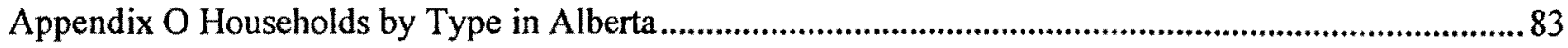

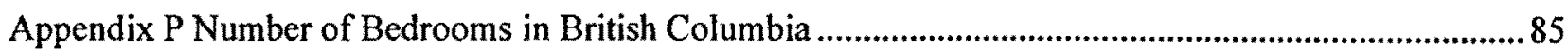

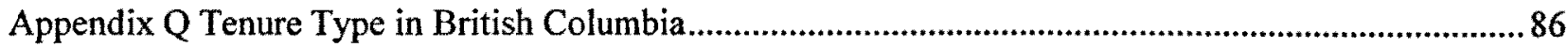

Appendix R Households by Dwelling Type in British Columbia....................................................................... 87 
Appendix S Household by Size in British Columbia ........................................................................ 88

Appendix T Household Types in British Columbia ............................................................................... 89

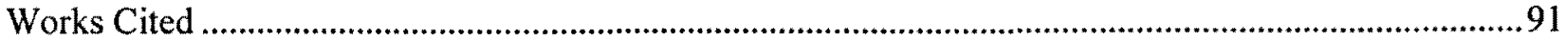




\section{Introduction}

Shelter and transportation are two of the highest annual expenditures for Canadian households. Investing in a home and the means to move around enables individuals to live and work in a way which reflects their lifestyle. Shelter costs include expenses such as mortgages, rents and fees, repairs and renovations and insurance premiums. These costs are all reflected in the type of home and are influenced by the characteristics of the households which reside within them. Transportation expenditures include the operational costs of private vehicles, and public transportation fees. By incurring transportation costs, Canadians enable themselves to get to work, the grocery store and necessary social services.

When shelter and transportation expenses are combined, they make up a significant portion of the household expenditure figure, which then can be compared to other cities, regions and provinces across Canada. These costs can vary significantly between areas (rural, urban) and household compositions, and thus knowing and understanding which variables influence annual shelter and transportation expenditures can planners better understand the residents they are planning for. This paper illustrates that it is actually the characteristics and size of a household which will influence the amount of annual income spent on shelter and transportation; not the density of an area, which is a common belief held by current planners and scholars alike. It will additionally prove that the theoretical model of high housing costs leading to lower transportation costs is incorrect, and that in actuality higher shelter expenses lead to higher transportation expenses because of increased needs for shelter and transportation from larger household units. 


\section{Rationale for Research}

As sustainable initiatives continue to overarch many urban agendas in order to increase environmental protection, economic growth and social equity, it is important to step back and take a look at the human element of settlement. In urban settings, sustainable development initiatives often include higher density development for its perceived economic, social and environmental advantages. High density development does have its merits; however, the rationale is usually based on environmental efficiencies, more opportunity for social interaction and a perceived drop in transportation expenses.

Every household has a unique set of needs, and living within new and sustainable compact environments (as well as many other things that appear to be part of a balanced and sustainable lifestyle) may not fit their lifestyles. Household size will dictate how individuals live and what expenses they will have to incur; whether it is the need for a larger, more expensive home or the operation of private automobiles. Understanding how the size of a household can influence annual expenditures might better inform future planning practitioners in large Canadian cities so as they may create economically sustainable communities that meet the needs of various types of households.

This research has been undertaken to re-evaluate the assumption that households within higher density environments have smaller annual transportation expenditures as a product of the built form. In academic literature, high density environments and transportation appear inseparable and are believed to be the remedy to reducing automobile dependence within Canadian municipalities. The causation between the choices to purchase expensive urban homes as opposed to the perceived reduced priced suburban homes and their subsequent transportation 
costs is derived from the needs of the household. This research will prove that household size and characteristics dictate how much households spent on shelter and transportation in 2008 . It further highlights that consistent arguments for higher density development and increased public transit investment in actuality only cater to smaller sized households, such as one to two person homes, which are predominantly rental properties. 


\section{Literature Review}

\section{Understanding and Defining Household Transportation Expenditures}

Understanding the scenarios and circumstance by which household costs are incurred and what they primarily consist of is necessary in order to understand why they are important. Academic focus into the subject of transportation costs and their role in daily life is not thoroughly explored, as initially transportation costs appear as a fairly basic concept. Most of the academic transportation cost research available is related to issues of infrastructure funding, fare structure and road pricing but there is an opportunity to explore the economic effects of household transportation expenditures in the daily life of Canadians. After examining the available research, it appears that there is some consensus surrounding a possible definition of transportation costs which can be constructed upon research by academics like Eric Miller, Brian Taylor, Alexandra Norton and J.C.D. Blaine.

One concept that may be shared by academics and researchers alike is that transportation costs are necessary charges incurred in order to satisfy daily needs or desires by members of a household. These charges could include fuel for a vehicle or buying a new bicycle to get to work; as long as the investment is justified. Norton and Taylor (2009) explain that transportation and its incorporated costs are the medium between home and an activity whereas "the demand for transportation is derived from a desire to consume non-transportation-related products and services and engage in non-transportation-related activities" (p.23). For example, unless a household member works from home, there is a guarantee that there will be a daily transportation cost incurred for access to work. Having access to transportation choices is enabling for a household, creating more opportunities for work, education, recreation, and health (p.23). Norton and Taylor's claims suggest that transportation is a very important investment, as it creates more 
opportunities for improving the quality of life. This could be taken a step further, in that the amount of annual income devoted to transportation can help us to understand the lifestyle of a given household. The necessity of transportation changes, as well as its cost, and is based on geography and the location of the household.

\section{Understanding Shelter Expenditures}

Shelter is a basic human need which comes in many forms; it also plays a significant role in the annual budgets of Canadians. Shelter is an expense which is interchangeable with other needs; seen as a trade-off by Eric Miller, Matthew J. Roorda, Murtaza Haider, and Abolfazl Mohammadian (2004). Households select the type and location of dwelling based on a number of different criteria, including cost, proximity to employment an entertainment and size of the household. Furthermore the benefits and shortfalls of shelter choices are often weighed against those of transportation when making a decision. Miller, Roorda, Haider and Abolfazl (2004) state that "By choosing different housing types at different locations, and by choosing different daily travel patterns and modes, each household can attempt to optimize its individual utility or well-being" (p.191), which illustrates that dwellings are not picked at random, but rather carefully by their future inhabitants to meet their daily needs in the most efficient way.

\section{The Link between Geographic Location and Annual Expenditures}

Transportation costs and household location are inherently linked as distance from services or work will dictate how far one must travel which will in turn create cost. Essentially, the further away a household is from the downtown of a city, the more likely higher transportation costs will be incurred due to the necessary need for a private automobile or additional public transit. While post-war populations moved further away from the centre of the city in the 1950's and 1960's to 
enjoy an improved quality of life and give birth to children, the exodus was supplemented by the absorption of higher transportation costs. Early writings on this subject, such as J.C.D. Blaine's 'Dynamics of Transportation' (1967), communicate the past perception that the urban shift further away from the core would reduce transportation costs, stating that "the handicap of space has been greatly reduced through more effective mobility which has in effect annihilated distances in terms of time and cost and extended the area of man's influence" (p.21). The preconceptions were proven erroneous over the past 50 years as the expansion of cities led to a need for increased accessibility and mobility. In 2004, a study by Eric Miller Matthew J. Roorda, Murtaza Haider, and Abolfazl Mohammadian on expenditures for shelter and transportation successfully showed an increase in average household expenditures as distance from Toronto's CBD increased (p.198). This study further counters Blaine's argument that increases in distance from central areas results in a reduction of household expenditures. A similar study on tradeoffs between shelter and transportation expenditures by Glen Weisbrod, Moshe Ben-Akiva and Steven Lerman (1978) suggests that related household expenses can have significant impacts on the choice of shelter and transportation stating that "Depending on how they are structured, rent control, rent subsidies, tax advantages, mortgage ceilings, and other price-related policies can potentially offset or enhance the impacts of transportation investments" (p.9). Cities inevitably will expand, yet, blaming sprawl for the increase in private automobile usage and its associated costs is flawed; a more appropriate critique may be better directed at the failure to invest and supply competitive public transit service as well as the limited promotion of complete, walkable neighbourhoods. 
The role which transportation plays in Canadian life is a product of years of planning history and investment. "As public investment in transportation began to focus more on the building of roads and highways, private spending on transportation skyrocketed" (Surface Transport Policy Project, 2003). As Eric Miller and Amer Shalaby (2003) have theorized, "As a society, we respect the rights of individuals to choose to live and travel where and how they wish within the context of a market-based economy. Currently, many people seem to prefer a suburban, autooriented lifestyle" (p.24). The cities Canadians desired and created over time are ones built upon the necessity of mobility which is intrinsically tied to the importance of household transportation investment. There are several factors influencing why persons choose to live where they do which in turn determines their transportation costs, as noted by Marine van Geenhuizen and Peter Nijkamp (2003). "Location and travel decisions are not taken in a Robinson-Crusoe economy on an isolated island, but in social interaction with others (the notion of the 'homo socialis'). For example, the need to live near one's relatives may lead to a residential location decision that is not optimal from a cost-minimizing viewpoint" (p.451). This type of decision making may be founded on the principle that transportation is needed regardless of location, consequently using its value to determine housing location is not nearly as important; locating near points of household interest will inherently reduce transportation costs regardless. The automobile oriented lifestyle that Canadians lead, which is built upon this assumption of mobility, comes with a substantial price tag which can be as rewarding as it is detrimental to a household's economic stability. It must also be considered that the location (high density, low density, urban, rural) and lifestyle choices is a product of demographics. Demographics may in fact be the underlying factor that determines location and lifestyle subsequently the type of transportation costs chosen to be incurred. 


\section{Linking Household Expenditures and Income}

Annual income is another variable which can influence where and how households live. Greater amounts of income create to opportunity for households to have more freedom in their choice of dwelling, location and preferred mode of transportation. A 2006 US study by Peter M Hass, Carrie Makarewicz, Albert Benedict, Thomas W. Sanchez and Casey J. Dawkins examined the trade offs between housing and transportation costs and how they relate to income. Hass et al (2006) were able to quantify and group different economic classes by neighbourhood based on their annual housing and transport expenditures. Their research on 28 metropolitan areas at the neighbourhood level suggests that annual expenditures can act as a burden to those households with limited income, which can be interpreted as those areas with highest costs also have the lowest annual income. Hass et al (2006) state that" [They] find that costs vary by neighborhood and by region and that lower income households most often have a higher cost burden for both housing and transportation in all neighborhoods and regions "(p.9). As shelter and transportation expenditures have been noted previously to account for significant portions of the annual expenses of Canadian households, it is understandable that high costs may be seen as a burden to a households quality of life. Conversely, this illustrates that some households may be able to absorb the higher burdens (expenditures) of certain types of transportation they desire because of a higher annual income. Income level does influence choice of shelter and transportation, however, it can be both limiting and enabling and thus, may not be the most accurate variable which determines levels of household expenditure

\section{Determinants of Transportation Choices}

Factors which influence Canadian households to locate in specific areas and absorb the subsequent costs of transportation can be linked to their demographic traits and lifestyle. Causation is the relation of cause to effect and the purpose of this research is to determine the 
cause of the different household transportation costs in Canada. In order to understand the factors behind cost variance it is important to look at two variables; density and demographics.

Arguments surrounding modal-choice typically revolve around population density and the built form; the argument that higher density urban environments are conducive to lower transportation costs must be reevaluated. Higher concentrations of people and jobs create environments that are more effective for the provisions of public transportation (light rail, subways, buses) and multi-modal options, however, these opportunities exist because a certain type of population wants the compact urban life. Ulf Christina Ewert and Alexia Prskawetz (2002) have conducted research on regional demographic variance and automobile usage and have looked critically at the role density plays in regards to modal choice in Austria. Through analysis they come to an 'obvious' conclusion, "that the increase of population, which in fact is an increase of population density, should accelerate the development and the provision of alternative means of transportation and subsequently lower car ownership and the use of cars" (p. 340). It is true that these compact environments both abroad and in Canada are conducive to more sustainable modes of transportation but once again the traits of these urban dwellers is lost amongst the calculations, which is a continuous trend throughout most transportation costs research.

Residents of municipalities across Canada that live outside the urban core tend to drive more and thus incur higher transportation costs because they live further away from amenities and employment. Arguably, most Canadian residents would not want to incur higher costs of living if they did not have to. However, this notion brings into question why people would choose to live away from urban/town centers and use expensive automobiles when there are more cost 
effective transportation services in higher density environments? Compact living may not be desirable for all individuals, which is why demographics and household traits need to be looked at more closely as the determining factor behind choice of residence.

There does appear to be a slow transition towards more demographically based research on this topic. As stated by Tim Schwanen, Martin Dijst and Frans M.Dielemen (2005), "the fact the most households with a given socio-demographic profile are not distributed uniformly across urban space, it has become standard practice to include socio-demographics as control variables in studies investigation the impact of urban form on travel behaviour" (p.17). This study uses that same method to explain shelter and transportation expenditures as they relate to households.

The demographic traits of the Canadian population have been evolving steadily over the past twenty years and will continue to do so as the baby boomers age and projected immigration levels continue to rise. "Among the main differences in patterns of population change are slower national population growth, higher life expectancy, markedly lower fertility, increasing cohabitation, rising levels of couple separation, surging net immigration and faltering net internal migration to the larger metropolitan centres" (Champion et al. Hall and White, 1995). It is the unique demographic characteristics and aspirations of certain demographic groups that dictate their need for transportation. According to Chandra R. Bhat, Sudeshna Sen and Naveen Eluru (2008), "There are several factors that influence household vehicle holdings and usage decisions, including household and individual demographic characteristics, vehicle attributes, fuel costs, travel costs, and the built environment characteristics (land-use and urban form attributes) of the 
residential neighborhood" (p.2). Lifestyles and choices of place of residence will dictate what level of transportation costs is incurred.

Lawrence Douglas Frank, Brian E. Sealens, Ken E. Powell and James E. Chapman (2007) have conducted research on the causation between built environments and driving, obesity and physical activity. The researchers concluded that households with the highest vehicle kilometers travelled had higher incomes, more vehicles, and licensed drivers, were in less walkable environments and ultimately were located in lower density environments (p.1908). The most interesting trait that they also mentioned was that these household also had the highest proportion of children less than 18 years of age, which helps to illustrate the validity behind the hypothesis that demographics dictate place of residence (p.1908).

The amount of privately operated vehicles can be linked with household characteristics, as illustrated by Chandra R. Bhat, Sudeshna Sen and Naveen Eluru (2008). They suggest that demographics are influential in regards to the amount of vehicles households will own and how often they are operated. They note that "the impact of household and individual demographic characteristics such as household income, household size, number of children in the household, and employment of individuals in the household" will influence the need for automobiles (p.2).

There are additional factors which contribute to modal choice that may be influenced by demographics. As noted by Martin Williams (1977), "Most empirical evidence suggests that comfort and convenience are relevant and important determinants of modal choice" (p.91). Forms of public transportation can be moderately comfortable, but make up for any lack leg 
room with their speed and efficiency. In higher density urban environments these readily available and efficient modes of transportation are ideal for travelling over short distances. In a suburban or rural environment, these modal choices may not exist. In addition, public transportation modes outside of the urban environment are typically slower, take longer to reach destinations and suffer from lower ridership mainly because the automobile is a more comfortable and convenient option. For example, the demographic composition of most suburban homes, as shown in research by Frank, Saleans, Powell and Chapman, illustrates younger families with children. Getting a full family onto a city bus daily and on time would be much more difficult than getting everyone in the car and driving to the doorstep of each destination. Conceivably, it may be the comfort and convenience of the automobile offsets the high costs and commute times and makes living away from high density environments more appealing.

Even in the urban core, some residents still use the automobile as a primary way to get around. This may be linked to the notion that "travelers consider walking, waiting and switching buses as inconveniences associated with transit use and prefer to use the automobile because of the level of convenience it offers (p.95). Given these different factors for selecting transportation modes have been shown it is next important to show how they are calculated and evaluated within the Canadian Survey of Household Spending.

\section{Calculating Household Transportation Expenditures in Canada}

What classifies something being a transportation cost is debatable and would differ by household if they were asked. In Canada, calculating the household transportation cost is done through the annual 'Survey of Household Spending', facilitated by Statistics Canada. In the survey the 
household expenditures for Canadian households are calculated looking at variables such as shelter, transportation, food and utilities to name a few. Shelter costs are derived from data collected across several different categories of questions within the SHS. The total household transportation expenditure is derived from a serious of questions within the questionnaire. These questions are within Automobiles and Trucks (AT), Vehicle Expenses (VE) and Transportation (TR). The Automobiles and Trucks section collects information on capital costs such as vehicle purchases as well as all associated operational costs that are related to the vehicle (not the driver) such as maintenance, accessories, fuels and parking to highlight a few. Within this survey, capital costs and operational costs are separated and defined. Capital costs apply only to purchased or owned vehicles that are operated by a household member; leased or rented vehicles do not count as a capital cost (Survey of Household Spending, 2008). Conversely, operational costs include items such as vehicle parts, fuels, regular maintenance and insurance and regulatory fees (Survey of Household Spending, 2008). The day to day investments and requirements to maintain person vehicles of any type (car, motorcycle, boat, etc.) are classified as operational and can change day to day.

Transportation is the section under which such expenses like bicycles, local commuter transportation and intercity transportation are listed. Within this category, costs associated airplanes, trains, limousines and highway busses as transportation services are requested and in later cumulative calculations are incorporated into the annual transportation costs of a household. Including these costs towards annual expenditure figures is problematic for this study. Given that academics such as Miller, Norton and Taylor separately suggest that transportation costs are inherently necessary expenses; this survey seems less accurate in its methodology. Grouping 
larger transportation costs such as vacation travel, sightseeing tours and limousines creates misrepresentative data, as these unique transportation expenditures are often high and not necessary for the day to day functioning of a household; they would be better grouped as recreation or leisure costs. This is suggested as the cost of an airplane trip or cruise is not being paid entirely by the household; they are paying a fraction of the cost that may be above or below its true value.

\section{The Annual Costs of Transportation in Canada}

Transportation costs make up a significant portion of a household budget, even more so if that household suffers from economic hardships. Data from the 2008 Survey of Household Spending reveals that the average amount of money spent on transportation per household was $\$ 9,722$ (Statistics Canada, 2008.) This cost was third highest behind income taxes $(\$ 14,599)$ and shelter $(\$ 14,183)$, which illustrates that transportation is one of the biggest expenses for households to incur (Statistics Canada, 2008). The expenditure trends are not uniform across Canada, as variance in transportation costs and annual household income between the different provinces can be attributed to different geographies, population sizes, employment types and demographics.

\section{Travel More, Pay More}

The rate at which people travel has increased consistently over the years. The trip rate is reflective of the inhabitants of the household. Amer Shalaby (2002) echoes this claim in that "The trip-making rate is related in part to the personal and household characteristics of the urban residents and to other characteristics of the transportation and urban activity systems" (p.703). As the demographics have changed across Canada, so has the need for transportation. With more and more households having dual-incomes, the need for travel has increased since the mid- 
1960's. Shalaby's claim is well founded, as his research is based on a series of calculations with three key variables; age, location and employment status. (p.704). These three factors would dictate the amount that a household travels as for example, a household of retirees would not be commuting daily like a younger employed household would. It is undeniable that increased accessibility and technological improvements have created more demand for travel, which in turn has a cost associated with it. Eric Miller and Amer Shalaby (2003) further this, citing that "people today are generally participating in a very wide range of activities, taking advantage of the accessibility which they have to an incredibly complex and varied "activity system" within the urban area" (p.15). The demand for transportation has been created through technological advancements; however these modes of travel all have a price attached to them. Miller and Shalaby acknowledge that the increases in travel are reflective of the adoption of the automobile between the 1960's and the 1980's, which set the trend for how households travel to work, play or other locales. In order to better understand the household cost of transportation it is important to note the importance of automobile to current travel trends and that "virtually the entire growth in per person trip-making has occurred in the auto-drive mode, given that the average number of daily trips per person made by auto passenger and transit is virtually unchanged from 1964 levels" (p.16).

\section{Urban Planning and Transportation Expenses}

Household transportation expenditure figures are a reflection of how Canadian cities are planned. Carrie Makarewicz, a researcher in the United States with the Centre for Neighbourhood technology, has been vocal on the importance of planning proper cities, stating that "How cities are developed affects transportation costs" (Finkel, 2006). As discussed earlier, transportation expenditures vary with location and Makarewicz makes an excellent point in suggesting that 
when cities are created, the transportation costs are as well. A poorly planned city that is not well connected and serviced with good job dispersion and transit supply demands expensive individual investments into private transportation such as an automobile.

There is room for more research on the subject of transportation and shelter expenditures and how they relate to the characteristics of Canadian households. Exploring deeper into the geographies and economic makeup of the surveyed areas may bring new information forward about how these costs can be understood better by changes in a household unit. Transportation and shelter will continue to account for a larger portion of annual household expenditures for Canadians. Improvements technology and transportation system investments (transit frequency, infrastructure, etc) may help reduce costs, yet the choice of shelter and incurred costs are reflective of the characteristics within a household. The provided analysis will test some of the provided theories and show how a household's characteristics influence annual expenditures for shelter and transportation in Canada. 


\section{Methodology}

\section{Survey of Ilousehold Spending, 2008}

The most recent Canadian Census from 2006 offers limited information about annual shelter and transportation expenditures for households; in response to this, the 2008 Survey of Household Spending (SHS) was selected as a data set that could better illustrate this subject. The SHS is conducted by the Income Statistics Division of Statistics Canada as an annual survey; not as part of census. The survey provides detailed data not collected in the Census that can be used to better understand the economic behaviours of Canadian households. The dataset includes detailed figures related to the amount of annual income households spend on housing and transportation as well as details about the characteristics of the households themselves.

Analyzing household shelter and transportation expenditures and their relation to household composition and size is the next step in understanding how Canadians spend their money. Using the SHS data, urban planners can obtain a better understanding of the population they are planning for and what their daily needs include. For instance, using the data it could be shown that four bedroom households in one province have higher transportation expenses than two person households, or perhaps that a young population with children tends to locate in single detached dwellings, despite higher costs. It was assumed that there would be variance in costs based on household composition, as no two households of any type or size would use transportation in the same manner. 


\section{Statistical Analysis}

In order to conduct the statistical analysis, variables have been re-calculated and filtered. Some variables produced in response to questions asked within the SHS are beyond the scope of this study and were removed, such as questions about vacations, household appliances and income.

\section{Controlling Variables}

Shelter and transportation variables have been readjusted and regrouped in a way which reflected realistic annual expenditures. The totals provided for each group in the 2008 Survey of Household Spending included several variables that had to be excluded from the main equations because they were either irrelevant to this study or because their values were flawed. Questions within the survey that have been identified as irrelevant to the study have been removed from the 'total' equations in order to create a strong data set based on daily behaviours and spending within a full year.

The SHS variable 'RENT', is not comprised of true annual figures and was removed. Some renters may have only rented for two months; therefore their expenditure would be much lower than that of a household renting a principle residence. In regards to transportation, 'Intercity transportation' has been excluded from the data set because the costs accrued under it are not typical. Long haul bus and train, as well as aviation costs, are included within this heading and their high costs and low use frequency were the reason they were left out.

\section{Scope}

To ensure a broad Canadian context, data was selected from the four provinces of Quebec, Ontario, Alberta and British Columbia. Within these provinces, households located inside municipalities of 100,000 persons or more were isolated and analyzed to better reflect the 
questions asked in the 2008 SHS. Larger urban centres offer more housing style choices (single detached, duplex, apartment, condominiums) as well as additional transportation choices beyond just the automobile (bicycle, bus, subway) which will make the results more relevant.

Only variables with annual totals were considered for this study. Principle residences that were not occupied for the full year by a household unit were filtered out because costs and charges would be significantly lower, as discovered in some preliminary calculations. Variables for rent provided the most issues during the filtering process as some respondents only rented units for a couple months and therefore their expenditures skewed the annual rent totals. The variable category 'FYPYFLAG' indicates which households were inhabited year-round. All households coded as 1 , to signify occupied for a full year, were isolated and used for the provincial data subsets.

\section{Shelter Expenditures}

The costs for principal accommodation (Variable G002) were selected as the most appropriate variable to represent annual shelter expenditures, based on the questions asked within the SHS. This variable includes expenditures on rent, mortgages, condominium charges, property tax, annual repairs and renovation and insurance premiums. 'Principal Accommodation' and its subsequent costs have been included for the reason that they all have an impact on the price and function of a dwelling.

\section{Transportation Expenditures}

Transportation expenditures were recalculated by selecting appropriate variables and removing others based on the questionnaire. Operational expenditures of private automobiles were included rather than capital expenditures, such as vehicle purchase, because they (capital costs) 
are not an annual occurrence and the cost associated with it would skew the totals. The total operational cost variable includes expenses such as fuels, maintenance and insurance which are incurred by both owned and leased vehicles.

Public transportation and other transportation services such as taxi's, bicycles, as well as the associated operational costs make up an additionally important part of transportation expenditures as well. 'Local and Commuter Transportation' (Variable K032TOT) includes subways, city buses and other forms of local transportation. Inter-city transportation modes such as airplanes, long haul buses and trains have been excluded because they are not daily functions and have too much variance in frequency of usage and price. The same rationale applies to services such as limousine and ferry's, as well as moving truck expenses. These variables are not appropriate for this analysis

Both Local and Commuter Transportation Costs and Operation Expenditure for Private or Leased Vehicles were combined into a new variable called 'TransportationCosts'. This variable was calculated for each provincial data set and is the annual transportation costs figure used within the analysis.

\section{Limitations}

The format of the data used within this study presented some challenges. Firstly, the names of the municipalities surveyed were not included within the data set. Although there can be some estimation of which cities these are in each province by the use of only those over 100,000 persons in this particular study, it would have been beneficial to be able to discern the identities of cities to show variance within the provinces. Some variance could be expected between large 
capital cities and others that may be less urban. In addition to this, a further disclosure of the urban and suburban households would have been beneficial to the accuracy of this report. These would have been an opportunity to determine the location of types of dwellings, larger households and different tenure types.

Going forward with this study there is an opportunity to examine the four major cities in each province which could include Montreal, Toronto, Calgary and Vancouver, and highlight the determinants of their annual shelter and transportation expenses. There is also an opportunity to compare urban and suburban areas of these cities to one another and determine amore precise shelter and transportation expenditure figures. 


\section{Analysis}

This analysis was conducted to test the theory that as housing cost increases, the cost of transportation will decline within urban areas. In order to illustrate the findings a comparison of means, standard deviations and scatter plot graphing was used to present the findings of this study. Each province (Quebec, Ontario, Alberta, and British Columbia) was analyzed separately using the constant variables of Principal Accommodation (G002) and REALCOST (Operation of owned and leased vehicles (K019) + Local and Commuter transportation (K032TOT)). These figures were analyzed under five variables which included Number of Bedrooms (NUMBEDRP), Tenure Type (TENURYRP), Dwelling Type (TYPDWELP), Household Size (HHSZTOTP) and Household Type (HHTYPEP). Graphs for each provincial variable set have been provided in the Appendix for consultation.

In the section below, each province will be discussed independently. Each provincial section will include a summary of findings related to shelter and transportation expenditures and how they relate to the constant variables of number of bedrooms, tenure type, type of dwelling, household size and household type. A discussion of the annual expenditures, marginal increases and possible reasons for certain amounts will be provided. After each province has been discussed independently, an interprovincial analysis will be provided in relation to highest means, variable with highest marginal increases and additional findings and points of interest. These summaries are meant to give a clear picture of what variables have the most impact on annual shelter and transportation expenditures. 


\section{Quebec}

In Quebec, 2,254,193 households which meet the criteria for this study were analyzed. The annual household expenditure for shelter was $\$ 11,237$. The annual transportation expenditure for 2008 was $\$ 3,937$.

\section{Number of Bedrooms}

Report

Principal accommodation
\begin{tabular}{|l|r|r|r|r|}
\hline Number of bedrooms & \multicolumn{1}{|c|}{ Mean } & \multicolumn{1}{c|}{$\mathrm{N}$} & Std. Deviation & \% of Total N \\
\hline No bedrooms & 6609.65 & 55137 & 3166.629 & $2.4 \%$ \\
One bedroom & 8209.39 & 413654 & 4876.410 & $18.4 \%$ \\
Two bedrooms & 9504.12 & 698498 & 4928.301 & $31.0 \%$ \\
Three bedrooms & 12759.37 & 737262 & 7991.442 & $32.7 \%$ \\
Four bedrooms & 15261.69 & 265481 & 9111.137 & $11.8 \%$ \\
5 or more bedrooms & 17515.58 & 84161 & 7576.286 & $3.7 \%$ \\
Total & 11237.60 & 2254193 & 7226.031 & $100.0 \%$ \\
\hline
\end{tabular}

In Quebec, households with two or less bedrooms had below average annual shelter expenditures in 2008 . Households without any bedrooms, which only account for $2.4 \%$ of those surveyed, spent an average of $\$ 6,609$ on their principal accommodation. One bedroom households spent an average of $\$ 8,209$ on shelter; an increase of $24 \%$ higher than the annual expenditures for zero bedroom households. Two bedroom households, which were also below the average, spent $\$ 9,509$ for an increase above a benchmark of zero bedroom households of $44 \%$. Three bedroom households account for roughly $33 \%$ of surveyed households and spent an above average amount of annual income on shelter, equating to $\$ 12,759$. Four bedroom households spent an average of $\$ 15,261 ; 36 \%$ above the provincial average. Five or more bedroom households, which only account for $3.7 \%$ of the cases, spent the most on shelter. These households devoted an average of $\$ 17,515$ to shelter. These forms of households are not prevalent within the dataset, possibly as this analysis was conducted in cities with populations of over 100,000 persons and a lack of 
larger sized dwellings. Overall, an increase in the number of bedrooms created a rise in annual shelter expenditures. This can be related to a growth in housing size and subsequent costs and possible increases in household size.

TransportationCosts
\begin{tabular}{|l|r|r|r|r|}
\hline Number of bedrooms & \multicolumn{1}{c|}{ Mean } & \multicolumn{1}{c|}{$\mathrm{N}$} & Std. Deviation & \% of Total N \\
\hline No bedrooms & 963.7106 & 55137 & 1286.55064 & $2.4 \%$ \\
One bedroom & 1773.6661 & 413654 & 2026.30786 & $18.4 \%$ \\
Two bedrooms & 3197.2752 & 698498 & 2372.69489 & $31.0 \%$ \\
Three bedrooms & 4684.8900 & 737262 & 2914.56237 & $32.7 \%$ \\
Four bedrooms & 6775.3916 & 265481 & 3925.51380 & $11.8 \%$ \\
5 or more bedrooms & 7156.9747 & 84161 & 3923.83939 & $3.7 \%$ \\
Total & 3937.1863 & 2254193 & 3235.70421 & $100.0 \%$ \\
\hline
\end{tabular}

Transportation expenditures also increased with the number of bedrooms. 'No bedroom' households spent the least amount on transportation in 2008 , incurring a cost of only $\$ 963$. One bedroom households, accounting for $18 \%$ of those surveyed, spent an average of $\$ 1,773$ on transportation. These 413,645 households had transportation expenditures $84 \%$ higher than those with no bedrooms. Those households which had two bedrooms spent $\$ 3,197$ on transportation; slightly below the average of $\$ 3,937$. Three bedroom households were the most prevalent form of cases surveyed, comprising of $33.7 \%$ of all cases. Four bedroom households had an annual transportation expenditure of $\$ 6,775$ in 2008 , which was $72 \%$ above the average. Although these types of households are not as prevalent as two and three bedroom households, they continue to exhibit the rise in transportation expenditures that accompanies a growth in the number of bedrooms. Five or more bedroom households had the highest annual transportation expenditure, equating to $\$ 7,156$, or $81 \%$ above average. It can be seen in the growing 
expenditures that an increased number of bedrooms within a household increases the amount of annual income needed to support transportation needs within Quebec.

\section{Tenure Type}

\begin{tabular}{|c|c|c|c|c|}
\hline Tenure group & Mean & $\mathrm{N}$ & Std. Deviation & $\%$ of Total $N$ \\
\hline $\begin{array}{l}\text { Owned without mortgage } \\
\text { during the reference year }\end{array}$ & 7384.98 & 488555 & 4488.530 & $21.7 \%$ \\
\hline $\begin{array}{l}\text { Owned with mortgage during } \\
\text { the reference year }\end{array}$ & 18136.58 & 647128 & 7375.717 & $28.7 \%$ \\
\hline $\begin{array}{l}\text { Rented or occupied rent free } \\
\text { during the reference year }\end{array}$ & 8488.05 & 1080292 & 3991.032 & $47.9 \%$ \\
\hline $\begin{array}{l}\text { Mixed tenure during the } \\
\text { reference year }\end{array}$ & 21390.07 & 38218 & 11766.187 & $1.7 \%$ \\
\hline Total & 11237.60 & 2254193 & 7226.031 & $100.0 \%$ \\
\hline
\end{tabular}

The tenure group with the highest annual shelter costs was mixed tenure households with an average shelter expenditure of $\$ 21,390$; however, these cases represent the smallest percentage of results at $1.7 \%$. Households owned with a mortgage represent roughly $29 \%$ of those studied within Quebec, and subsequently spent an average of $\$ 18,136$ on shelter. This value is $61 \%$ higher than the average for all households surveyed. Owned homes without mortgages, which represent $21.7 \%$ of those included within the survey, had the smallest shelter expenses in 2008 , incurring an expense of $\$ 7,384$, or $34 \%$ below average. Households which rented, or occupied a dwelling rent-free only, spent an average of $\$ 8,488$. Renting households represent nearly $48 \%$ of the surveyed households and significantly influence the average shelter costs by tenure type. Rented or occupied rent free dwellings spent $24 \%$ less than the average. 


TransportationCosts
\begin{tabular}{|l|r|r|r|r|}
\hline Tenure group & \multicolumn{1}{|c|}{ Mean } & \multicolumn{1}{|c|}{$\mathrm{N}$} & Std. Deviation & $\%$ of Total N \\
\hline $\begin{array}{l}\text { Owned without mortgage } \\
\text { during the reference year } \\
\text { Owned with mortgage during } \\
\text { the reference year }\end{array}$ & 4972.7299 & 488555 & 3678.64610 & $21.7 \%$ \\
$\begin{array}{l}\text { Rented or occupied rent free } \\
\text { during the reference year } \\
\text { Mixed tenure during the } \\
\text { reference year }\end{array}$ & 2362.1660 & 1080292 & 2161.55117 & $28.7 \%$ \\
Total & 4881.7083 & 38218 & 2025.50450 & $47.9 \%$ \\
\end{tabular}

Transportation expenditures were much closer among tenure types. Households who owned their dwellings and had mortgages spent the most on transportation, averaging $\$ 5,728$. Homes owned without mortgages spent a similar amount on transportation equaling $\$ 4,972$ on average. Both households which owned their dwelling had above average transportation expenditures. As rented dwellings make up the most significant tenure type in the data set, their annual expenditure have balanced out the high costs incurred by households which own their homes around the mean. Renting households spent $\$ 2,362$ on transportation; $40 \%$ below the average. Mixed tenure households made up $1.7 \%$ of the data set and had an above average cost of $\$ 4,881$. The findings illustrate that households which owned a dwelling as opposed to renting it had increased transportation and shelter expenditures. 


\section{Dwelling Type}

Principal accommodation
\begin{tabular}{|l|r|r|r|r|}
\hline Type of dwelling & \multicolumn{1}{|c|}{ Mean } & \multicolumn{1}{c|}{$\mathrm{N}$} & \multicolumn{1}{c|}{ Std. Deviation } & \% of Total N \\
\hline Single detached & 13459.58 & 774103 & 7995.976 & $34.3 \%$ \\
Semi-detached (double) & 13597.13 & 147028 & 8658.984 & $6.5 \%$ \\
Row or terrace & 14397.96 & 83514 & 10650.522 & $3.7 \%$ \\
Duplex & 12022.86 & 183914 & 7929.318 & $8.2 \%$ \\
Apartment & 8942.57 & 1051675 & 4844.695 & $46.7 \%$ \\
Hotel, rooming or lodging & 6817.61 & 13959 & 2187.840 & $.6 \%$ \\
house, mobile home, or other & & & & \\
Total & 11237.60 & 2254193 & 7226.031 & $100.0 \%$ \\
\hline
\end{tabular}

Apartments are the most dominant form of dwelling within this data set, and can be justified by the high percentage of renting households in the previous section. Apartments represent $46.7 \%$ of households within the data set; these dwellings also have one of the lowest annual shelter expenditure values, averaging $\$ 8,942$. This annual expenditure for apartments is $20 \%$ below the average of $\$ 11,237$. In Quebec, single detached homes spent $\$ 13,495$ on shelter, which is close to $\$ 2,000$ more than the mean shelter expenditure of $\$ 11,579$. Semi-detached dwellings and row or terrace houses also had above average shelter expenditures, spending $\$ 13,597$ and $\$ 14,397$ respectively. Although these dwelling types only represent roughly $10 \%$ of the dwellings, they help illustrate that the size of a dwelling will have an impact on the amount of annual income devoted to keeping it running; the larger dwellings were also the most expensive. 


TransportationCosts
\begin{tabular}{|l|r|r|r|r|}
\hline Type of dwelling & \multicolumn{1}{|c|}{ Mean } & \multicolumn{1}{c|}{$\mathrm{N}$} & \multicolumn{1}{c|}{ Std. Deviation } & \% of Total N \\
\hline Single detached & 5859.6613 & 774103 & 3472.26178 & $34.3 \%$ \\
Semi-detached (double) & 4781.0279 & 147028 & 2894.88984 & $6.5 \%$ \\
Row or terrace & 4667.9603 & 83514 & 3260.17126 & $3.7 \%$ \\
Duplex & 3522.7109 & 183914 & 2871.97644 & $8.2 \%$ \\
Apartment & 2422.3563 & 1051675 & 2212.95214 & $46.7 \%$ \\
Hotel, rooming or lodging & 3653.8364 & 13959 & 1327.39626 & $.6 \%$ \\
house, mobile home, or other & & & & \\
Total & 3937.1863 & 2254193 & 3235.70421 & $100.0 \%$ \\
\hline
\end{tabular}

The largest dwellings also had the highest annual transportation expenditures within Quebec.

Single detached dwellings spent $\$ 5,859$ or $48 \%$ more than the provincial average. Households

living within semi-detached dwellings had the second highest shelter expenditure, equaling

- $\$ 4,781$. Apartments, which are the dominant housing type in this data set, had the lowest annual transportation expenditure. Households living in these dwellings spent an average of $\$ 2,422$, which is $38 \%$ below average. Dwelling size, and in all likelihood the inclusion of more household members per unit, has substantial impacts on annual transportation expenditures.

\section{Household Size}

Principal accommodation

\begin{tabular}{|l|r|r|r|r|}
\hline Total household size & \multicolumn{1}{c|}{ Mean } & \multicolumn{1}{c|}{$\mathrm{N}$} & Std. Deviation & \% of Total N \\
\hline One member & 8876.94 & 755643 & 5166.081 & $33.5 \%$ \\
Two members & 10322.70 & 782186 & 6418.623 & $34.7 \%$ \\
Three members & 12666.05 & 259864 & 7689.910 & $11.5 \%$ \\
Four members & 15731.95 & 272993 & 8887.213 & $12.1 \%$ \\
Five members & 15757.61 & 140786 & 8712.040 & $6.2 \%$ \\
6 or more members & 17439.52 & 42721 & 7286.456 & $1.9 \%$ \\
Total & 11237.60 & 2254193 & 7226.031 & $100.0 \%$ \\
\hline
\end{tabular}


Of the households examined, only those with two or less members spent less than the average of $\$ 11,237$ on shelter. One person households, which accounted for $33.5 \%$ of the cases, spent an average of $\$ 8,876$ on shelter, whereas those with an additional person spent $\$ 10,322$. The impact of adding one person increased the annual shelter expenditure by $14 \%$. One and two member households are the most prevalent type of household sizes in the data set which makes this percentage of change very significant within Quebec, possibly signifying a need for a larger and more expensive dwelling. The amount of low number households is reflected by the amount of smaller sized dwellings such as apartments within the data set. Three and four member households spent averages of $\$ 12,666$ and $\$ 15,731$ respectively on transportation. This growth from three to four persons has the largest impact on annual shelter expenditure with this control variable, increasing the amount by $24 \%$. It can be seen though these figures that as the number of persons within a household increases, the average cost of shelter increases as well.

TransportationCosts
\begin{tabular}{|l|r|r|r|r|}
\hline Total household size & \multicolumn{1}{|c|}{ Mean } & \multicolumn{1}{c|}{$\mathrm{N}$} & Std. Deviation & \% of Total N \\
\hline One member & 1954.0701 & 755643 & 2026.61386 & $33.5 \%$ \\
Two members & 4124.6419 & 782186 & 2558.32241 & $34.7 \%$ \\
Three members & 4698.6233 & 259864 & 2947.28150 & $11.5 \%$ \\
Four members & 5860.4681 & 272993 & 3565.50634 & $12.1 \%$ \\
Five members & 7714.4990 & 140786 & 4297.38401 & $6.2 \%$ \\
6 or more members & 6212.3518 & 42721 & 3932.36558 & $1.9 \%$ \\
Total & 3937.1863 & 2254193 & 3235.70421 & $100.0 \%$ \\
\hline
\end{tabular}

Growth in household size contributed to significant increases in annual transportation expenditures. One person households were the only group that spent less than the average on transportation, equating to an average of $\$ 1,954$. Two member households spent $\$ 4,124$ on transportation; however the change between this and the former is an incredible $111 \%$. Costs continue to increase with three members, averaging $\$ 4,698$. Another increase in cost occurs 
between three and four person households. Four member households incurred an expense of $\$ 5,860$, an increase of $25 \%$ over three member households. Costs continued to rise with additional family members throughout the data set. Transportation costs are impacted by increases in household size, which can be associated with need for more mobility options and vehicles.

\section{Household Type}

\begin{tabular}{l} 
Principal accommodation \\
\hline Household type
\end{tabular}

Household types can be seen to have a significant impact on the amount of money spent annually on both shelter and transportation within Quebec. Smaller household sizes which include singles, couples and couples with children represent $82 \%$ of cases. One person households had a below average shelter expenditure of $\$ 8,876$. Couples only spent $\$ 10,169$ on shelter, and the addition of one extra person led to an expense increase of $14 \%$. Adding children to a household had the most significant impact on the amount of money spent on shelter. Couples with single 
children spent an average of $\$ 14,854$ in $2008 ; 67 \%$ more than single person households and $46 \%$ more than couples only. Couples with relatives and other unrelated persons had the highest annual expenditure of $\$ 16,376$ however; they only represent $4.4 \%$ of cases. Lone parent families also spent an above average amount on shelter of $\$ 12,388$ which further shows the impact children have on shelter expenditures. Again increases in household size, especially those including children, lead to a rise annual shelter expenditures within Quebec.

\begin{tabular}{|c|c|c|c|c|}
\hline Household type & Mean & $\mathrm{N}$ & Std. Deviation & $\%$ of Total N \\
\hline One person & 1954.0701 & 755643 & 2026.61386 & $33.5 \%$ \\
\hline Couple only & 4288.3768 & 574564 & 2489.75164 & $25.5 \%$ \\
\hline $\begin{array}{l}\text { Couple with single children } \\
\text { only }\end{array}$ & 6006.1454 & 520781 & 3532.07560 & $23.1 \%$ \\
\hline $\begin{array}{l}\text { Couple with other relatives or } \\
\text { unrelated persons }\end{array}$ & 6524.5245 & 98300 & 4211.99731 & $4.4 \%$ \\
\hline $\begin{array}{l}\text { Lone parent with no additional } \\
\text { persons }\end{array}$ & 3598.4395 & 146051 & 2690.68253 & $6.5 \%$ \\
\hline $\begin{array}{l}\text { Other household with } \\
\text { relative(s) }\end{array}$ & 4986.4841 & 63425 & 3614.67866 & $2.8 \%$ \\
\hline $\begin{array}{l}\text { Other household with unrelated } \\
\text { person(s) }\end{array}$ & 3390.8015 & 95429 & 2828.96993 & $4.2 \%$ \\
\hline Total & 3937.1863 & 2254193 & 3235.70421 & $100.0 \%$ \\
\hline
\end{tabular}

Transportation expenditures also increased in concert with household types that included multiple persons. One person households spent only half the Quebec average on transportation, incurring a cost of only $\$ 1,954$. 'Couples only' spent $\$ 4,288$, only slightly higher than the average $\$ 3,937$. The addition of children increased transportation expenditures $207 \%$ over single person households and $40 \%$ higher than just couples. It should be noted that 'couples only' were above the provincial average. Other housing types represent a minimal portion of the data set; however, those with more members can be seen to have higher than average transportation 
expenditures. Although the transportation expenditures are more evenly valued than those for shelter, the trends are the same; households with more members pay more for both shelter and transportation. This may be based on the increased need for more space or transportation services for larger households.

\section{Ontario}

In Ontario 3,833,033 households met the criteria for analysis. The annual household transportation expenditure for 2008 was $\$ 5,494$. The annual household expenditure for shelter was $\$ 15,348$.

\section{Number of Bedrooms}

Principal accommodation
\begin{tabular}{|l|r|r|r|r|}
\hline Number of bedrooms & \multicolumn{1}{|c|}{ Mean } & \multicolumn{1}{c|}{$\mathrm{N}$} & Std. Deviation & $\%$ of Total N \\
\hline No bedrooms & 7382.35 & 54948 & 6463.323 & $1.4 \%$ \\
One bedroom & 10094.46 & 608254 & 6589.258 & $15.9 \%$ \\
Two bedrooms & 12046.74 & 752083 & 7899.779 & $19.6 \%$ \\
Three bedrooms & 16367.47 & 1470265 & 9133.775 & $38.4 \%$ \\
Four bedrooms & 18512.24 & 805729 & 12548.299 & $21.0 \%$ \\
5 or more bedrooms & 29952.21 & 141724 & 16728.695 & $3.7 \%$ \\
Total & 15348.56 & 3833003 & 10630.053 & $100.0 \%$ \\
\hline
\end{tabular}

Increasing the number of bedrooms within a dwelling is seen to increase the annual transportation expenditure for Ontario households. One bedroom households, which equate for $15.9 \%$ of the households within this data set had an average shelter expenditure of $\$ 10,094$. Two bedroom households had a higher expenditure value for shelter of $\$ 12,046$, which is $19 \%$ higher than one bedroom households. Three bedroom households are the most dominant type of households and had an average shelter expenditure of $\$ 16,367$; an increase of $35 \%$ from two bedroom households. Four bedroom households continued the trend of increased shelter 
expenses, equaling $\$ 18,512$. Households with five or more bedrooms had the highest expenditure which equaled $\$ 29,952$ yet these cases only represent $3.7 \%$ of the data and may be an anomaly. An increase in the number of bedrooms within Ontario households increases annual shelter expenditures.

TransportationCosts
\begin{tabular}{|l|r|r|r|r|}
\hline Number of bedrooms & Mean & \multicolumn{1}{|c|}{$\mathrm{N}$} & Std. Deviation & $\%$ of Total N \\
\hline No bedrooms & 1035.0944 & 54948 & 1372.43400 & $1.4 \%$ \\
One bedroom & 2485.7674 & 608254 & 2577.12185 & $15.9 \%$ \\
Two bedrooms & 4255.0042 & 752083 & 3143.31928 & $19.6 \%$ \\
Three bedrooms & 5852.5080 & 1470265 & 3613.41229 & $38.4 \%$ \\
Four bedrooms & 7949.1849 & 805729 & 5296.48573 & $21.0 \%$ \\
5 or more bedrooms & 9042.2304 & 141724 & 5716.01952 & $3.7 \%$ \\
Total & 5494.4121 & 3833003 & 4351.67760 & $100.0 \%$ \\
\hline
\end{tabular}

The number of bedrooms also has an association with the amount of household income spent on transportation. Zero to two bedrooms households were below the average for transportation, but saw rises in mean expenditures as the number of bedrooms increased. Three bedroom households, representing the most significant portion of the data at $38.4 \%$, spent $\$ 5,852$ on transportation; $6 \%$ above the average of $\$ 5,335$. Four bedroom households spent an average of $\$ 7,949$ on transportation, presenting a rise of roughly $36 \%$ from three bedroom households. Five or more bedroom households paid the highest amount for transportation in 2008 , averaging $\$ 9,042$. Increases in bedrooms correlate with an increase in household size and subsequently a need for more space (which costs more money) and additional transportation. 


\section{Tenure Type}

\begin{tabular}{|c|c|c|c|c|}
\hline Tenure group & Mean & $\mathrm{N}$ & Std. Deviation & $\%$ of Total N \\
\hline Owned without mortgage & 9416.14 & 1075329 & 5586.353 & $28.1 \%$ \\
\hline during the reference year & & & & \\
\hline $\begin{array}{l}\text { Owned with mortgage during } \\
\text { the reference year }\end{array}$ & 24580.85 & 1352284 & 10959.386 & $35.3 \%$ \\
\hline $\begin{array}{l}\text { Rented or occupied rent free } \\
\text { during the reference year }\end{array}$ & 10457.76 & 1306180 & 5800.781 & $34.1 \%$ \\
\hline $\begin{array}{l}\text { Mixed tenure during the } \\
\text { reference year }\end{array}$ & 18200.18 & 99210 & 8999.144 & $2.6 \%$ \\
\hline Total & 15348.56 & 3833003 & 10630.053 & $100.0 \%$ \\
\hline
\end{tabular}

Households that own their homes and have mortgages spent the highest amount of annual income on shelter, averaging $\$ 24,580$. When compared to households which owned dwellings without mortgages, owned dwelling with mortgages cost $161 \%$ higher. Mortgaged homes represent $35.3 \%$ of the data, which is the highest percentage. Households which rent or occupied spaces rent free spent an average of $\$ 10,457$ on shelter in 2008 . This equated to nearly $\$ 14,000$ less annually, and a difference of $135 \%$.

TransportationCosts
\begin{tabular}{|l|r|r|r|r|}
\hline Tenure group & \multicolumn{1}{|c|}{ Mean } & \multicolumn{1}{|c|}{$\mathrm{N}$} & Std. Deviation & $\%$ of Total N \\
\hline $\begin{array}{l}\text { Owned without mortgage } \\
\text { during the reference year } \\
\text { Owned with mortgage during } \\
\text { the reference year }\end{array}$ & 5693.9821 & 1075329 & 4194.52000 & $28.1 \%$ \\
$\begin{array}{l}\text { Rented or occupied rent free } \\
\text { during the reference year } \\
\text { Mixed tenure during the } \\
\text { reference year }\end{array}$ & 3276.8486 & 1306180 & 3161.67801 & $34.1 \%$ \\
Total & 5134.8832 & 99210 & 2577.20797 & $2.6 \%$ \\
\hline
\end{tabular}


Households who owned their homes and had a mortgage had an average transportation expenditure of $\$ 7,504$; the highest out of the tenure types. Those households who own their homes but do not have a mortgage had similarly high transportation expenditure, which were slightly above the average at $\$ 5,693$. The higher costs may be attributed to the fact that dwellings that are owned or may require a mortgage are often larger, such as large detached dwellings which typically require private automobiles as the primary form of transportation. Accordingly, households which rented their dwellings had the lowest transportation expenditures with an average annual cost of $\$ 3,276$ which is $40 \%$ less than the provincial average. Rental units can be seen to have the lowest shelter and transportation expenditures in 2008 . This could be attributed to small household sizes as well as smaller financial investments into housing, such as through mortgaging and required utilities.

\section{Dwelling Type}

Principal accommodation
\begin{tabular}{|l|r|r|r|r|}
\hline Type of dwelling & \multicolumn{1}{|c|}{ Mean } & \multicolumn{1}{|c|}{$\mathrm{N}$} & \multicolumn{1}{|c|}{ Std. Deviation } & $\%$ of Total N \\
\hline Single detached & 17621.99 & 2070931 & 12016.510 & $54.0 \%$ \\
Semi-detached (double) & 17152.62 & 282176 & 8130.660 & $7.4 \%$ \\
Row or terrace & 14678.04 & 273266 & 7596.193 & $7.1 \%$ \\
Duplex & 9901.38 & 78472 & 3456.756 & $2.0 \%$ \\
Apartment & 11266.49 & 1117330 & 7668.946 & $29.2 \%$ \\
Hotel, rooming or lodging & 11150.61 & 10828 & 3485.218 & $.3 \%$ \\
house, mobile home, or other & & & & $100.0 \%$ \\
Total & 15348.56 & 3833003 & 10630.053 & \\
\hline
\end{tabular}

Single detached dwellings comprise $54 \%$ of the households surveyed and additionally have the highest shelter costs of any other dwelling type. Households that reside in single detached dwellings spent $\$ 17,291$ on shelter, followed closely by semi-detached dwellings that spent $\$ 17,152$. Smaller sized dwellings such as duplexes, hotel rooms and most notably, apartments, 
contained households which spent less than average on shelter. Apartment households only spent an average of $\$ 11,266$ on shelter, which is $36 \%$ below the average. Additionally, households living within single detached dwellings spent $56 \%$ more than those living within apartments. Larger sized dwellings, such as single and semi-detached appear to cost more annually than do smaller ones such as apartments.

TransportationCosts
\begin{tabular}{|l|r|r|r|r|}
\hline Type of dwelling & \multicolumn{1}{|c|}{ Mean } & \multicolumn{1}{c|}{$\mathrm{N}$} & \multicolumn{1}{c|}{ Std. Deviation } & \% of Total N \\
\hline Single detached & 6755.3086 & 2070931 & 4623.67589 & $54.0 \%$ \\
Semi-detached (double) & 6141.1429 & 282176 & 4224.06494 & $7.4 \%$ \\
Row or terrace & 5179.2269 & 273266 & 3718.76404 & $7.1 \%$ \\
Duplex & 4067.5407 & 78472 & 2560.03898 & $2.0 \%$ \\
Apartment & 3206.5348 & 1117330 & 2892.66213 & $29.2 \%$ \\
Hotel, rooming or lodging & 1864.1340 & 10828 & 2079.34987 & $.3 \%$ \\
house, mobile home, or other & & & & \\
Total & 5494.4121 & 3833003 & 4351.67760 & $100.0 \%$ \\
\hline
\end{tabular}

Transportation expenditures for households living within single detached dwellings were $\$ 6,755$ annually, which is more than $\$ 1,000$ higher than the provincial average. Larger dwelling types such as semi-detached and row houses also had high annual transportation costs. Households within semi-detached dwellings spent an average of $\$ 6,141$ while those within row or terrace houses spent $\$ 5,179$. Apartment households had one of the smallest transportation expenditures, averaging $\$ 3,206$. When compared to single detached dwelling, which are the other dominant housing type within the data set, the detached dwellings spent $110 \%$ more. Larger dwelling types incur higher annual transportation costs, which may be attributed to larger household sizes within as well as further distance from the downtown and a reliance on the automobile as the primary mode of transportation. 


\section{Household Size}

Principal accommodation
\begin{tabular}{|l|r|r|r|r|}
\hline Total household size & \multicolumn{1}{|c|}{ Mean } & \multicolumn{1}{c|}{$\mathrm{N}$} & Std. Deviation & \% of Total N \\
\hline One member & 10339.18 & 976037 & 7021.296 & $25.5 \%$ \\
Two members & 13675.72 & 1228615 & 8708.890 & $32.1 \%$ \\
Three members & 15333.68 & 491671 & 8507.680 & $12.8 \%$ \\
Four members & 21432.10 & 656750 & 12224.842 & $17.1 \%$ \\
Five members & 21480.14 & 289313 & 13952.537 & $7.5 \%$ \\
6 or more members & 21552.86 & 190617 & 12816.582 & $5.0 \%$ \\
Total & 15348.56 & 3833003 & 10630.053 & $100.0 \%$ \\
\hline
\end{tabular}

As the size of each household increases so does the price of shelter increases. One member households spent an average of $\$ 10,339$ in 2008 . Two member households spent $\$ 13,675$, which is still below average shelter expenditures. It is important to note that an increase from a one to two member household equated to a rise of $32 \%$ in annual shelter costs. Three member households are slightly below the average shelter expenditure of $\$ 15,348$ with an average expenditure of $\$ 15,333$. Households with four or more members have significantly higher annual shelter costs, spending an average of $\$ 21,432$ on shelter; $39 \%$ higher than the average. The trend continued for five-plus member households, however they represent a small portion of the data and average increases are minimal.

TransportationCosts
\begin{tabular}{|l|r|r|r|r|}
\hline Total household size & \multicolumn{1}{|c|}{ Mean } & \multicolumn{1}{c|}{$\mathrm{N}$} & Std. Deviation & \% of Total N \\
\hline One member & 2501.5575 & 976037 & 2468.16360 & $25.5 \%$ \\
Two members & 4940.6339 & 1228615 & 3307.38605 & $32.1 \%$ \\
Three members & 6895.5408 & 491671 & 3838.02472 & $12.8 \%$ \\
Four members & 7535.6731 & 656750 & 4347.75984 & $17.1 \%$ \\
Five members & 7749.8977 & 289313 & 4884.36303 & $7.5 \%$ \\
6 or more members & 10318.1333 & 190617 & 6443.11010 & $5.0 \%$ \\
Total & 5494.4121 & 3833003 & 4351.67760 & $100.0 \%$ \\
\hline
\end{tabular}


Transportation expenditures rose as the number of household members increased, with only one and two member households spending below the average of $\$ 5,494$. One member households spent an average of $\$ 2,501$ on transportation in 2008 , whereas two member households spent $\$ 4,940$. This difference represents an increase of $97.5 \%$ in annual transportation costs. Adding a third member to the household increased the annual cost to $\$ 6,895$, or a rise of $39.6 \%$ from two member households. Transportation costs continue to rise as household members are added; peaking at an average value of $\$ 10,318$ annually for households of six or more persons; albeit this only represents $5 \%$ of the data. It can be concluded that within Ontario transport costs increase as the number of household members rises.

\section{Household Type}

\begin{tabular}{|c|c|c|c|c|}
\hline Household type & Mean & $N$ & Std. Deviation & $\%$ of Total N \\
\hline One person & 10339.18 & 976037 & 7021.296 & $25.5 \%$ \\
\hline Couple only & 14030.78 & 929574 & 8416.150 & $24.3 \%$ \\
\hline $\begin{array}{l}\text { Couple with single children } \\
\text { only }\end{array}$ & 20718.88 & 1155139 & 12850.495 & $30.1 \%$ \\
\hline $\begin{array}{l}\text { Couple with other relatives or } \\
\text { unrelated persons }\end{array}$ & 19136.73 & 233131 & 9616.327 & $6.1 \%$ \\
\hline $\begin{array}{l}\text { Lone parent with no additional } \\
\text { persons }\end{array}$ & 15222.77 & 242637 & 10361.706 & $6.3 \%$ \\
\hline $\begin{array}{l}\text { Other household with } \\
\text { relative(s) }\end{array}$ & 12006.85 & 162875 & 7426.678 & $4.2 \%$ \\
\hline $\begin{array}{l}\text { Other household with unrelated } \\
\text { person(s) }\end{array}$ & 12373.67 & 133610 & 6725.181 & $3.5 \%$ \\
\hline Total & 15348.56 & 3833003 & 10630.053 & $100.0 \%$ \\
\hline
\end{tabular}

Couples with single children spent an average of $\$ 20,718$ on shelter in 2008 , which was the highest expenditure by household type. Couples with single children also represent the largest percentage of the data set, equating to $30.1 \%$ of all cases. One person households had the lowest 
annual shelter expenditures with an average of $\$ 10,339$ annually. 'Couples only' households spent $\$ 14,030$ on shelter; $35.6 \%$ more than single person households. Couples with single children had expenses that were $47.6 \%$ higher than couples who did not have any children. Increases in household size again lead to greater principal of accommodation.

\begin{tabular}{l} 
TransportationCosts \\
\hline Household type
\end{tabular}

Couples with relatives or other unrelated persons had the highest annual transportation expenditures in Ontario, averaging $\$ 9,004$. Couples with single children spent $\$ 7,814$ on transportation, making them the second highest spending household type. Couples with relatives and other unrelated person may have higher transportation expenses because they may require independent mobility as opposed to travelling as a family unit as those couples with children would. One person households had spent only 2,501 on transportation in 2008. Larger household units can be seen to have higher transportation costs within this data set. 


\section{Alberta}

In Alberta 829,116 households met the criteria for analysis. The annual household transportation expenditure for 2008 was $\$ 5,580$. The annual household expenditure for shelter was $\$ 15,904$.

\section{Number of Bedrooms}

Principal accommodation
\begin{tabular}{|l|r|r|r|r|}
\hline Number of bedrooms & Mean & N & Std. Deviation & \% of Total N \\
\hline No bedrooms & 10337.00 & 924 & .000 & $.1 \%$ \\
One bedroom & 10045.55 & 99265 & 4697.142 & $12.0 \%$ \\
Two bedrooms & 13739.08 & 166909 & 6398.576 & $20.1 \%$ \\
Three bedrooms & 17043.40 & 283011 & 8773.462 & $34.1 \%$ \\
Four bedrooms & 18742.75 & 179520 & 10911.009 & $21.7 \%$ \\
5 or more bedrooms & 17075.14 & 99487 & 8850.305 & $12.0 \%$ \\
Total & 15904.68 & 829116 & 8931.543 & $100.0 \%$ \\
\hline
\end{tabular}

One bedroom households, which account for $12 \%$ of cases in Alberta, spent an average of $\$ 10,045$ on shelter in 2008 . Two bedroom households spent $\$ 13,739$, rising $36.7 \%$ in total from one bedroom households. Three bedroom households saw a further increase in the expenditure average, equaling $\$ 17,043$. Three bedroom households account for $34.1 \%$ of the data set, which is the highest percentage. Three bedroom households spent $24 \%$ more than two bedrooms households. Four bedroom households had the highest annual expenditure, valuing $\$ 18,742$, but only seeing a slight marginal increase of $9 \%$ from three bedroom households. An increase in the number of bedrooms correlates with a rise in annual expenditure for shelter for this data set. 


TransportationCosts
\begin{tabular}{|l|r|r|r|r|}
\hline Number of bedrooms & \multicolumn{1}{c|}{ Mean } & \multicolumn{1}{c|}{$\mathrm{N}$} & Std. Deviation & $\%$ of Total N \\
\hline No bedrooms & 900.0000 & 924 & .00000 & $.1 \%$ \\
One bedroom & 2662.0242 & 99265 & 2690.80957 & $12.0 \%$ \\
Two bedrooms & 3982.6128 & 166909 & 3185.05374 & $20.1 \%$ \\
Three bedrooms & 5836.7976 & 283011 & 3600.22876 & $34.1 \%$ \\
Four bedrooms & 7425.2021 & 179520 & 4515.16758 & $21.7 \%$ \\
5 or more bedrooms & 7158.4710 & 99487 & 3995.25683 & $12.0 \%$ \\
Total & 5580.4451 & 829116 & 4034.71616 & $100.0 \%$ \\
\hline
\end{tabular}

Average annual transportation expenditures rose as the number of bedrooms increased. One bedroom households had below average expenditures for transportation in 2008 , equating to $\$ 2,662$. Two bedroom households spent $\$ 3,982$, for a marginal increase from one bedroom households of $49.5 \%$. Three bedroom households, which represent $34.1 \%$ of cases, spent $\$ 5,836$ on shelter and had a marginal increase over two bedroom households of $46.5 \%$. Four bedroom households had the highest transportation expenditure in Alberta, averaging $\$ 7,425$. The trend of roughly 50\% marginal increases in expenditures ends for this type of household with a marginal increase of $27 \%$ between three and four bedroom households. For both variables, costs increased as the number of bedrooms rose; possibly due to the subsequent rise in household members that would accompany such an increase in dwelling size 


\section{Tenure Type}

\begin{tabular}{|c|c|c|c|c|}
\hline Tenure group & Mean & $\mathrm{N}$ & Std. Deviation & $\%$ of Total $N$ \\
\hline Owned without mortgage & 8769.12 & 224872 & 5956.498 & $27.1 \%$ \\
\hline $\begin{array}{l}\text { Owned with mortgage during } \\
\text { the reference year }\end{array}$ & 22702.82 & 340746 & 7340.410 & $41.1 \%$ \\
\hline $\begin{array}{l}\text { Rented or occupied rent free } \\
\text { during the reference year }\end{array}$ & 12301.90 & 238185 & 5192.941 & $28.7 \%$ \\
\hline $\begin{array}{l}\text { Mixed tenure during the } \\
\text { reference year }\end{array}$ & 21683.27 & 25313 & 9418.155 & $3.1 \%$ \\
\hline Total & 15904.68 & 829116 & 8931.543 & $100.0 \%$ \\
\hline
\end{tabular}

Households which owned their dwelling and had a mortgage spent an average of $\$ 22,702$ on shelter, making it the group with the highest annual expenditure. Mixed tenure households spent $=$ an average of $\$ 21,683$, however, this only represented $3.1 \%$ of cases. Households which owned their dwelling but had no mortgage had the lowest shelter expenditure, spending an average of $\$ 8,769$. Adding a mortgage to households which owned their dwellings equates to an increase of $158 \%$ in annual expenditures for shelter. Rented dwellings, which would include apartments and other smaller dwellings, spent an average of $\$ 12,301$ on shelter. Renting households spent roughly $\$ 10,000$ less on shelter than those who owned their homes. 
TransportationCosts

\begin{tabular}{|c|c|c|c|c|}
\hline Tenure group & Mean & $N$ & Std. Deviation & $\%$ of Total $\mathrm{N}$ \\
\hline $\begin{array}{l}\text { Owned without mortgage } \\
\text { during the reference year }\end{array}$ & 5360.8458 & 224872 & 3499.60831 & $27.1 \%$ \\
\hline $\begin{array}{l}\text { Owned with mortgage during } \\
\text { the reference year }\end{array}$ & 7207.0890 & 340746 & 4147.99773 & $41.1 \%$ \\
\hline $\begin{array}{l}\text { Rented or occupied rent free } \\
\text { during the reference year }\end{array}$ & 3652.6153 & 238185 & 3435.35301 & $28.7 \%$ \\
\hline $\begin{array}{l}\text { Mixed tenure during the } \\
\text { reference year }\end{array}$ & 3774.6335 & 25313 & 2732.96788 & $3.1 \%$ \\
\hline Total & 5580.4451 & 829116 & 4034.71616 & $100.0 \%$ \\
\hline
\end{tabular}

Owned homes with mortgages also had the highest transportation expenditures. Households with a mortgage spent an average of $\$ 7,207$, roughly $29 \%$ above the provincial average. Those households which owned their dwellings without a mortgage spent $\$ 5,360$ on shelter in 2008 . Households which rent their dwelling had the lowest transportation expenditure of $\$ 3,489$. The tenure groups which spent the most on shelter also had the highest transportation costs, supporting the hypothesis that as cost of shelter increases so does the cost of transport.

\section{Type of Dwelling}

Principal accommodation
\begin{tabular}{|l|r|r|r|r|}
\hline Type of dwelling & \multicolumn{1}{|c|}{ Mean } & \multicolumn{1}{c|}{$\mathrm{N}$} & Std. Deviation & $\%$ of Total N \\
\hline Single detached & 17688.18 & 502470 & 9986.583 & $60.6 \%$ \\
Semi-detached (double) & 14406.88 & 30301 & 5589.837 & $3.7 \%$ \\
Row or terrace & 15385.66 & 81656 & 6823.706 & $9.8 \%$ \\
Duplex & 15283.29 & 27933 & 6515.762 & $3.4 \%$ \\
Apartment & 11776.68 & 177112 & 5289.509 & $21.4 \%$ \\
Hotel, rooming or lodging & 9691.64 & 9644 & 2252.056 & $1.2 \%$ \\
house, mobile home, or other & & & & \\
Total & 15904.68 & 829116 & 8931.543 & $100.0 \%$ \\
\hline
\end{tabular}

Single detached dwellings were the most prevalent form of housing within the data set, accounting for $60.6 \%$ of cases. Households which reside in single detached dwellings had the 
highest annual shelter expenditure, averaging $\$ 17,688$. Row or terrace housing was the second most expensive dwelling type with an average cost per household of $\$ 15,385$, which is slightly below the Alberta average $\$ 15,904$. Duplexes and semi-detached dwellings were also slightly below the average yet cost more than the smaller sized dwelling groups. Apartment households, which are the second most prevalent type of dwelling in the set representing $21.4 \%$ of cases, spent an average of $\$ 11,776$ on shelter. Single detached dwellings cost $50 \%$ more annually than apartment buildings. Again, an increase in annual shelter expenditures can be correlated with a growth in dwelling size.

TransportationCosts
\begin{tabular}{|l|r|r|r|r|}
\hline Type of dwelling & \multicolumn{1}{|c|}{ Mean } & \multicolumn{1}{|c|}{$\mathrm{N}$} & \multicolumn{1}{c|}{ Std. Deviation } & \% of Total N \\
\hline Single detached & 6786.9996 & 502470 & 4072.86463 & $60.6 \%$ \\
Semi-detached (double) & 4847.8475 & 30301 & 2531.59592 & $3.7 \%$ \\
Row or terrace & 4956.7285 & 81656 & 3652.52832 & $9.8 \%$ \\
Duplex & 3947.0959 & 27933 & 2543.83676 & $3.4 \%$ \\
Apartment & 2948.0458 & 177112 & 2898.75485 & $21.4 \%$ \\
Hotel, rooming or lodging & 3374.4201 & 9644 & 2902.69500 & $1.2 \%$ \\
house, mobile home, or other & & & & \\
Total & 5580.4451 & 829116 & 4034.71616 & $100.0 \%$ \\
\hline
\end{tabular}

Annual transportation expenditures were highest for single detached dwelling with an average of $\$ 6,786$ spent in 2008 . Single detached dwellings were the only dwelling type that spent above the average amount of $\$ 5,361$. Apartment households spent $\$ 3,374$ on transportation, roughly $\$ 2,000$ below the average. As can be seen in the data sets, the largest dwelling types have the highest shelter and transportation costs. Furthermore, this correlation shows that as price of shelter increases so does transportation. 


\section{Household Size}

Principal accommodation
\begin{tabular}{|l|r|r|r|r|}
\hline Total household size & \multicolumn{1}{|c|}{ Mean } & \multicolumn{1}{c|}{$\mathrm{N}$} & \multicolumn{1}{c|}{ Std. Deviation } & \% of Total N \\
\hline One member & 11786.34 & 209178 & 7240.528 & $25.2 \%$ \\
Two members & 14949.50 & 276639 & 8899.413 & $33.4 \%$ \\
Three members & 17454.41 & 107447 & 8287.382 & $13.0 \%$ \\
Four members & 19505.47 & 144825 & 8527.735 & $17.5 \%$ \\
Five members & 20713.78 & 60214 & 8924.956 & $7.3 \%$ \\
6 or more members & 20712.03 & 30813 & 9037.137 & $3.7 \%$ \\
Total & 15904.68 & 829116 & 8931.543 & $100.0 \%$ \\
\hline
\end{tabular}

One and two member households are the most common type of households within Alberta cities of 100,000 persons or more however a trend in the data set shows that as household members increase so does the cost for shelter. This can be attributed to the need for more room (larger homes), more utility costs or other expenses related to the operation of a dwelling. One and two member households spent below the average of $\$ 15,187$, incurring expenses of $\$ 11,786$ and $\$ 14,949$ respectively. Between a one person household and a two person household the annual shelter expense marginal increase was $26.8 \%$. Three member households' shelter expenses rose $16.7 \%$ to a value of $\$ 17,454$. Four member households spent nearly double that of a single person household, with an average shelter cost of $\$ 19,505$. Five member household had the highest annual shelter expenditure of $\$ 20,713$. Increases in the size of a household unit will increase the annual cost of shelter within Alberta. 


TransportationCosts
\begin{tabular}{|l|r|r|r|r|}
\hline Total household size & \multicolumn{1}{|c|}{ Mean } & \multicolumn{1}{c|}{$\mathrm{N}$} & Std. Deviation & \% of Total N \\
\hline One member & 2960.4523 & 209178 & 2741.26495 & $25.2 \%$ \\
Two members & 5204.8502 & 276639 & 3363.97362 & $33.4 \%$ \\
Three members & 6868.7267 & 107447 & 4365.55051 & $13.0 \%$ \\
Four members & 7456.3058 & 144825 & 3841.79643 & $17.5 \%$ \\
Five members & 8760.6864 & 60214 & 4881.41923 & $7.3 \%$ \\
6 or more members & 7214.8370 & 30813 & 3225.52839 & $3.7 \%$ \\
Total & 5580.4451 & 829116 & 4034.71616 & $100.0 \%$ \\
\hline
\end{tabular}

Transportation expenditures also increased with the number of household members. One and two member household had below average transportation expenditures as was the case for shelter; however, there is a significant marginal increase in the annual expenditures between the two types of households of $75.8 \%$. Three member household spent $\$ 6,868$ on transportation in 2008 and four member households spent $\$ 7,456$. Five member households had the highest transportation expenditure of $\$ 8,760$. Expenditures rose for each subsequently larger household group, except for those with six or more members, who were still $29.2 \%$ higher than the Alberta average. As the number of household members increases so does the amount of money spent annually on transportation. 


\section{Household Type}

\begin{tabular}{|c|c|c|c|c|}
\hline Household type & Mean & $\mathrm{N}$ & Std. Deviation & $\%$ of Total N \\
\hline One person & 11786.34 & 209178 & 7240.528 & $25.2 \%$ \\
\hline Couple only & 15694.01 & 188144 & 9826.880 & $22.7 \%$ \\
\hline $\begin{array}{l}\text { Couple with single children } \\
\text { only }\end{array}$ & 19699.45 & 244003 & 8894.151 & $29.4 \%$ \\
\hline $\begin{array}{l}\text { Couple with other relatives or } \\
\text { unrelated persons }\end{array}$ & 18110.47 & 48328 & 6266.622 & $5.8 \%$ \\
\hline $\begin{array}{l}\text { Lone parent with no additional } \\
\text { persons }\end{array}$ & 13891.66 & 45501 & 7101.712 & $5.5 \%$ \\
\hline $\begin{array}{l}\text { Other household with } \\
\text { relative(s) }\end{array}$ & 14079.34 & 31191 & 9732.964 & $3.8 \%$ \\
\hline $\begin{array}{l}\text { Other household with unrelated } \\
\text { person(s) }\end{array}$ & 16176.97 & 62771 & 6865.507 & $7.6 \%$ \\
\hline Total & 15904.68 & 829116 & 8931.543 & $100.0 \%$ \\
\hline
\end{tabular}

The requirements for shelter and transportation are contingent on the type of household being examined. The smallest household types such as singles, couples only, and lone parent families had the lowest annual shelter expenditures within the data set. The rise in annual was significant between one person households and couples only, rising from $\$ 11,786$ to $\$ 15,649$, or $32.7 \%$. Adding children to the household raised the annual expenditure to $\$ 19,699$, which had a marginal increase of $25.8 \%$ from couples only and $67.1 \%$ from single person households. Other households with unrelated persons had an above annual expenditure of $\$ 16,176$, and accounted for $7.6 \%$ of cases. 


\begin{tabular}{|c|c|c|c|c|}
\hline Household type & Mean & $\mathrm{N}$ & Std. Deviation & $\%$ of Total N \\
\hline One person & 2960.4523 & 209178 & 2741.26495 & $25.2 \%$ \\
\hline Couple only & 5431.2008 & 188144 & 2899.86094 & $22.7 \%$ \\
\hline $\begin{array}{l}\text { Couple with single children } \\
\text { only }\end{array}$ & 7563.6076 & 244003 & 4284.16708 & $29.4 \%$ \\
\hline $\begin{array}{l}\text { Couple with other relatives or } \\
\text { unrelated persons }\end{array}$ & 7971.3809 & 48328 & 4136.36210 & $5.8 \%$ \\
\hline $\begin{array}{l}\text { Lone parent with no additional } \\
\text { persons }\end{array}$ & 5862.9132 & 45501 & 4379.41151 & $5.5 \%$ \\
\hline $\begin{array}{l}\text { Other household with } \\
\text { relative(s) }\end{array}$ & 4358.6730 & 31191 & 3143.58665 & $3.8 \%$ \\
\hline $\begin{array}{l}\text { Other household with unrelated } \\
\text { person(s) }\end{array}$ & 5611.2435 & 62771 & 4244.24420 & $7.6 \%$ \\
\hline Total & 5580.4451 & 829116 & 4034.71616 & $100.0 \%$ \\
\hline
\end{tabular}

- Transportation expenditures were highest for households of couples with relatives or other unrelated persons, averaging $\$ 7,971$ across $5.8 \%$ of cases. Couples with single children, which represent a significant portion of the data had the second highest annual expenditures with an average of $\$ 7,563$. One person households had the lowest annual transportation expenditure with an average value of $\$ 2,960$. Couples only spent an average of $\$ 5,431$ on transportation, which is $83.4 \%$ higher than one person households. It can be determined more people within a household will increase the transportation expenditures for households.

\section{British Columbia}

In British Columbia 1,189,670 households met the criteria for analysis. The annual household transportation expenditure for 2008 was $\$ 5,058$. The annual household expenditure for shelter was $\$ 14,664$. 


\section{Number of Bedrooms}

Principal accommodation
\begin{tabular}{|l|r|r|r|r|}
\hline Number of bedrooms & \multicolumn{1}{|c|}{ Mean } & \multicolumn{1}{|c|}{$\mathrm{N}$} & Std. Deviation & $\%$ of Total N \\
\hline No bedrooms & 5638.53 & 54042 & 3652.683 & $4.5 \%$ \\
One bedroom & 8937.02 & 207127 & 4709.929 & $17.4 \%$ \\
Two bedrooms & 13101.22 & 297370 & 9526.224 & $25.0 \%$ \\
Three bedrooms & 16000.47 & 325779 & 12131.757 & $27.4 \%$ \\
Four bedrooms & 19882.49 & 178976 & 12542.824 & $15.0 \%$ \\
5 or more bedrooms & 20754.60 & 126376 & 11049.493 & $10.6 \%$ \\
Total & 14664.33 & 1189670 & 11074.308 & $100.0 \%$ \\
\hline
\end{tabular}

Households residing in dwellings with no bedrooms have an average shelter expenditure of $\$ 5,638$ annually in British Columbia. One bedroom households expend an average of $\$ 8,937$ on shelter, equaling a marginal increase of $58.5 \%$. There is a substantial increase between one and - two bedroom households of $46.5 \%$, to an average of $\$ 13,101$. Three bedroom households spent an average of $\$ 16,000$, and four bedroom households spent an average of $\$ 19,882$. Five bedroom households spent $\$ 20,754$ on shelter, or $41.5 \%$. As the number of bedrooms increases (which are assumed to be required and occupied), so does the cost of shelter. This also is true in regards to transportation expenditures as an increase in bedrooms leads to an increase in annual transportation costs. This can possibly be attributed to the need for more mobility because there are more occupants in the household.

TransportationCosts
\begin{tabular}{|l|r|r|r|r|}
\hline Number of bedrooms & \multicolumn{1}{|c|}{ Mean } & \multicolumn{1}{c|}{$\mathrm{N}$} & \multicolumn{1}{c|}{ Std. Deviation } & $\%$ of Total N \\
\hline No bedrooms & 1092.9317 & 54042 & 1331.90476 & $4.5 \%$ \\
One bedroom & 2409.5150 & 207127 & 1979.87775 & $17.4 \%$ \\
Two bedrooms & 4010.6165 & 297370 & 2599.27646 & $25.0 \%$ \\
Three bedrooms & 5682.5574 & 325779 & 3608.61352 & $27.4 \%$ \\
Four bedrooms & 7394.4249 & 178976 & 4033.13116 & $15.0 \%$ \\
5 or more bedrooms & 8648.7795 & 126376 & 5024.18221 & $10.6 \%$ \\
Total & 5058.9302 & 1189670 & 3956.47477 & $100.0 \%$ \\
\hline
\end{tabular}


As the cost of principal accommodation increases so does the cost of transportation, which is contrary to the theoretical model. Households within households with no bedrooms had the lowest annual transportation expenditure, with an average cost incurred of $\$ 1,092$. One bedroom households saw a marginal increase from no bedroom households of $120 \%$, with an average expenditure of $\$ 2,409$. Transportation expenditures continue to rise with increases in the number of bedrooms, reaching $\$ 4,010$ for two bedrooms. An expenditure of $\$ 5,682$ was incurred for three bedroom households, which was the first category above the mean and also the most predominant category, representing $27.4 \%$ of the data. Costs increased for every subsequent category of bedrooms, providing proof that an increase in bedrooms increases transportation costs.

\section{Tenure Group}

\begin{tabular}{|c|c|c|c|c|}
\hline Tenure group & Mean & $\mathrm{N}$ & Std. Deviation & $\%$ of Total N \\
\hline Owned without mortgage & 8649.83 & 347563 & 6709.778 & $29.2 \%$ \\
\hline $\begin{array}{l}\text { during the reference year } \\
\text { Owned with mortgage during } \\
\text { the reference year }\end{array}$ & 24786.55 & 356751 & 10965.285 & $30.0 \%$ \\
\hline $\begin{array}{l}\text { Rented or occupied rent free } \\
\text { during the reference year }\end{array}$ & 10494.85 & 451672 & 6305.441 & $38.0 \%$ \\
\hline $\begin{array}{l}\text { Mixed tenure during the } \\
\text { reference year }\end{array}$ & 25427.54 & 33684 & 15905.807 & $2.8 \%$ \\
\hline Total & 14664.33 & 1189670 & 11074.308 & $100.0 \%$ \\
\hline
\end{tabular}

Mortgages and rent make up significant portions of principal accommodation costs within British Columbia. There is fairly even distribution of household with and without mortgages in this data set, as well as a comparable number of rented properties. Households which own their dwellings with mortgages incurred the second highest shelter costs in 2008 , spending $\$ 24,786$. Mixed 
tenure households had the highest shelter costs in 2008 , however, only represented $2.8 \%$ of the data and are not as common as other forms of tenure. Rented properties spent $\$ 10,494$ on shelter and close to $\$ 4,000$ below the average.

TransportationCosts
\begin{tabular}{|l|r|r|r|r|}
\hline Tenure group & Mean & \multicolumn{1}{|c|}{$\mathrm{N}$} & Std. Deviation & \% of Total N \\
\hline $\begin{array}{l}\text { Owned without mortgage } \\
\text { during the reference year } \\
\text { Owned with mortgage during } \\
\text { the reference year }\end{array}$ & 5353.1943 & 347563 & 3927.81588 & $29.2 \%$ \\
$\begin{array}{l}\text { Rented or occupied rent free } \\
\text { during the reference year }\end{array}$ & 3369.1934 & 451672 & 2997.72326 & $30.0 \%$ \\
$\begin{array}{l}\text { Mixed tenure during the } \\
\text { reference year }\end{array}$ & 4630.4411 & 33684 & 3246751 & $38.0 \%$ \\
Total & 5058.9302 & 1189670 & 3956.47477 & $2.8 \%$ \\
\hline
\end{tabular}

The highest transportation expenditure based on tenure group were those households with a mortgage at $\$ 6,652$ and those without a mortgage at $\$ 5,353$, which are both above the mean expenditure for transportation in British Columbia. This may be attributed to the size of the dwellings once again. Rented properties are most likely apartments and therefore are smaller than mortgaged properties which may include single detached dwellings, semi-detached homes or row houses. Accordingly, renting households had the lowest average transportation expenditure, spending an average of $\$ 3,369$. Mixed tenure household were also below the mean for British Columbia with an average expenditure value of $\$ 4,630$. The data illustrates that as the cost of the dwelling increases so does the cost of annual transportation. 


\section{Type of Dwelling}

Principal accommodation
\begin{tabular}{|l|r|r|r|r|}
\hline Type of dwelling & \multicolumn{1}{|c|}{ Mean } & \multicolumn{1}{|c|}{$\mathrm{N}$} & Std. Deviation & \% of Total N \\
\hline Single detached & 17139.17 & 605423 & 11872.923 & $50.9 \%$ \\
Serni-detached (double) & 17891.01 & 38315 & 10803.545 & $3.2 \%$ \\
Row or terrace & 16788.72 & 92795 & 12541.561 & $7.8 \%$ \\
Duplex & 14484.80 & 75374 & 10274.775 & $6.3 \%$ \\
Apartment & 10071.11 & 354515 & 7500.532 & $29.8 \%$ \\
Hotel, rooming or lodging & 7042.40 & 23248 & 3145.772 & $2.0 \%$ \\
house, mobile home, or other & & & & 11074.308 \\
Total & 14664.33 & 1189670 & $100.0 \%$ \\
\hline
\end{tabular}

Dwelling type and its influence on transportation cost can be understood more clearly through the analysis of this section. Single detached homes were the second expensive form of principle accommodation within British Columbia, costing $\$ 17,139$ annually. Single detached homes also are the most prevalent housing form within the data set making up about $50.9 \%$ of households. Households living in semi-detached homes spent an average of $\$ 17,891$, but only make up $3.2 \%$ of the data set. Households living in Row or terrace homes spent an average of $\$ 16,788$. Households living in apartments spent $\$ 10,071$ on shelter in 2008 , which is $45 \%$ less than the mean. The size of the dwellings and their ability to hold multiple persons can be a reason why these household have higher annual shelter costs. As size increase, so does the amount of annual income required to maintain them. 


TransportationCosts
\begin{tabular}{|l|r|r|r|r|}
\hline Type of dwelling & Mean & \multicolumn{1}{|c|}{$\mathrm{N}$} & Std. Deviation & \% of Total N \\
\hline Single detached & 6408.7056 & 605423 & 4305.89315 & $50.9 \%$ \\
Semi-detached (double) & 3830.0333 & 38315 & 2761.76483 & $3.2 \%$ \\
Row or terrace & 5432.4373 & 92795 & 3416.75420 & $7.8 \%$ \\
Duplex & 4793.5308 & 75374 & 3419.28490 & $6.3 \%$ \\
Apartment & 2938.4733 & 354515 & 2484.42043 & $29.8 \%$ \\
Hotel, rooming or lodging & 3638.5286 & 23248 & 2389.75019 & $2.0 \%$ \\
house, mobile home, or other & & & & \\
Total & 5058.9302 & 1189670 & 3956.47477 & $100.0 \%$ \\
\hline
\end{tabular}

Transportation costs were highest for single detached dwellings at $\$ 6,408$. Apartments, which make up 29.85 of all cases within British Columbia, expended $\$ 2,938$ on transportation.

Households within row or terrace houses, the third most common dwelling type representing $7.8 \%$ of cases, spent an average of $\$ 5,432$ on transportation, which equates to only $7 \%$ above the mean annual transportation expenditure for all cases. Semi-detached homes were significantly lower in regards to transportation expenditures, costing $\$ 3,830$, and $\$ 2,578$ less than single detached dwellings.

\section{Household Size}

Principal accommodation
\begin{tabular}{|l|r|r|r|r|}
\hline Total household size & \multicolumn{1}{|c|}{ Mean } & \multicolumn{1}{c|}{$\mathrm{N}$} & \multicolumn{1}{c|}{ Std. Deviation } & $\%$ of Total N \\
\hline One member & 9123.94 & 376402 & 6001.960 & $31.6 \%$ \\
Two members & 14349.19 & 345329 & 11005.002 & $29.0 \%$ \\
Three members & 18067.61 & 150883 & 11911.469 & $12.7 \%$ \\
Four members & 18742.45 & 186170 & 11750.074 & $15.6 \%$ \\
Five members & 20696.08 & 89199 & 12259.457 & $7.5 \%$ \\
6 or more members & 23863.71 & 41687 & 12769.512 & $3.5 \%$ \\
Total & 14664.33 & 1189670 & 11074.308 & $100.0 \%$ \\
\hline
\end{tabular}


Households with only one member had the lowest shelter costs within data, possibly attributed to the high probability they will be located in apartments and renting, as seen in previous data sets. One member households had an average shelter expenditure of $\$ 9,123$. Two member households had a higher annual expenditure, spending $\$ 14,349$ in 2008 and representing a marginal increase of $57.2 \%$ over one person households. Increasing costs for shlter continue as the household size increase, suggesting that an increase in household members will increase the amount of annual income that will be devoted to shelter. One and two member households are the most prevalent forms of households within the data set and account for $60.6 \%$ of cases, which explains why the mean shelter expenditure for the province is substantially lower than the highest incurred expenditures.

TransportationCosts
\begin{tabular}{|l|r|r|r|r|}
\hline Total household size & \multicolumn{1}{c|}{ Mean } & \multicolumn{1}{c|}{$\mathrm{N}$} & Std. Deviation & \% of Total N \\
\hline One member & 2345.3131 & 376402 & 2014.98576 & $31.6 \%$ \\
Two members & 4846.8618 & 345329 & 2850.52039 & $29.0 \%$ \\
Three members & 6256.8350 & 150883 & 3830.22008 & $12.7 \%$ \\
Four members & 7244.9879 & 186170 & 3783.76881 & $15.6 \%$ \\
Five members & 9569.1276 & 89199 & 5804.37731 & $7.5 \%$ \\
6 or more members & 7568.5216 & 41687 & 3226.65315 & $3.5 \%$ \\
Total & 5058.9302 & 1189670 & 3956.47477 & $100.0 \%$ \\
\hline
\end{tabular}

One and two member households incurred below average transportation expenditures in 2008 . One member households spent an average of $\$ 2,345$ on transportation, while two member households spent $\$ 4,846$. The addition of one household member equated to a marginal increase of $106 \%$, which is the most significant increase in the data. Even between these two types of households a significant jump in transport cost can be observed. Transportation expenditures climax at five members with an average cost of $\$ 9,569$, before dropping to a value of $\$ \$ 7,568$ for 
households with six or more members. These findings illustrate that as household size increases so will transportation costs, which appear to peak at five members.

\section{Household Type}

\begin{tabular}{|c|c|c|c|c|}
\hline Household type & Mean & $\mathrm{N}$ & Std. Deviation & $\%$ of Total $N$ \\
\hline One person & 9123.94 & 376402 & 6001.960 & $31.6 \%$ \\
\hline Couple only & 15098.84 & 261199 & 11682.301 & $22.0 \%$ \\
\hline $\begin{array}{l}\text { Couple with single children } \\
\text { only }\end{array}$ & 18999.95 & 302444 & 12511.520 & $25.4 \%$ \\
\hline $\begin{array}{l}\text { Couple with other relatives or } \\
\text { unrelated persons }\end{array}$ & 21204.30 & 110335 & 11376.790 & $9.3 \%$ \\
\hline $\begin{array}{l}\text { Lone parent with no additional } \\
\text { persons }\end{array}$ & 14007.80 & 57450 & 10472.902 & $4.8 \%$ \\
\hline $\begin{array}{l}\text { Other household with } \\
\text { relative(s) }\end{array}$ & 14017.64 & 36142 & 7837.591 & $3.0 \%$ \\
\hline $\begin{array}{l}\text { Other household with unrelated } \\
\text { person(s) }\end{array}$ & 14667.40 & 45698 & 9925.110 & $3.8 \%$ \\
\hline Total & 14664.33 & 1189670 & 11074.308 & $100.0 \%$ \\
\hline
\end{tabular}

As the composition of a household varies, subsequently so do the daily activities and functions which in turn can have direct correlation to the amount of money spent annually on shelter and transportation. One person households had the lowest annual shelter expenditures with an average expenditure of $\$ 9,123$. When compared to households consisting of couples only, which spent an average of $\$ 15,098$, a marginal increase of $65.4 \%$ occurs. Couples with single children, who represent $25.4 \%$ and the second highest type of households within data set spent an average of $\$ 18,999$ on shelter, and spent $25.8 \%$ than couples only suggest that adding children to a household can have significant impacts on annual transportation expenditures. Couples with relatives or other unrelated person had the highest annual shelter expenditure figure of $\$ 21,204$. These households represent $9.3 \%$ of the data and further suggest that increasing household size 
raises shelter costs. Lone parent households and those other types listed likely have fewer members and therefore their costs are slightly below average. Household types which include multiple persons further prove that household size is a determining variable of the costs of shelter in Canada.

\begin{tabular}{|c|c|c|c|c|}
\hline Household type & Mean & $\mathrm{N}$ & Std. Deviation & $\%$ of Total N \\
\hline One person & 2345.3131 & 376402 & 2014.98576 & $31.6 \%$ \\
\hline Couple only & 4927.2481 & 261199 & 2868.36270 & $22.0 \%$ \\
\hline $\begin{array}{l}\text { Couple with single children } \\
\text { only }\end{array}$ & 7230.2772 & 302444 & 4576.70117 & $25.4 \%$ \\
\hline $\begin{array}{l}\text { Couple with other relatives or } \\
\text { unrelated persons }\end{array}$ & 8167.4300 & 110335 & 3642.66999 & $9.3 \%$ \\
\hline $\begin{array}{l}\text { Lone parent with no additional } \\
\text { persons }\end{array}$ & 5039.4156 & 57450 & 3753.96444 & $4.8 \%$ \\
\hline $\begin{array}{l}\text { Other household with } \\
\text { relative(s) }\end{array}$ & 5236.7619 & 36142 & 2646.93784 & $3.0 \%$ \\
\hline $\begin{array}{l}\text { Other household with unrelated } \\
\text { person(s) }\end{array}$ & 6170.8572 & 45698 & 4071.69405 & $3.8 \%$ \\
\hline Total & 5058.9302 & 1189670 & 3956.47477 & $100.0 \%$ \\
\hline
\end{tabular}

Transportation expenditures are highest for the largest household types within the data set. Although couples with relatives and other unrelated persons only represent $9.3 \%$ of the cases, it is the household type with the highest transportation costs; most likely attributed to its size and inclusion of independent individuals who travel to work. Couples with single children make up $25.4 \%$ of all cases, and incur the second highest transportation expenditure of $\$ 7,230$, which is $42.9 \%$ higher than the mean for British Columbia. Trends among household types suggest that number of persons within a household will increase the average expenditures for both principle accommodation and transportation. 


\section{Interprovincial Analysis}

\section{Shelter}

The province with the highest annual shelter expenditure in 2008 was Alberta, totaling $\$ 15,904$. Average Shelter Expenditures by Province

- Quebec- $\$ 11,237$

- Ontario - $\$ 15,348$

- Alberta - $\$ 15,904$

- British Columbia - $\$ 14,664$

Tenure type was the most significant variable for determining for how much households spent on shelter in 2008. Those households which owned their homes and had a mortgage paid significantly higher average shelter expenditures than other forms of tenure. Quebec contained the highest percentage of rental units for a province, which contributed to lower shelter annual shelter expenditures. Rental properties cost the least amount of money annually to run. Furthermore, these dwellings were occupied by one and two person households which also have the lowest shelter expenditures as they require less space, potentially less utilities and less transportation than larger households.

\section{Transportation}

The province with the highest transportation expenditure in 2008 was Alberta, totaling $\$ 5,580$. Average Transportation Expenditures by Province

- Quebec - $\$ 3,937$

- Ontario - $\$ 5,494$

- Alberta - $\$ 5,580$

- British Columbia - $\$ 5,508$

The variable 'household size' had the most significant margin of increase out of all variables tested. In several cases, the increase in transportation increases between one and two member 
households was near or above $100 \%$. This supports the hypothesis that household size dictates the amount of annual income that is dedicated to providing shelter and transportation. The margins of increase for the four provinces include $111 \%$ for Quebec; $97.5 \%$ for Ontario; $75.8 \%$ for Alberta; and 106\% for British Columbia. These subsequent increases in size were seen in household type data, where households containing more than one person had significantly higher annual expenditures. Alberta also had the largest amount of single detached dwellings equaling $60.6 \%$ of cases, which is a common indicator of lower density development which requires private automobiles. Larger households living in larger dwellings could necessitate and need for more transportation expenditures which is supported by the analysis. 


\section{Conclusions}

After analyzing the four provincial data sets, most trends appeared to be uniform regardless of location which supports the hypothesis presented that housing size and characteristics influence the annual shelter and transportation expenditures for Canadian households. It can also be seen though the analysis that the theoretical model is incorrect and that in actuality as shelter expenditures increase so too will transportation expenditures. Trade-off curves have been used to show this relationship. These curves are meant to illustrate the relationship of one variable to another. In the theoretical model, as shelter costs increase along the $\mathrm{X}$ axis, transportation values decrease. The actual model, as represented by the findings within this study shows that as shelter costs increase, so too do the values of transportation.

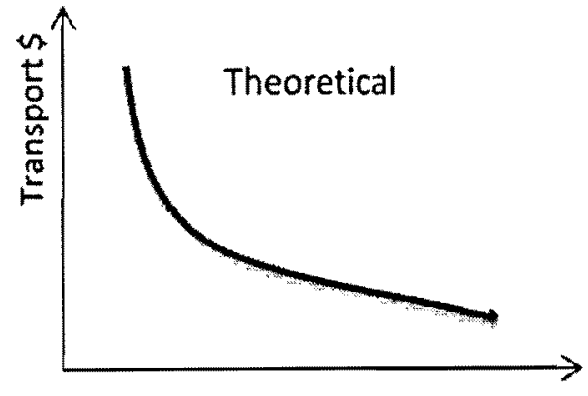

Shelter $\$$

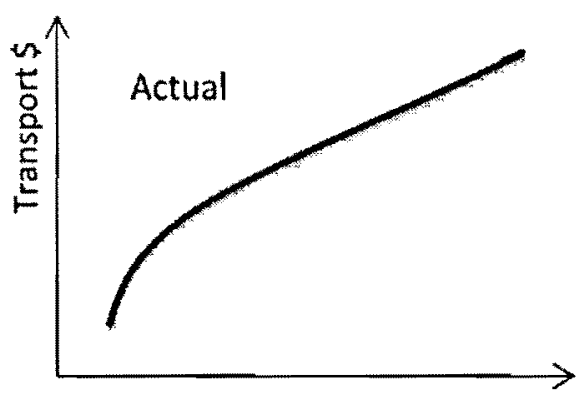

Shelter \$

\section{More Rooms $=$ Larger Household}

As the number of bedrooms increased in each data set so did the subsequent cost of shelter. This can be attributed to the fact that if a home has more rooms, it is larger and in all likelihood a single detached, semi-detached or row house dwelling. Smaller unit sizes, as those in apartments had lower shelter costs because of less space and estimated lower occupancy.

\section{More Household Members $=$ Higher Annual Expenditures}

Households which included more people had higher annual shelter and transportation costs than smaller one. This can be attributed to the need for more space, more transportation services 
(more private vehicles, more transit tickets), as well as other household costs associated with the upkeep of a large economic family unit.

\section{Families Incur Higher Annual Costs Than Singles and Couples}

When children were added to households in each province, those households immediately had the highest shelter and transportation costs. The same was true for households with extended families or other unrelated person; the more people making up an economic family unit, the higher the annual expenditures for both shelter and transportation.

\section{Renters Spend Less on Shelter and Transportation}

Households which owned their homes had much higher annual expenditures than those which rented. Smaller households, such as singles and couples, had the lowest expenditure of any household type. These types of household may be more incline to rent dwellings such as apartments as they would not require the additional space or amount of transportation that large household units would.

As Canadian cities continue to grow, planners and academics alike should consider the findings brought forward in this report. Planners must reevaluate the strategies currently being recommended that encourage increased urban living, which is expensive and has been shown to lead to increased transportation expenditures. Different households have different needs and there must be more variance in planning decisions to create economically sustainable alternatives. 
Academic literature needs to be expanded and focus on the importance of household characteristics and how they relate to annual expenditures. Literature based solely on density and income has influenced how cities and towns are planned within Canada. As the Canadian population continues to evolve, academics need to look more closely at household characteristics and how they influence annual expenditure levels.

The analysis provided has demonstrated that household size has a significant effect on the amount of annual income spent on shelter and transportation by Canadian households. The needs of larger households inherently lead to a consumption of more space, utilities and transportation service regardless of surrounding density and their location and of residence. 


\section{Appendix A Number of Bedrooms in Quebec}
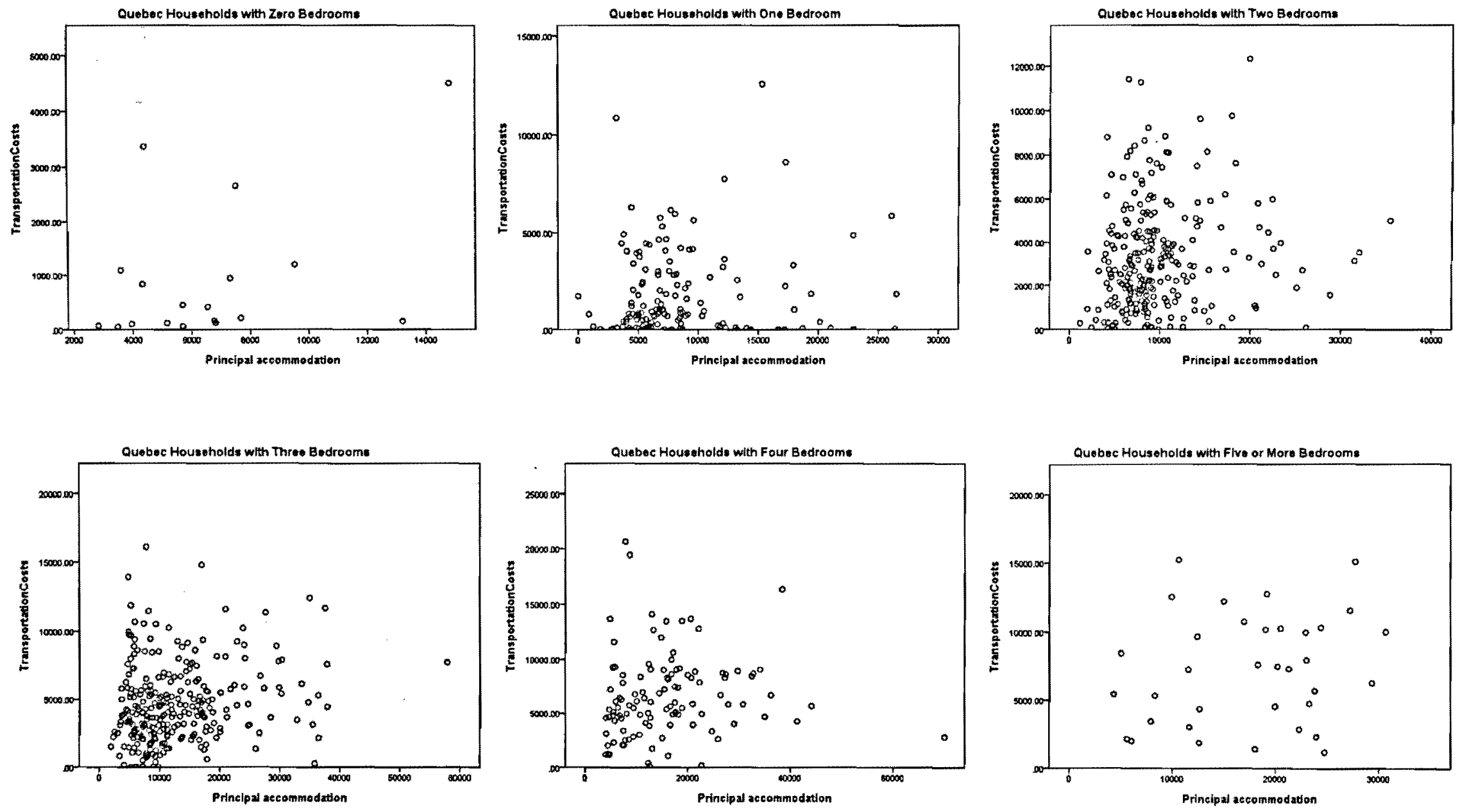


\section{Appendix B Tenure Type in Quebec}
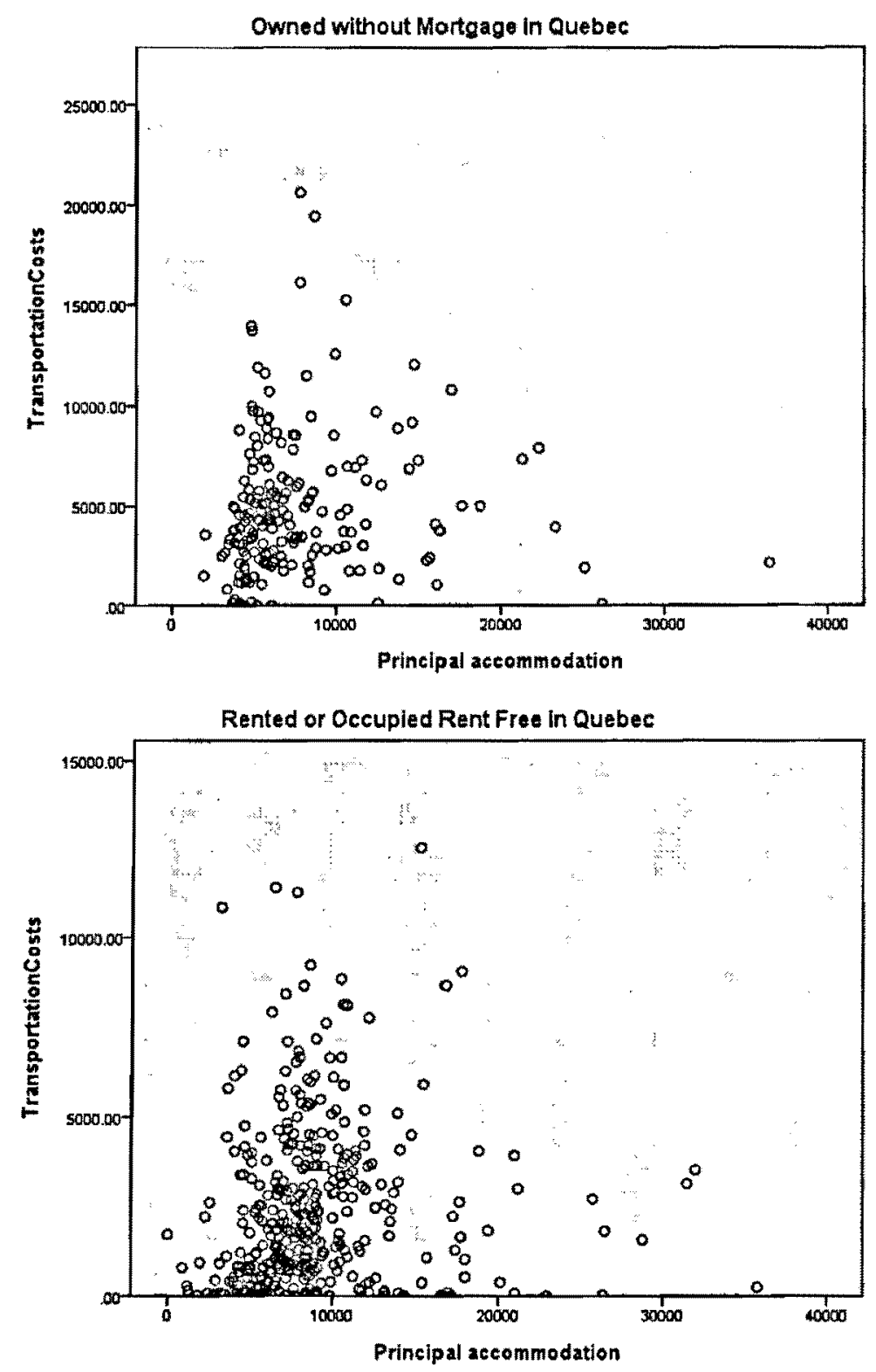
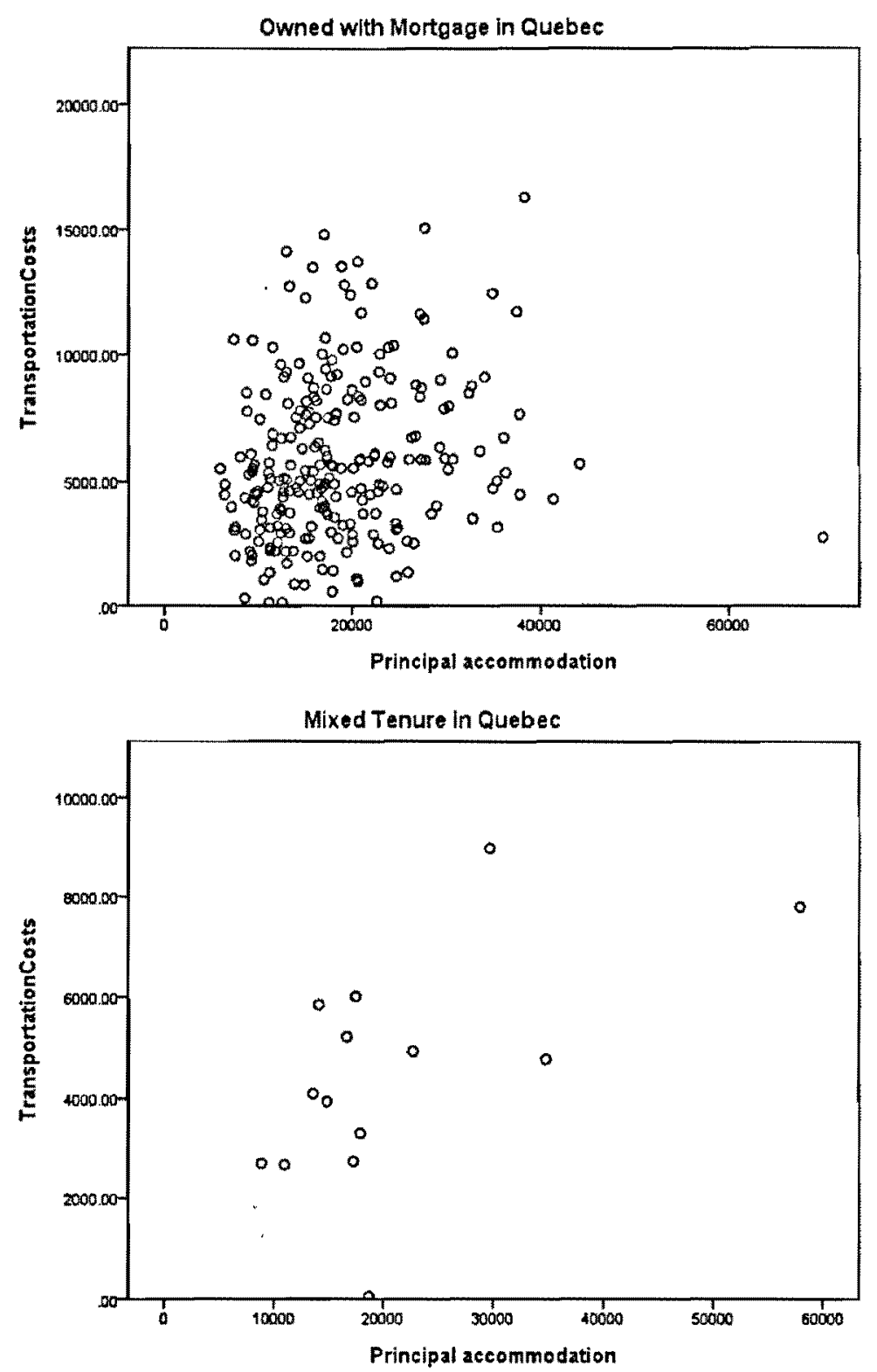

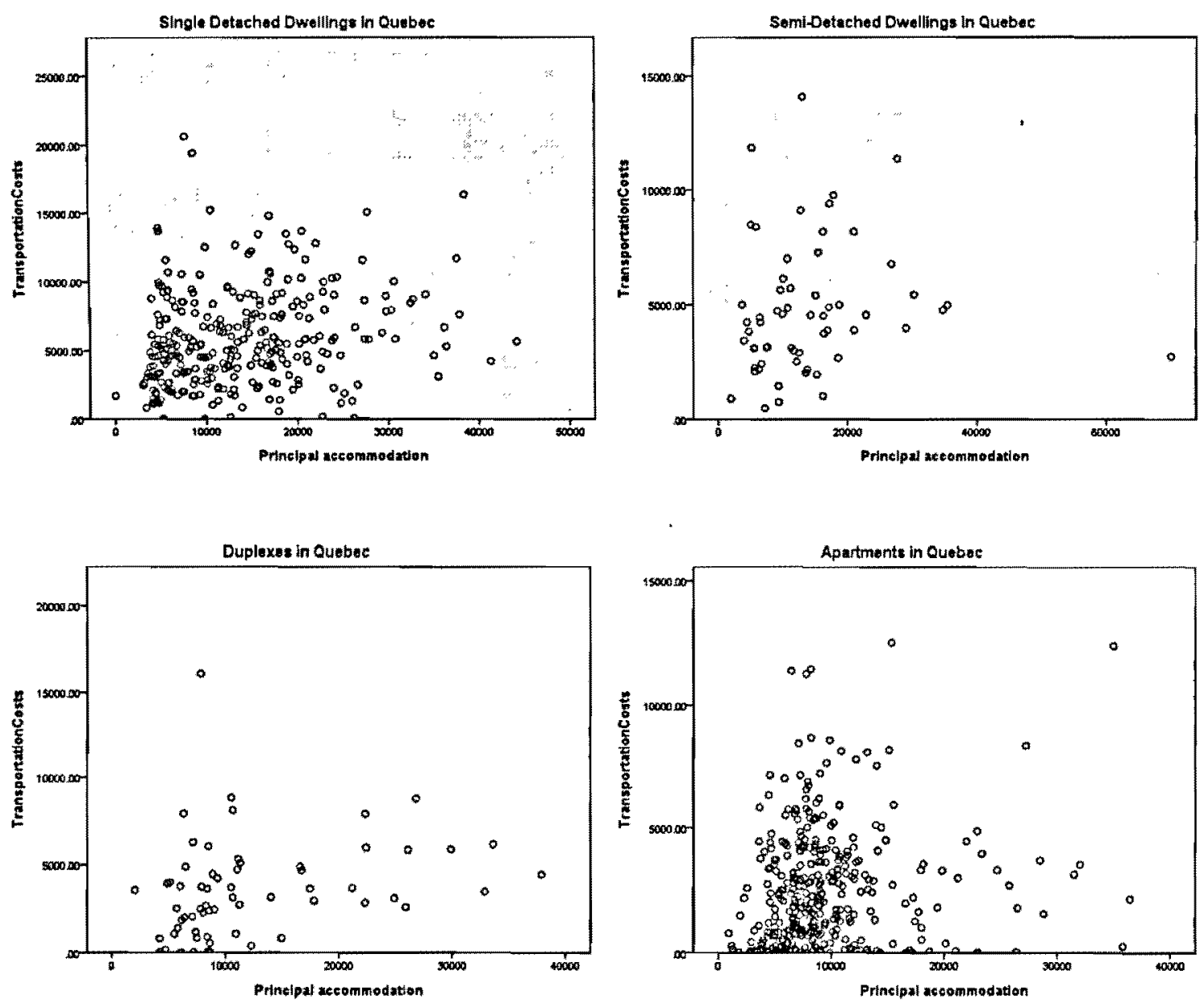
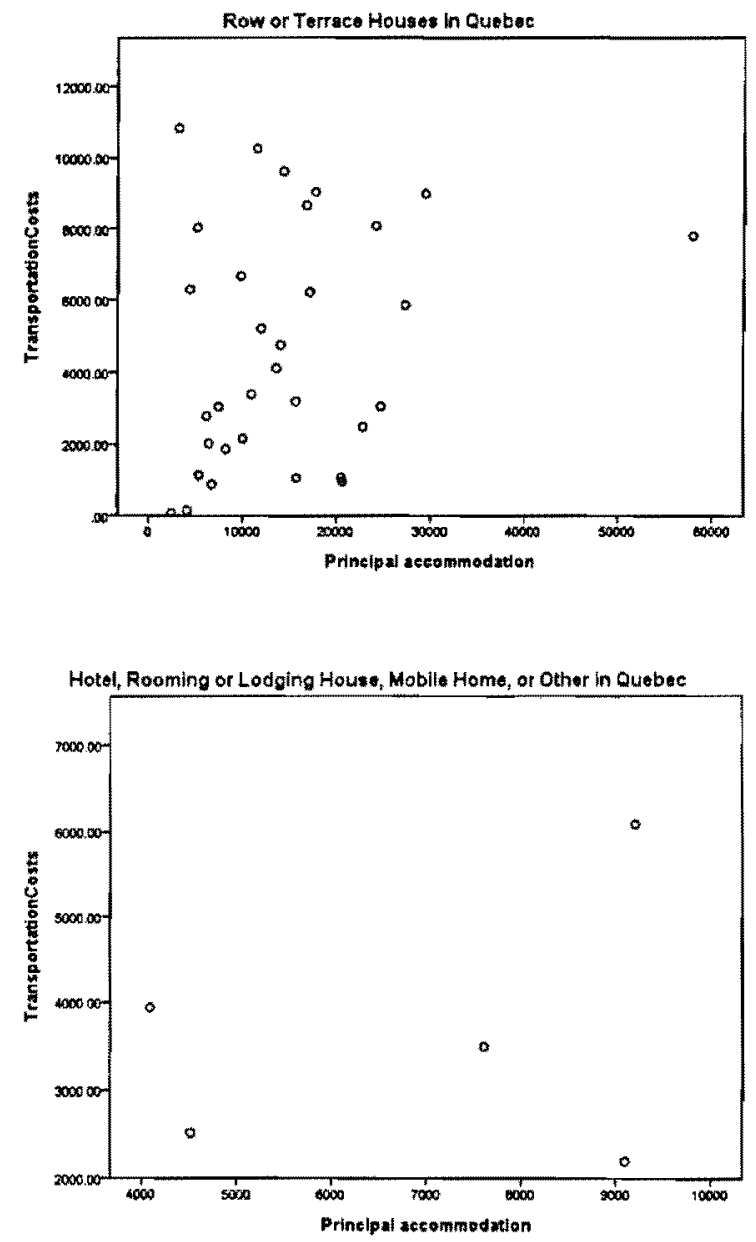


\section{Appendix D Households by Size in Quebec}
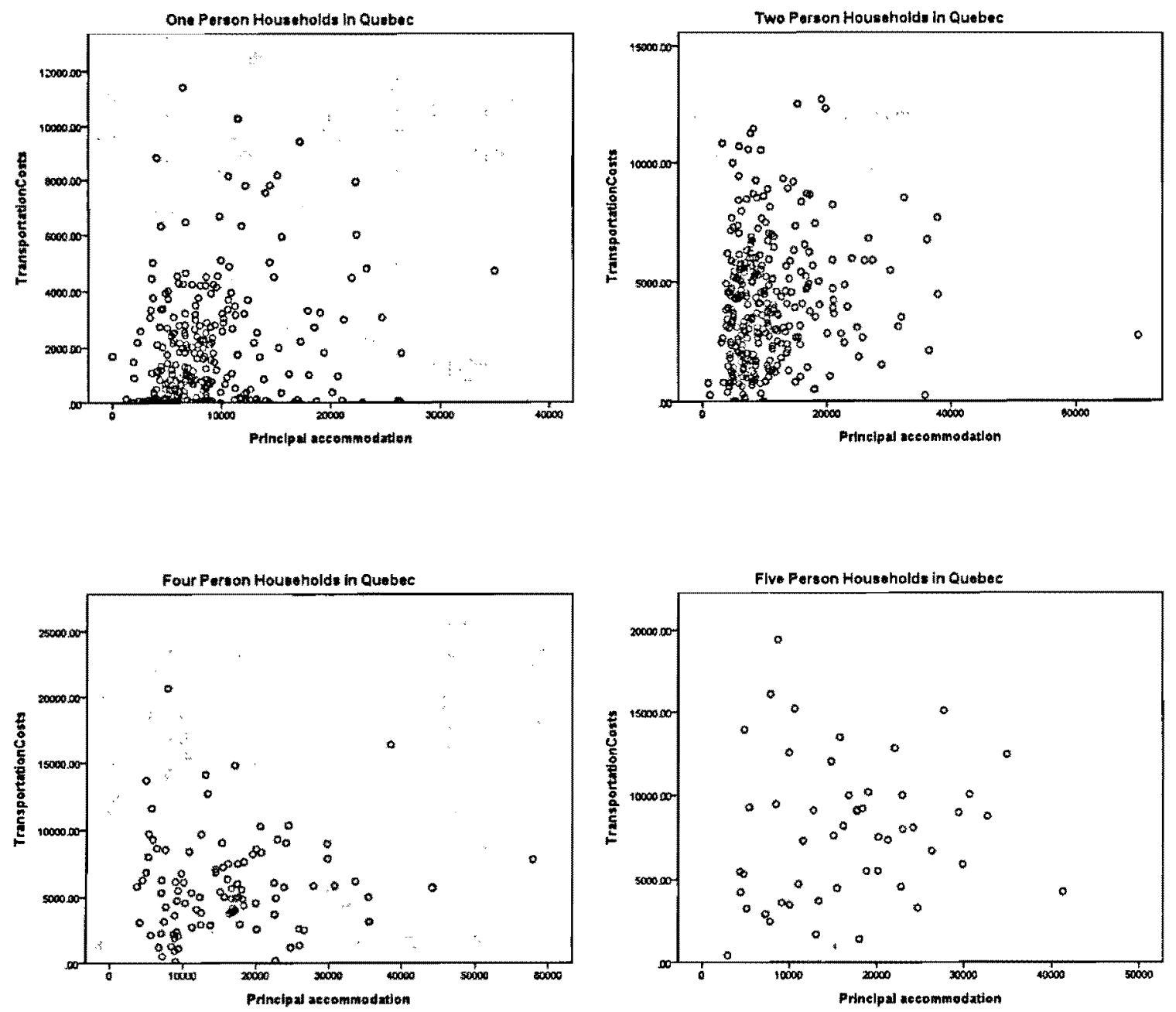
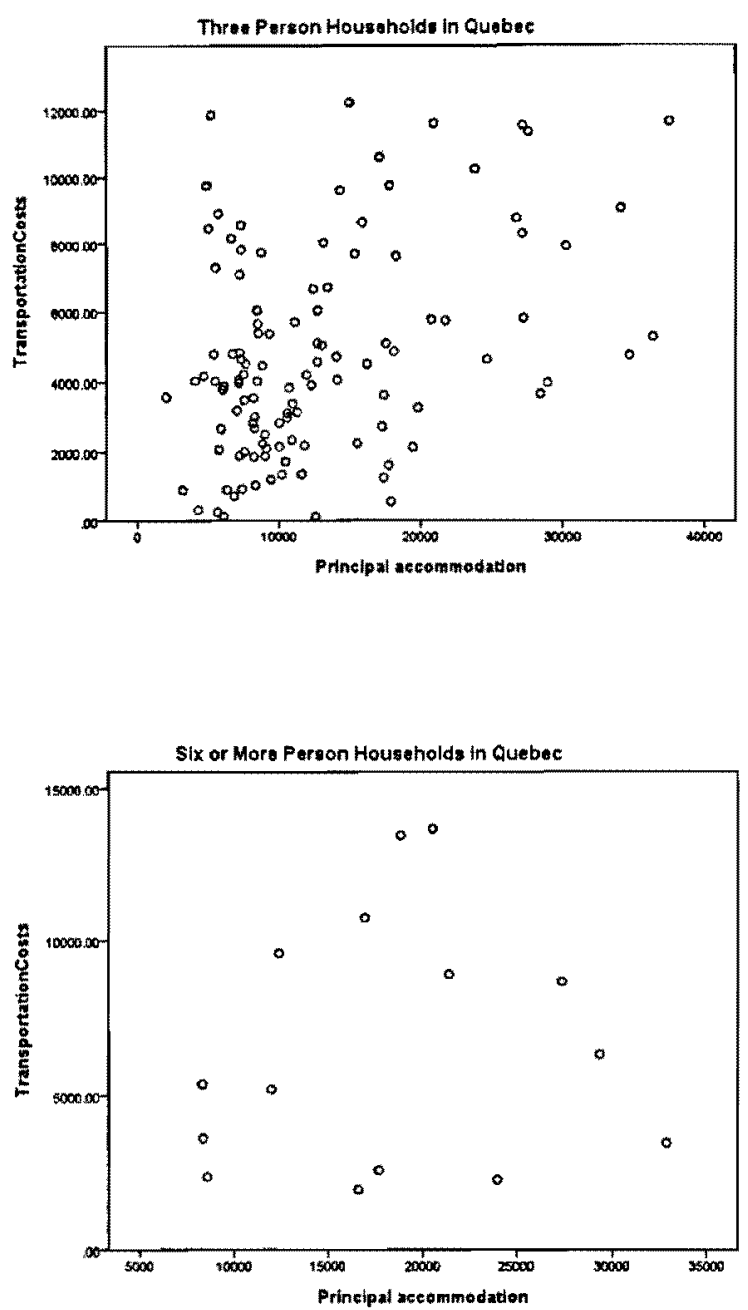


\section{Appendix E Household Types in Quebec}
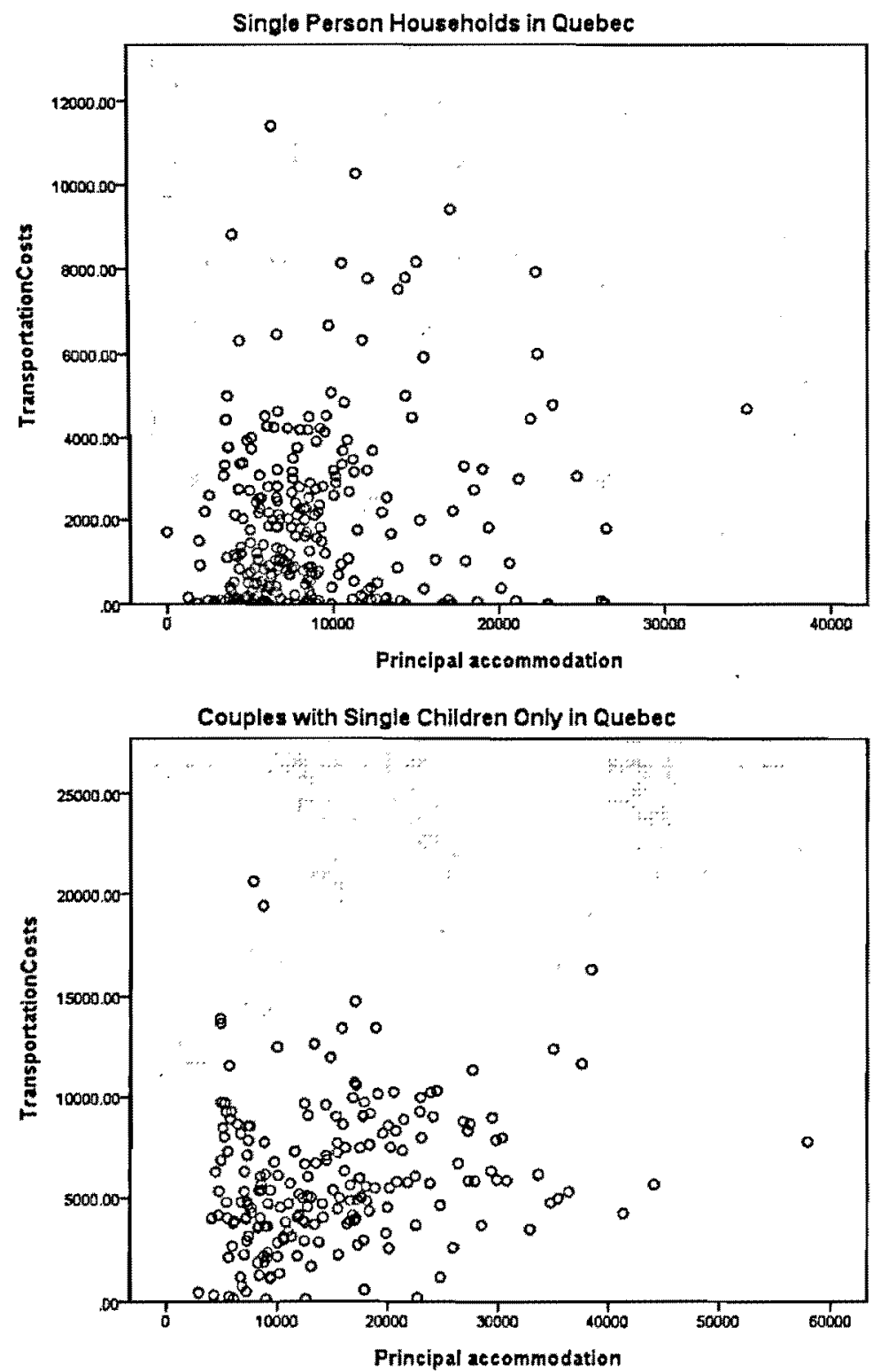
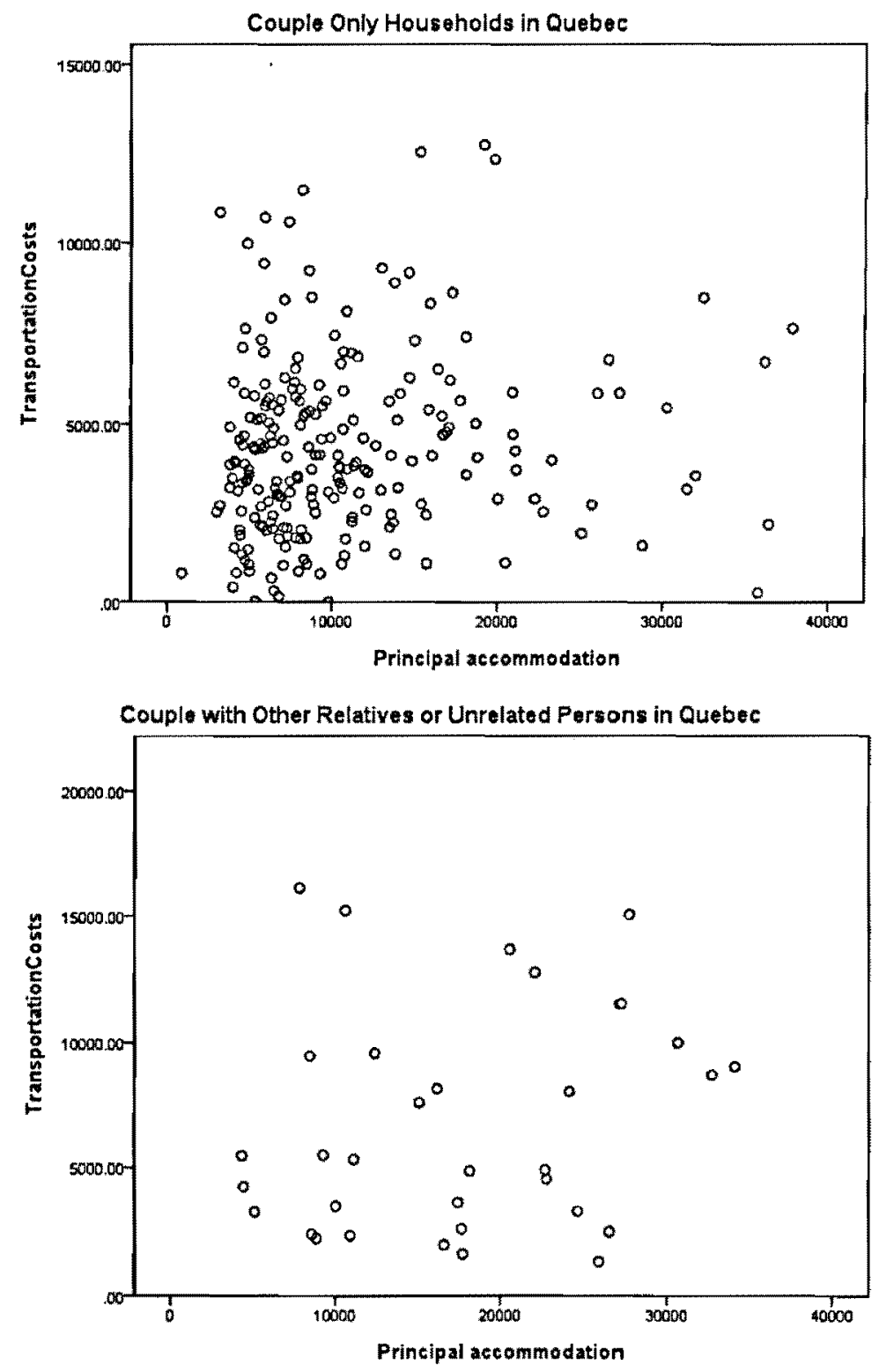

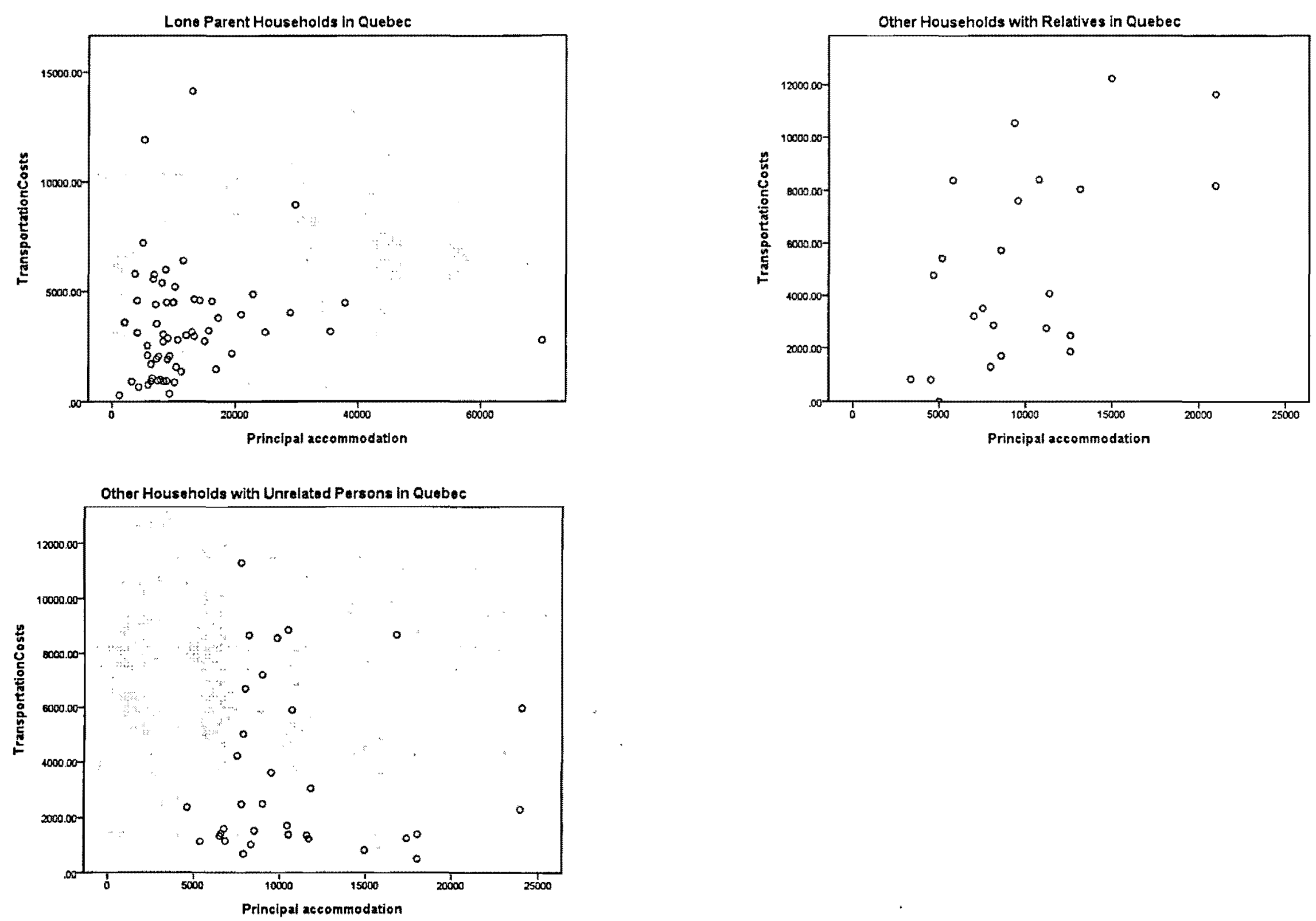

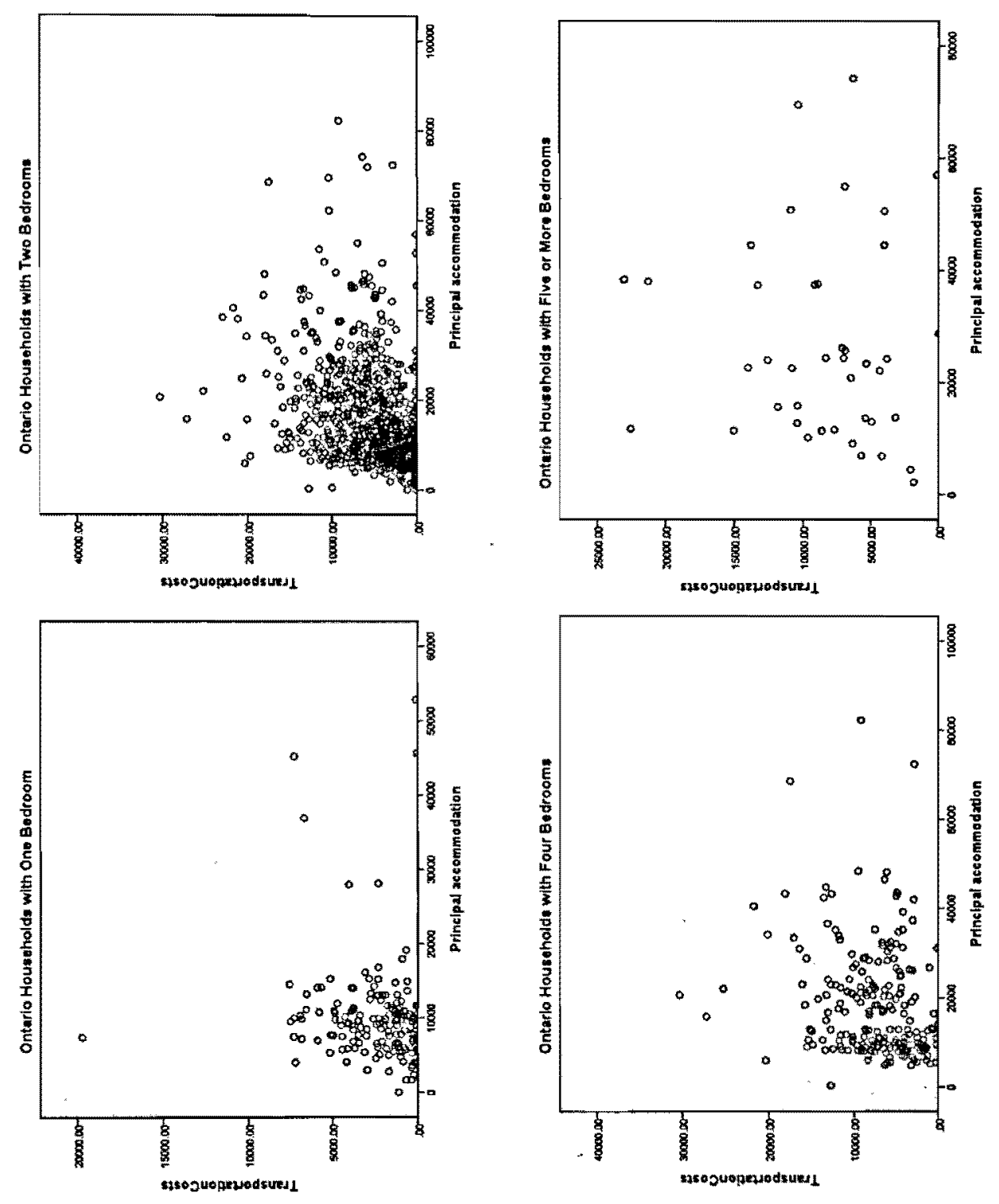

$m$
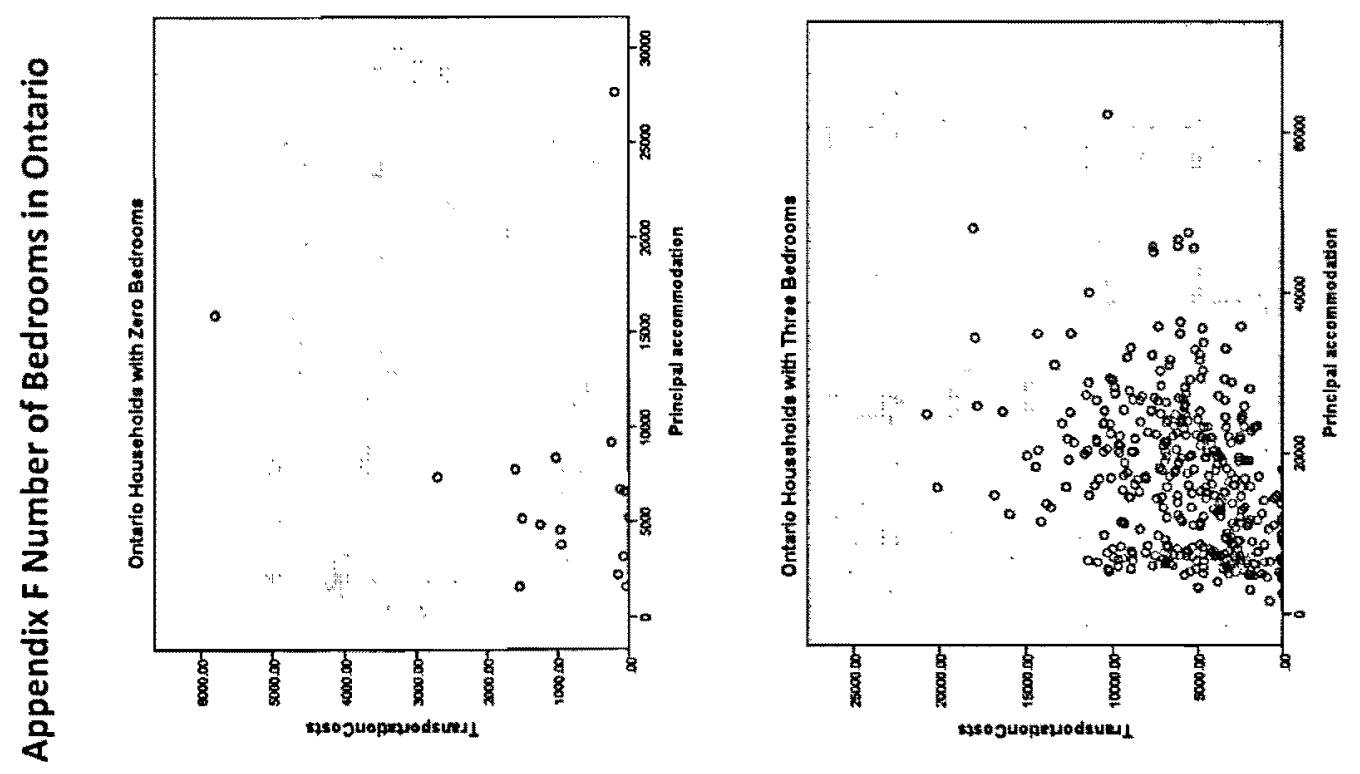


\section{Appendix G Tenure Type in Ontario}

Owned without Mortgage in Ontario

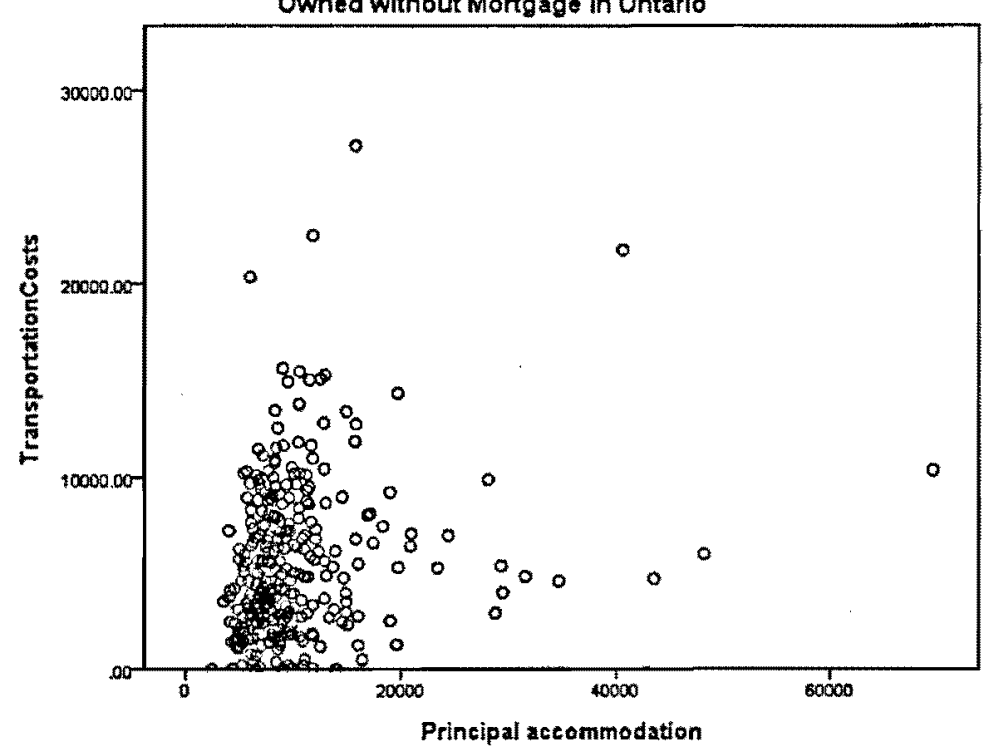

Rented or Occupied Rent Free in Ontario

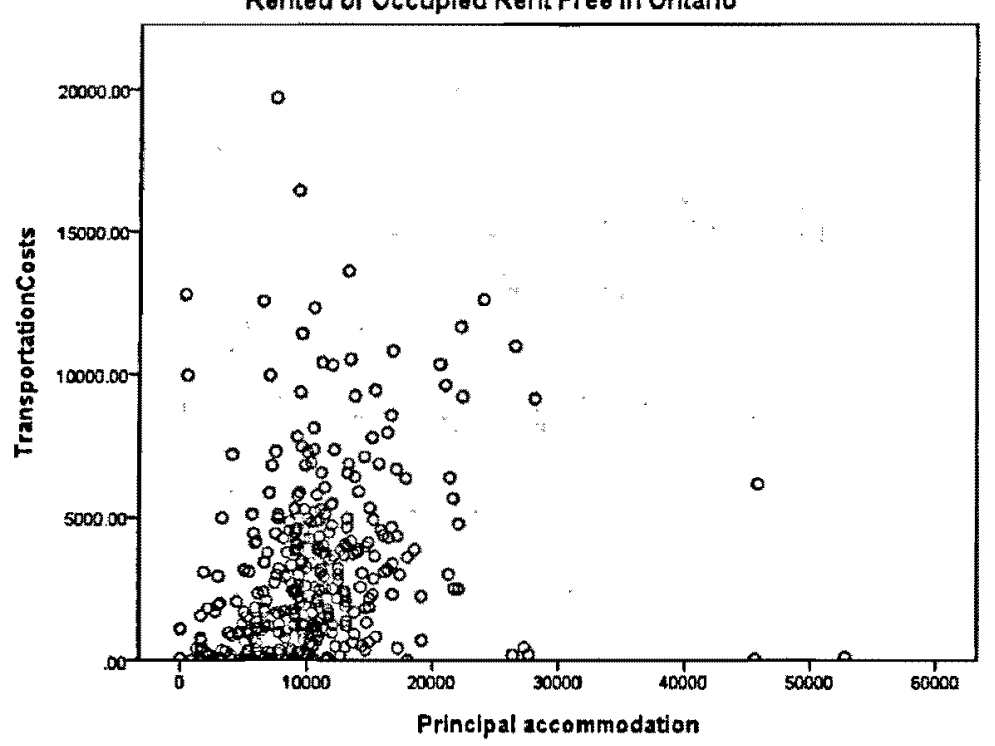

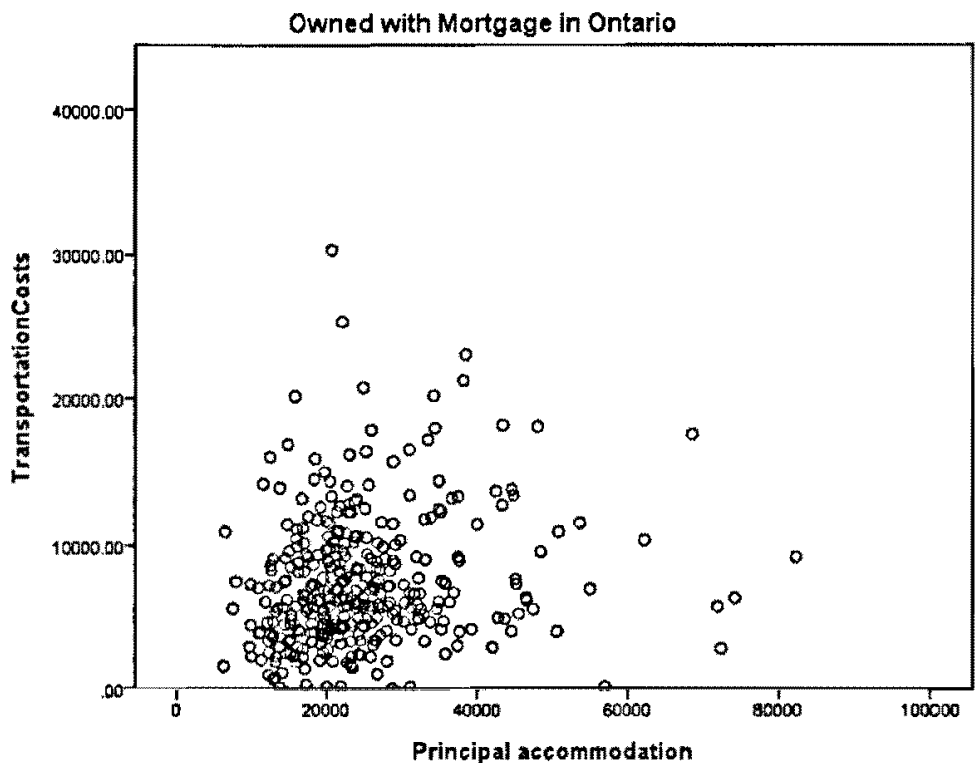

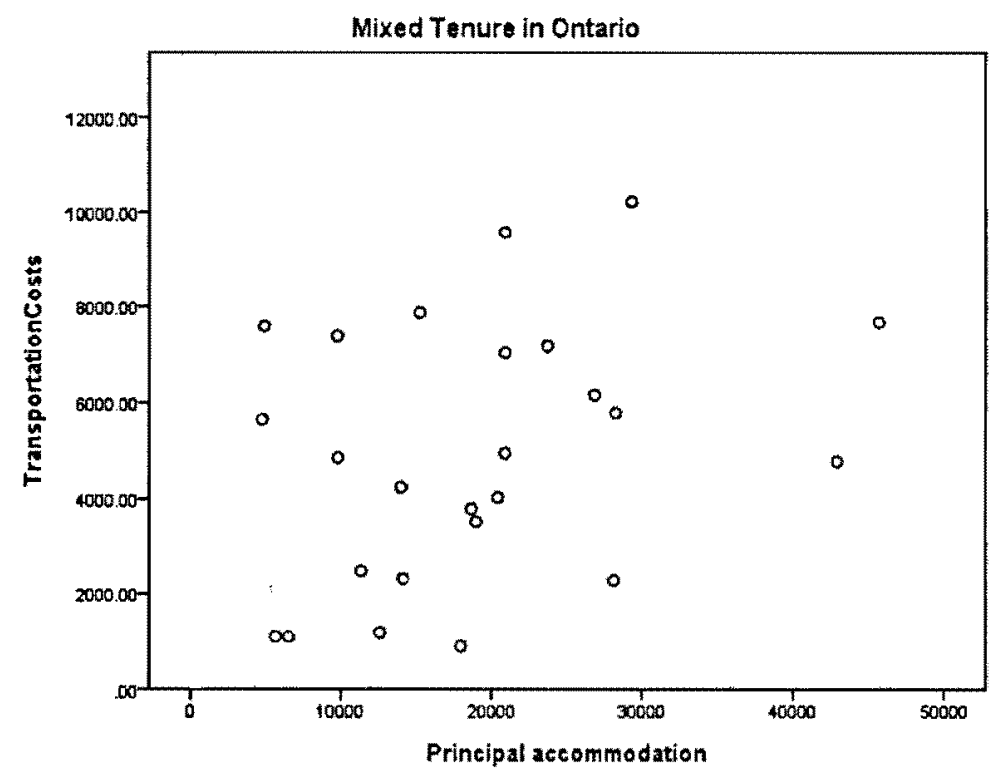




\section{Appendix $\mathrm{H}$ Households by Dwelling Type in Ontario}
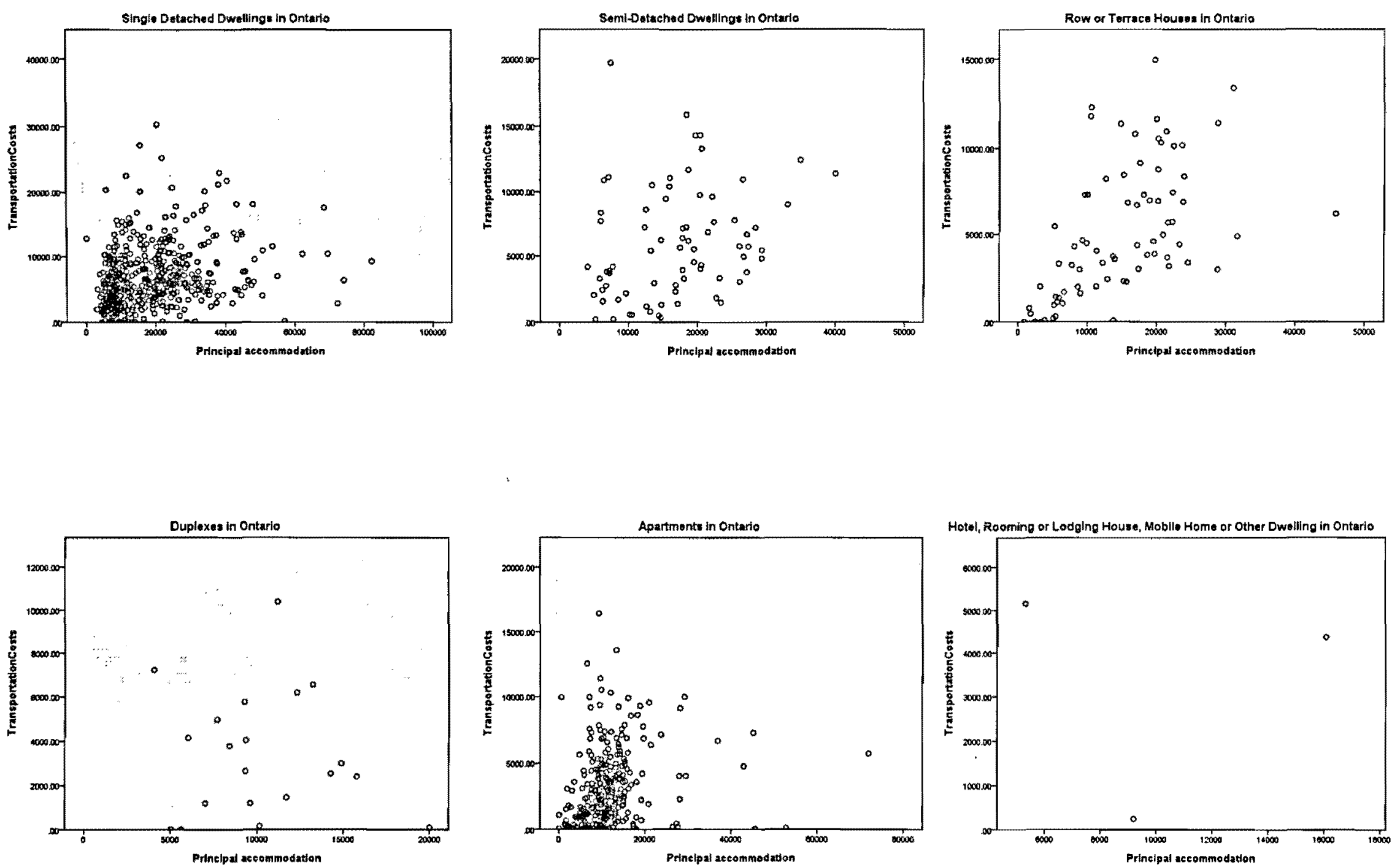

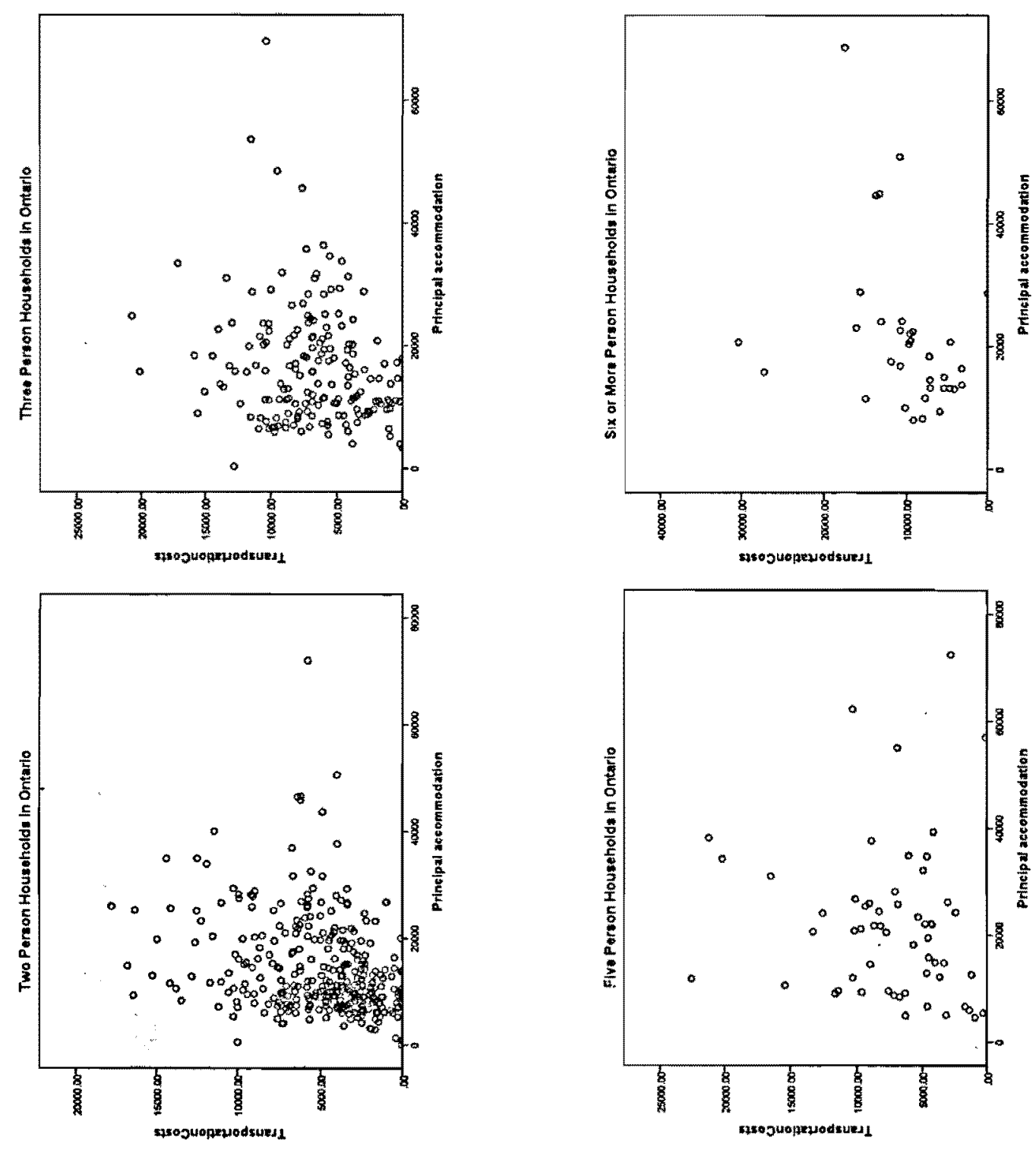

$\mathscr{R}$
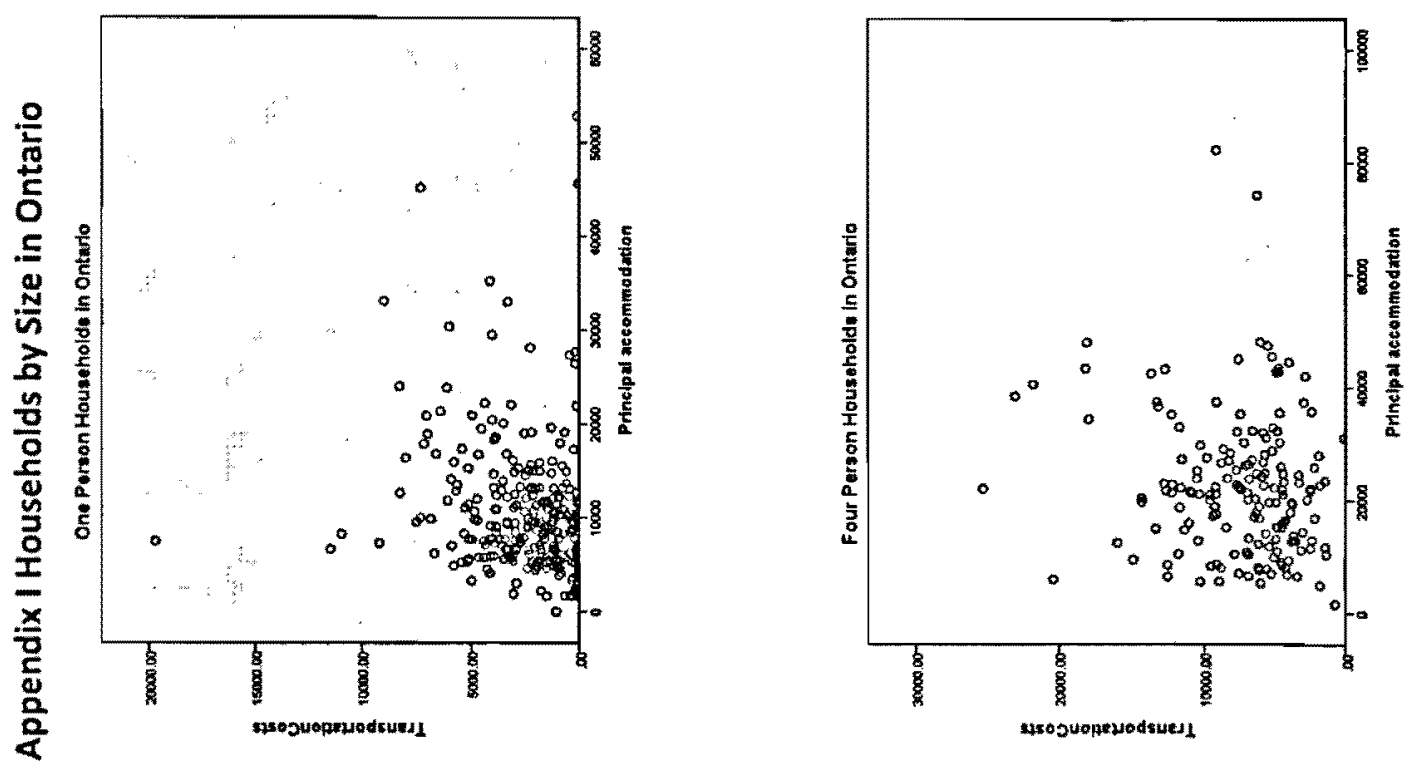


\section{Appendix J Households by Type in Ontario}
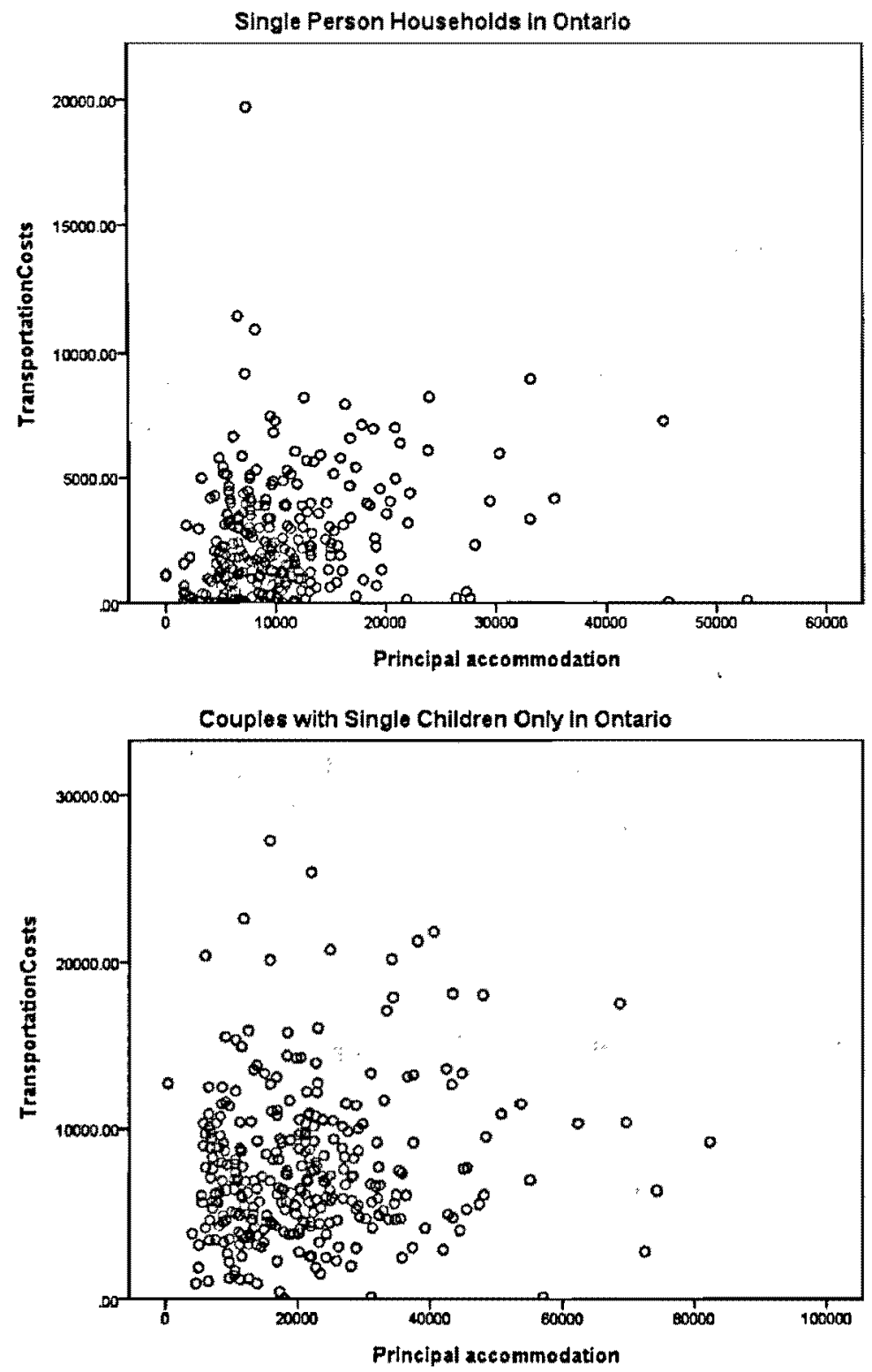
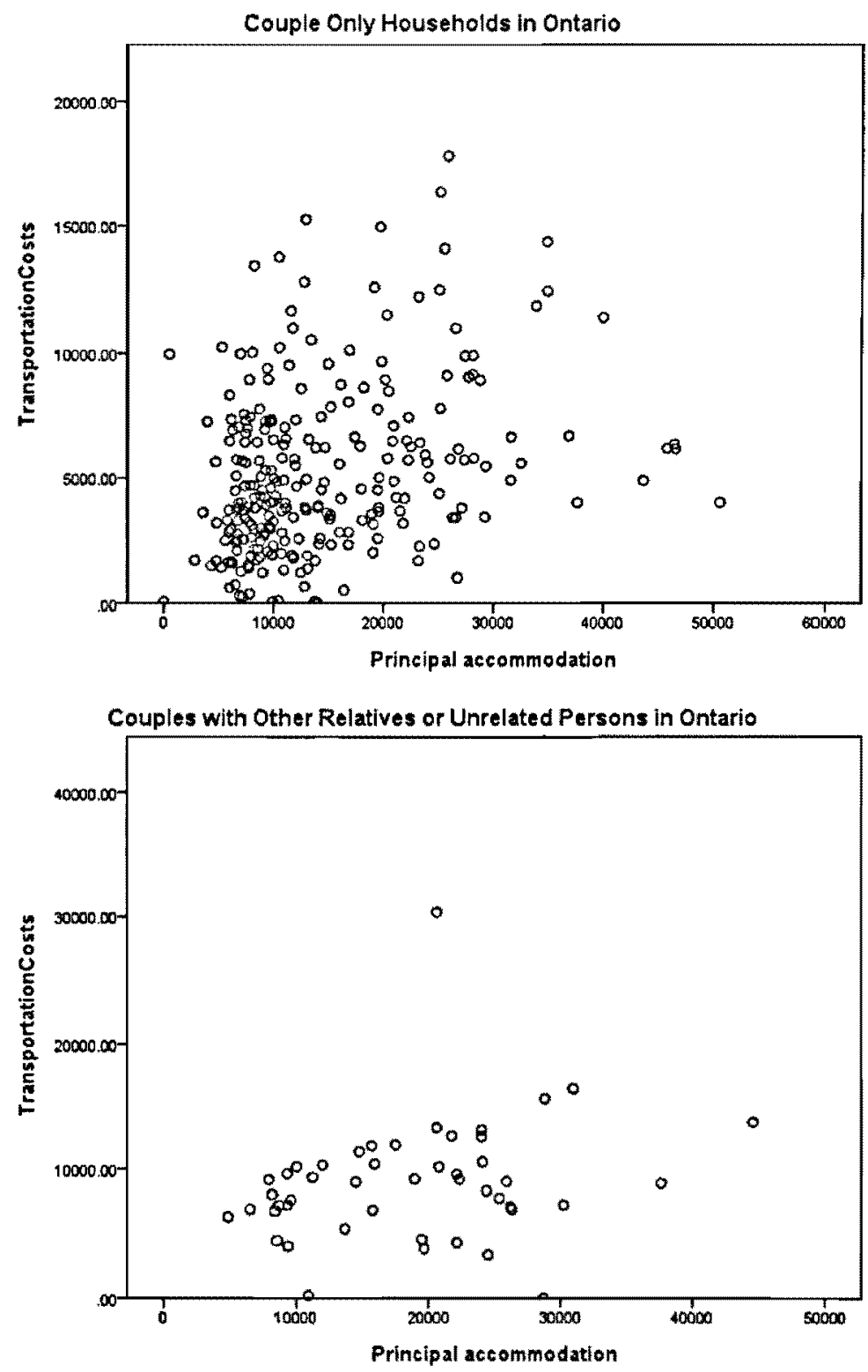

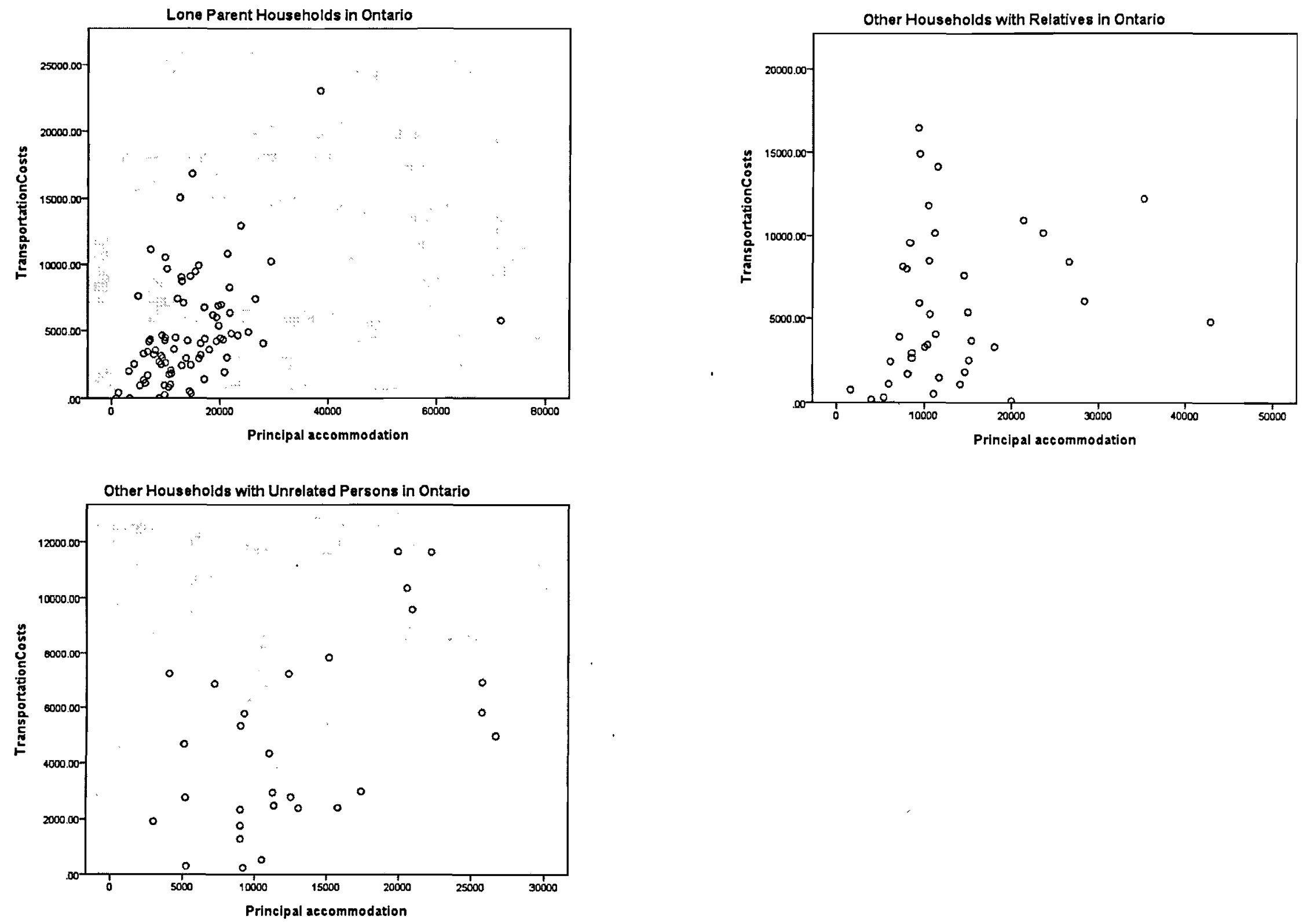


\section{Appendix $\mathrm{K}$ Number of Bedrooms in Alberta}
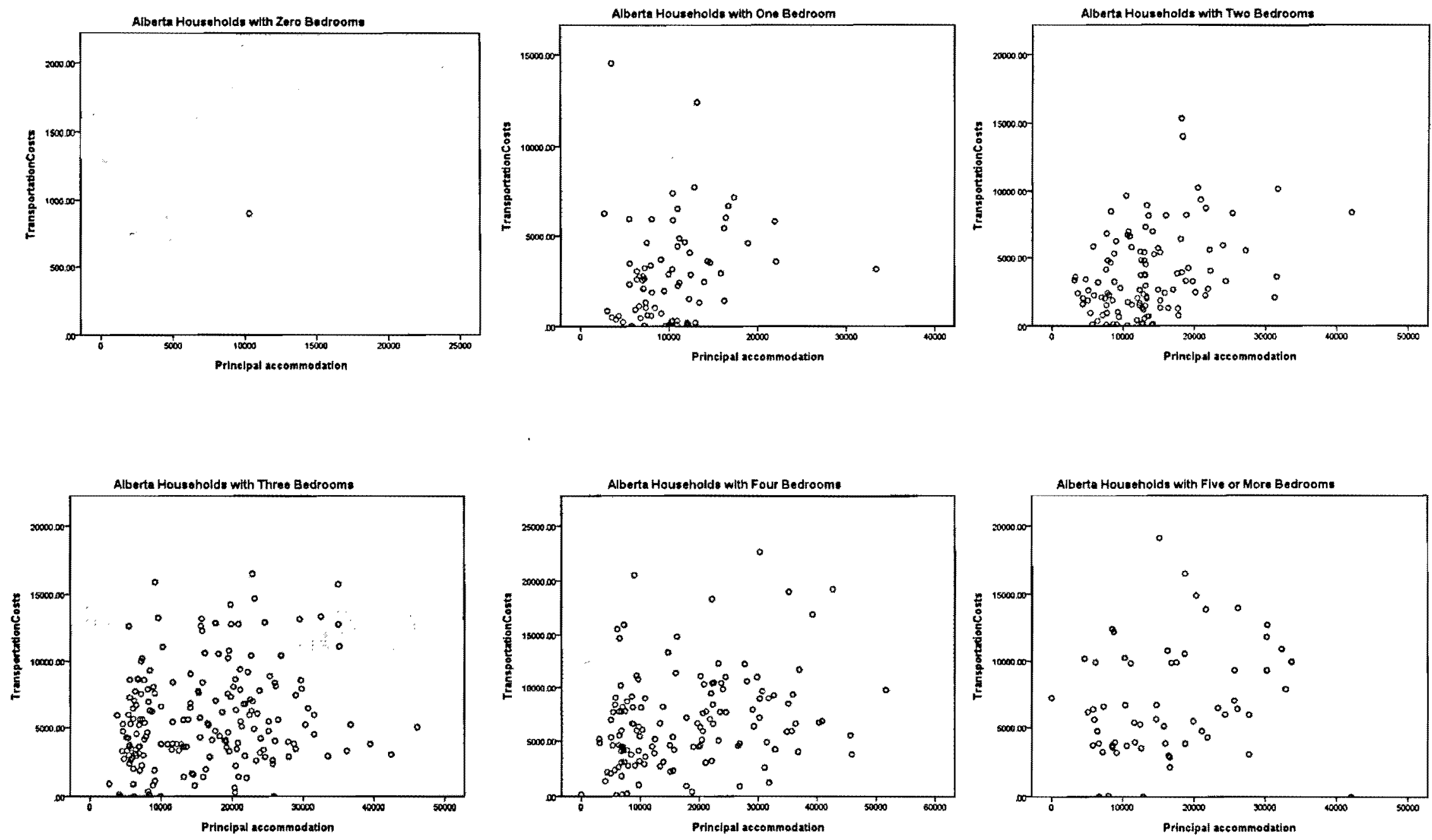


\section{Appendix L Tenure Type in Alberta}
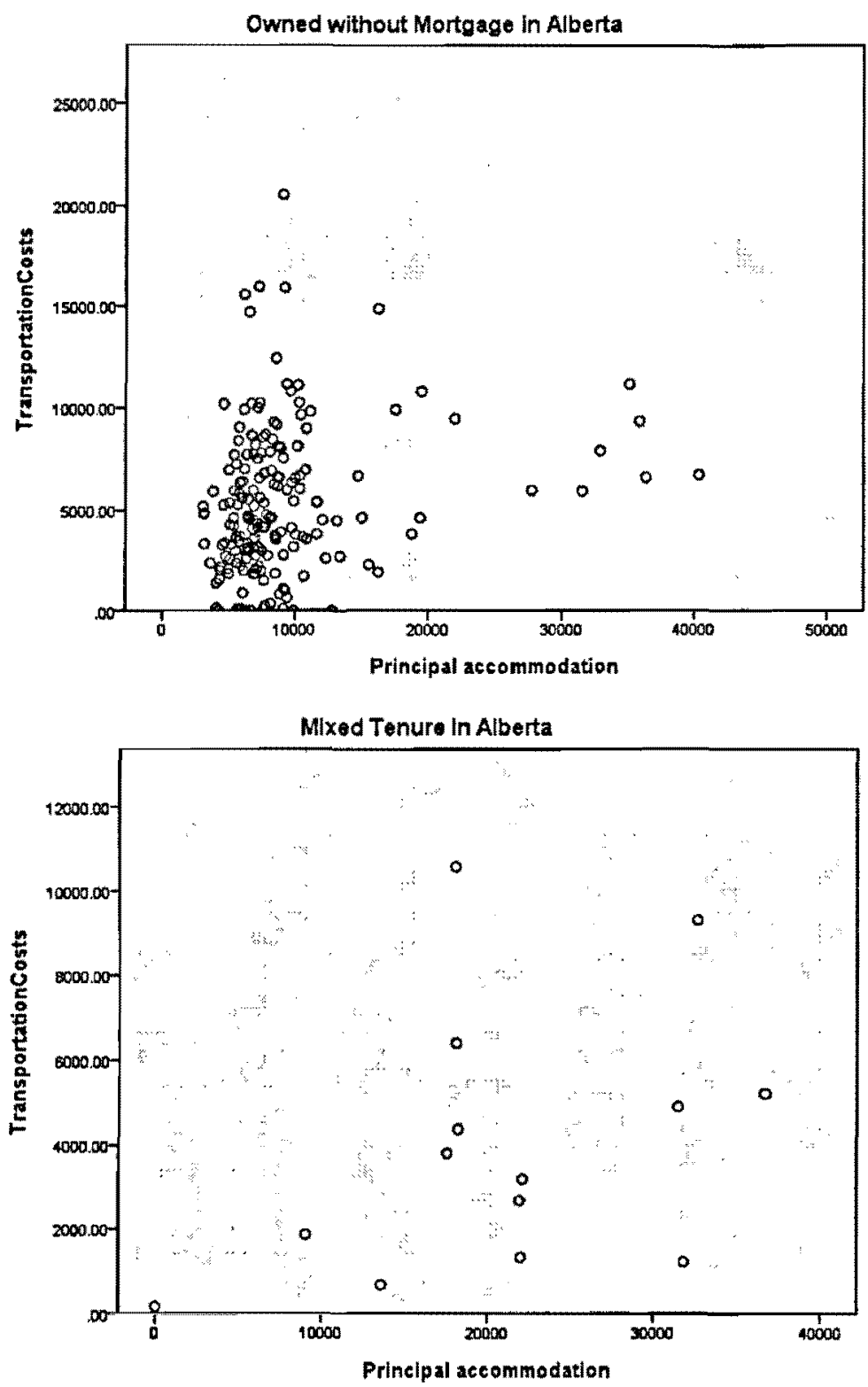
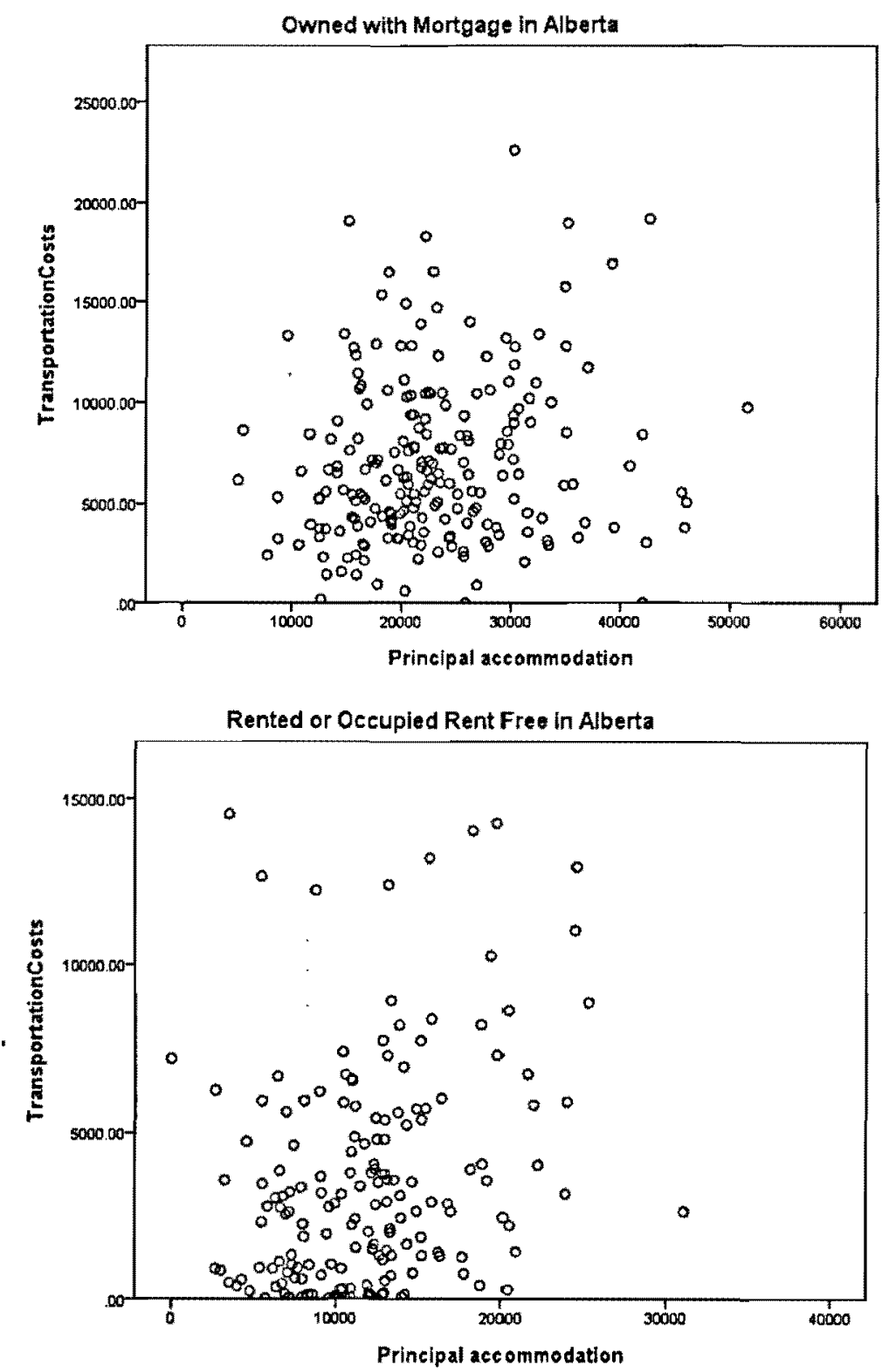


\section{Appendix $M$ Households by Dwelling Type in Alberta}
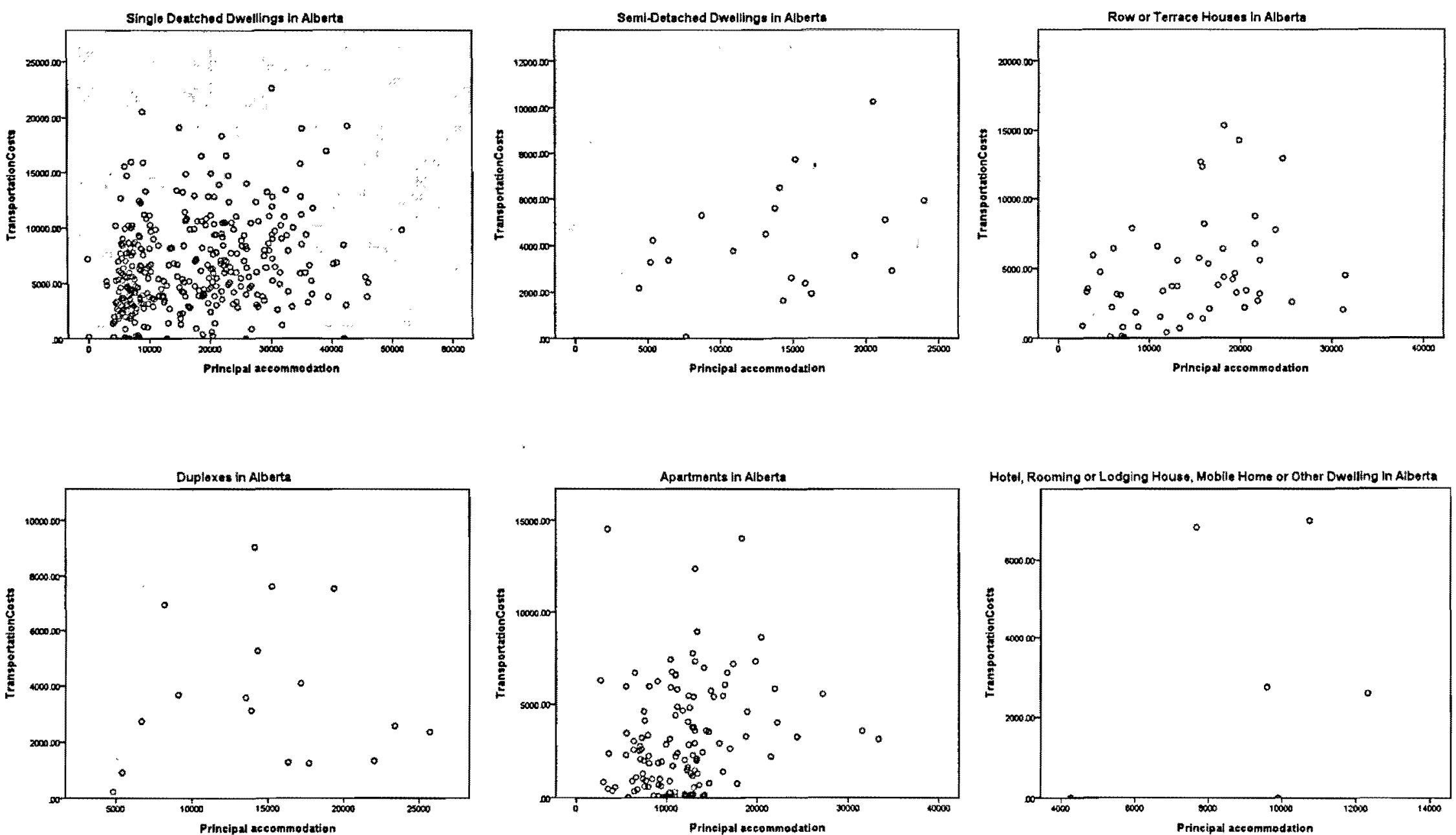

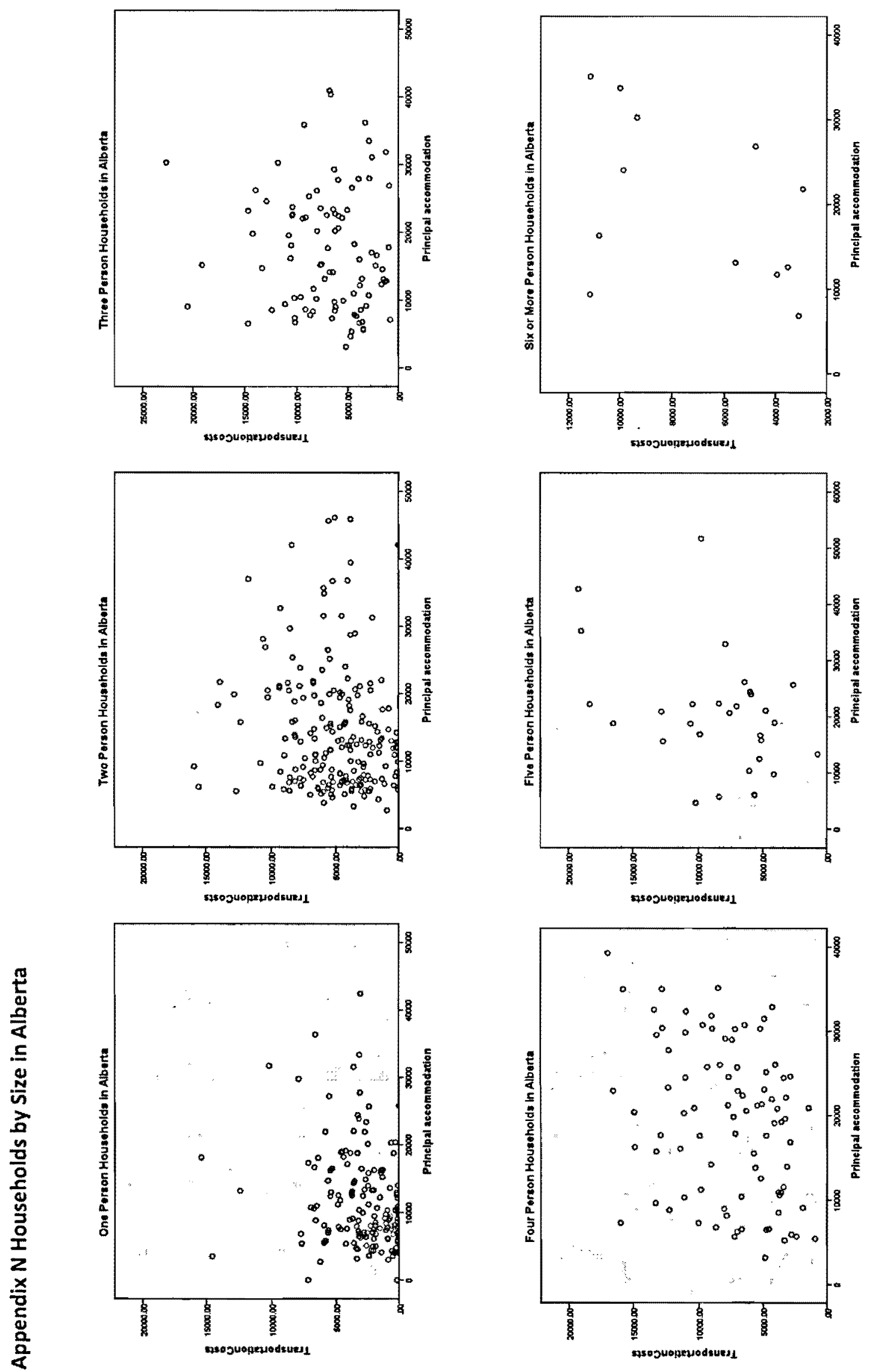

$\stackrel{N}{\infty}$ 


\section{Appendix $\mathrm{O}$ Households by Type in Alberta}
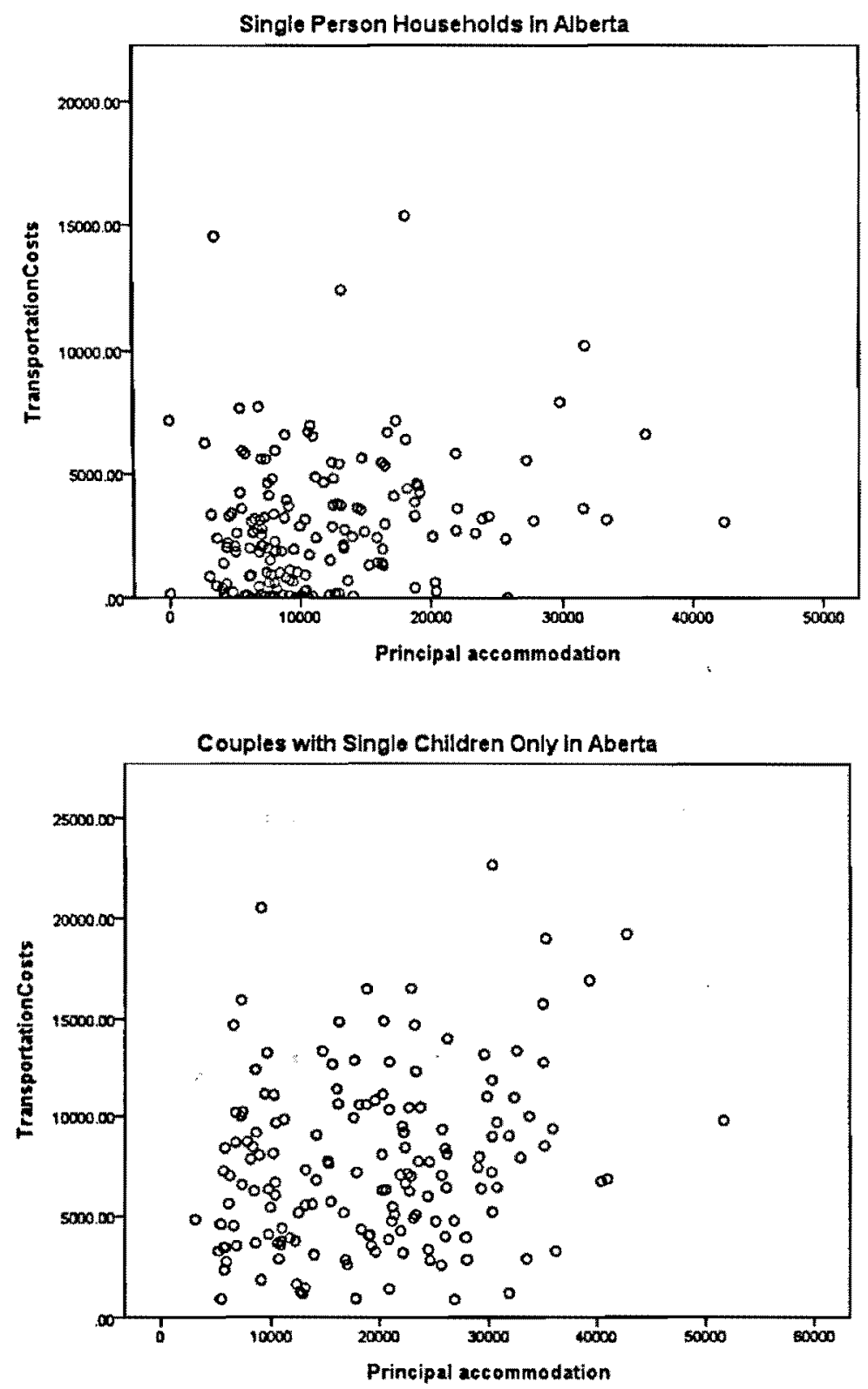
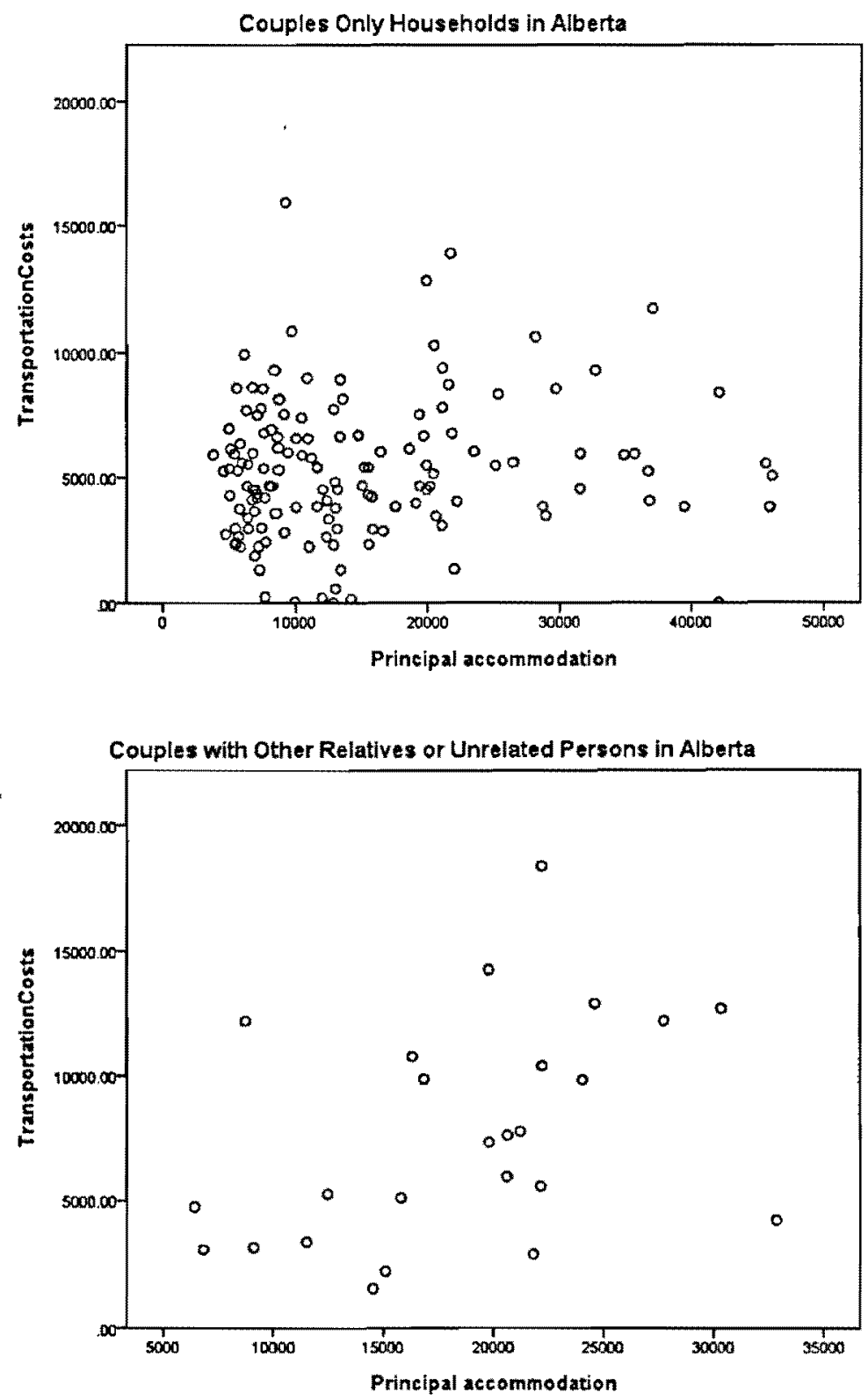

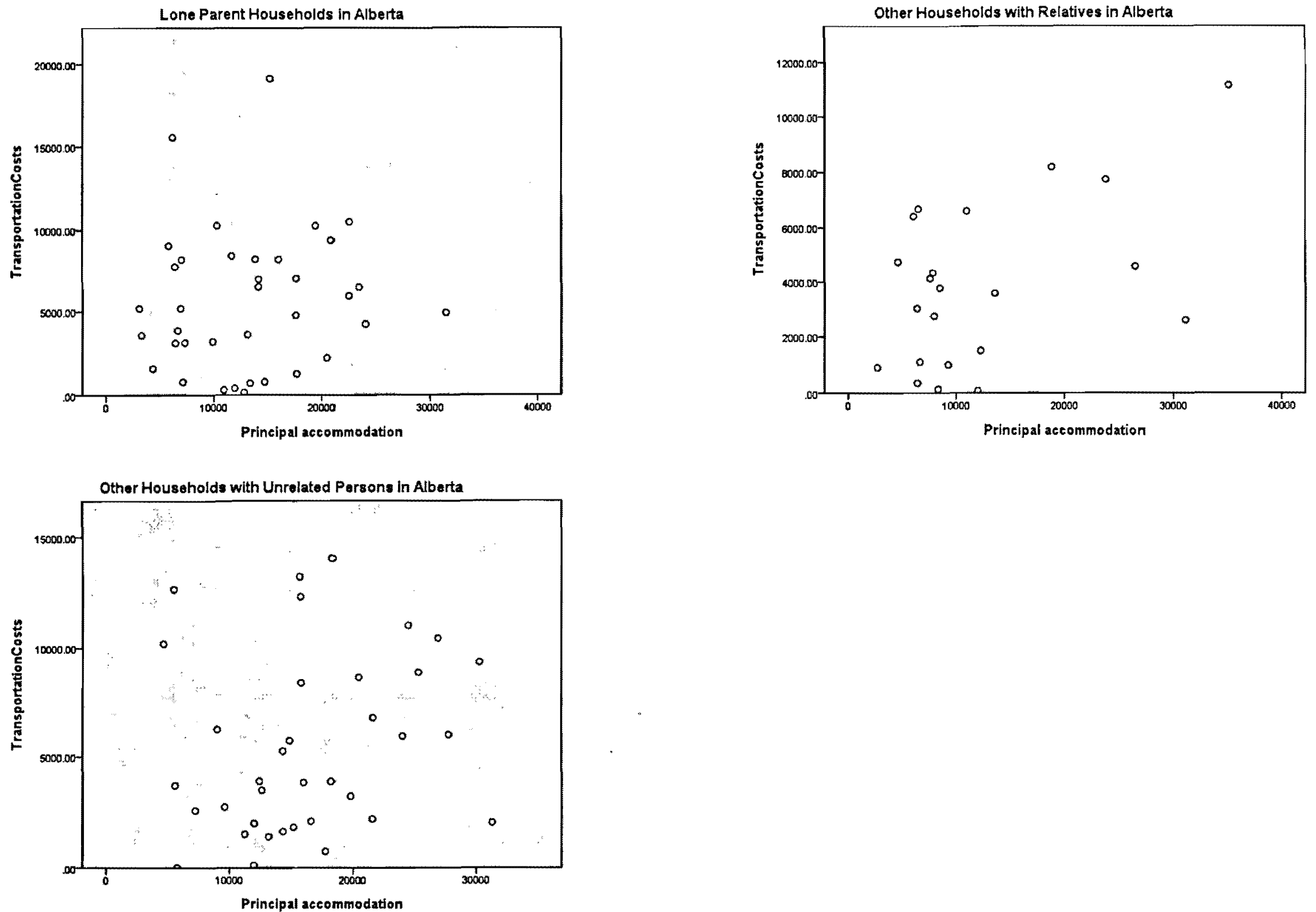
Appendix P Number of Bedrooms in British Columbia
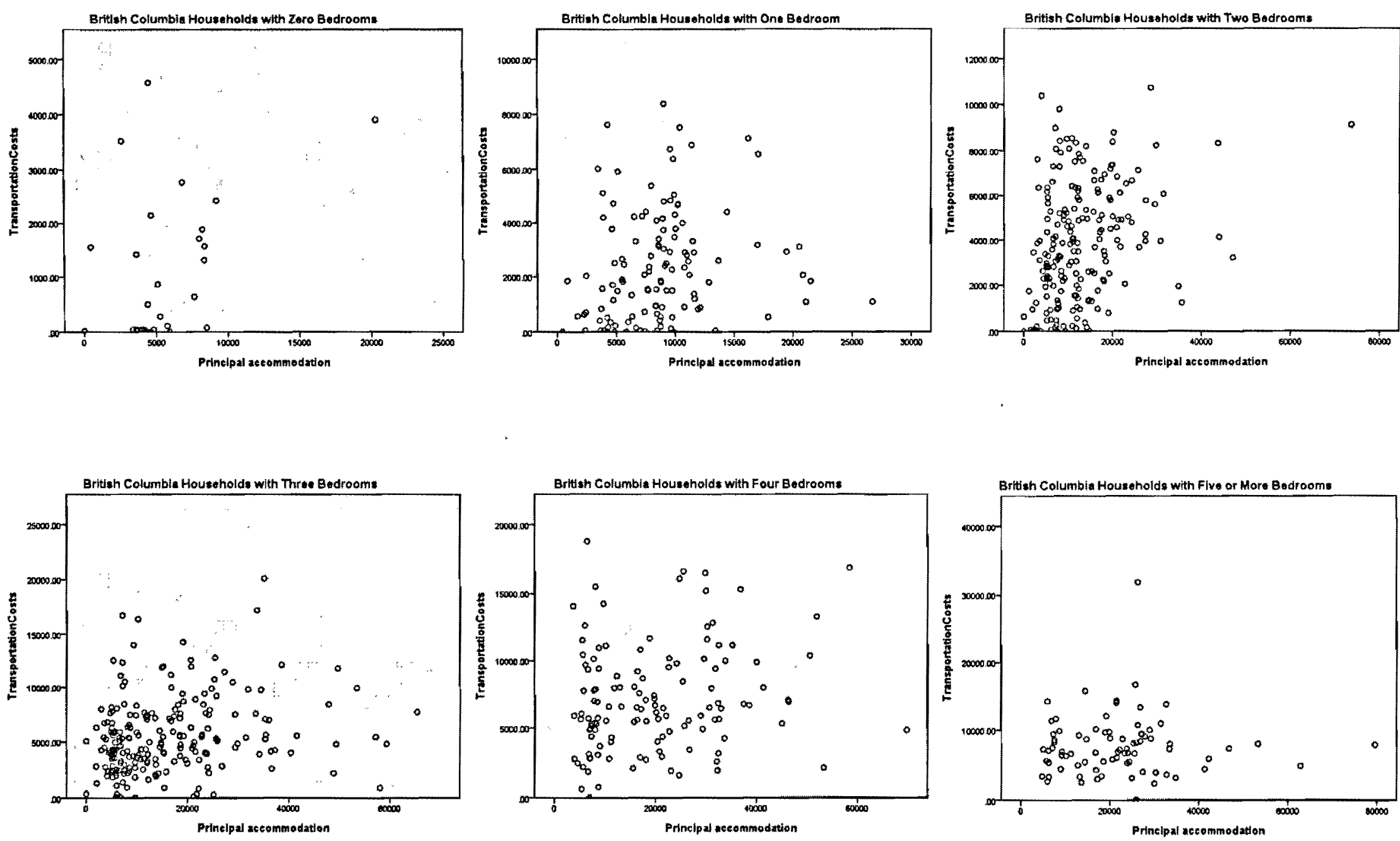
Appendix Q Tenure Type in British Columbia

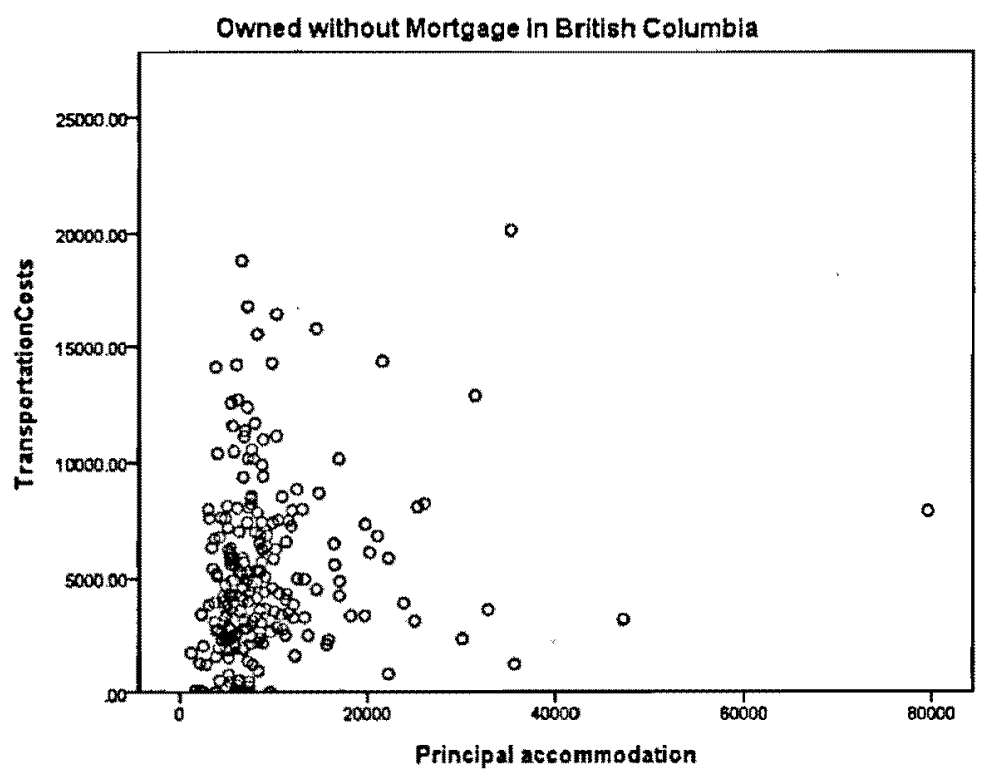

Rented or Occupled Rent Free In British Columbia

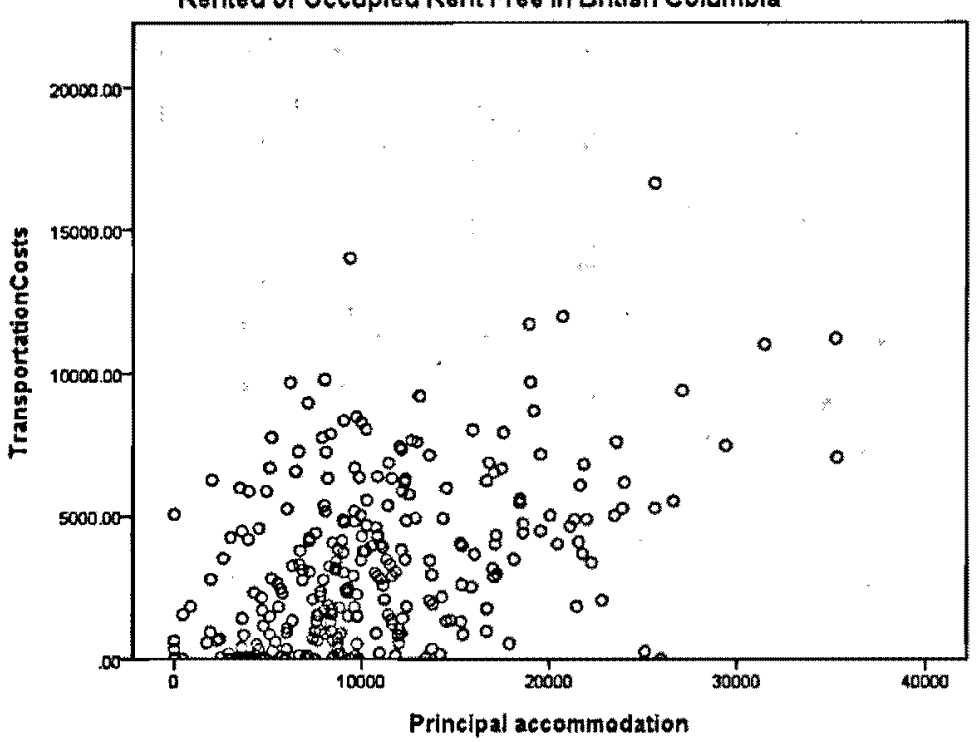

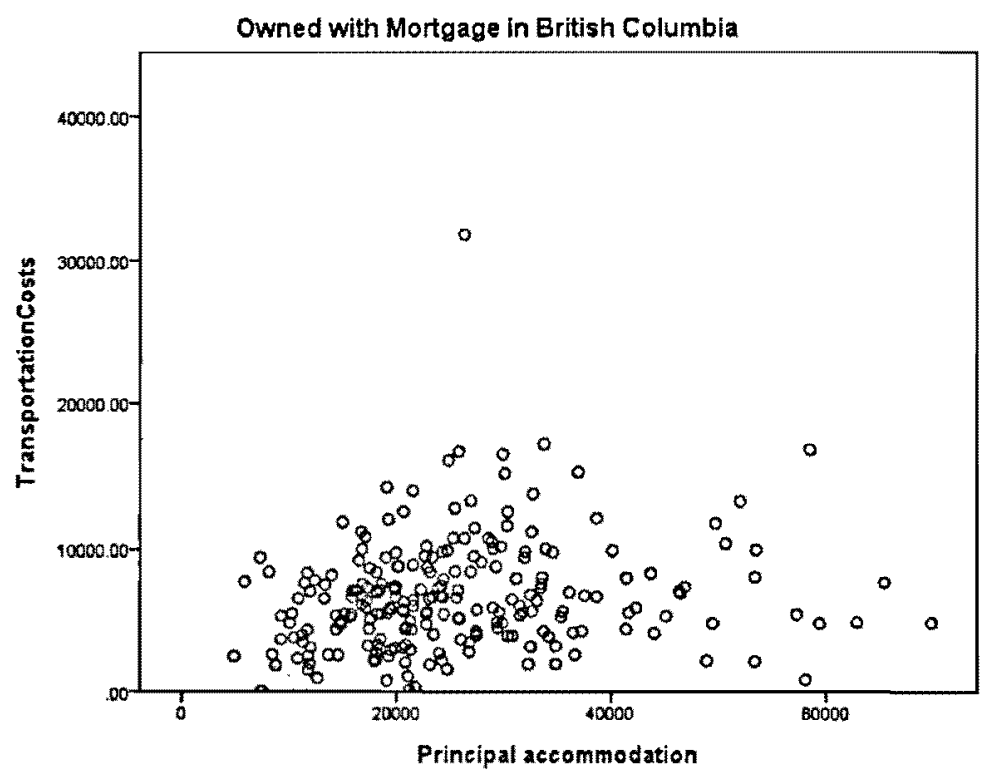

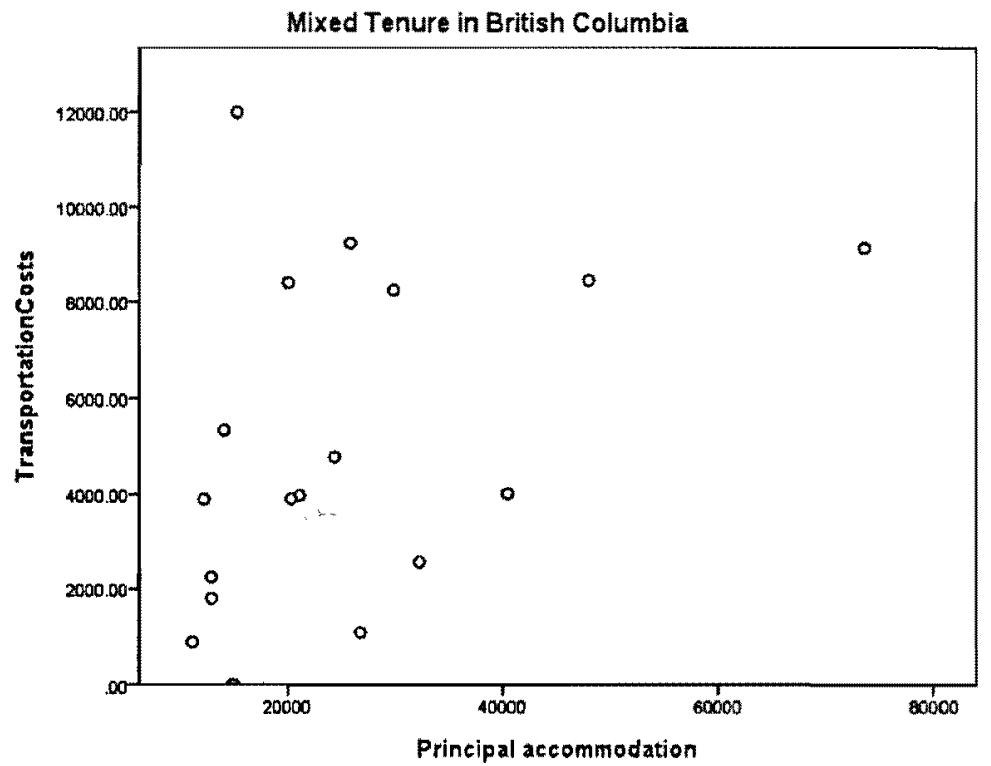


Appendix R Households by Dwelling Type in British Columbia
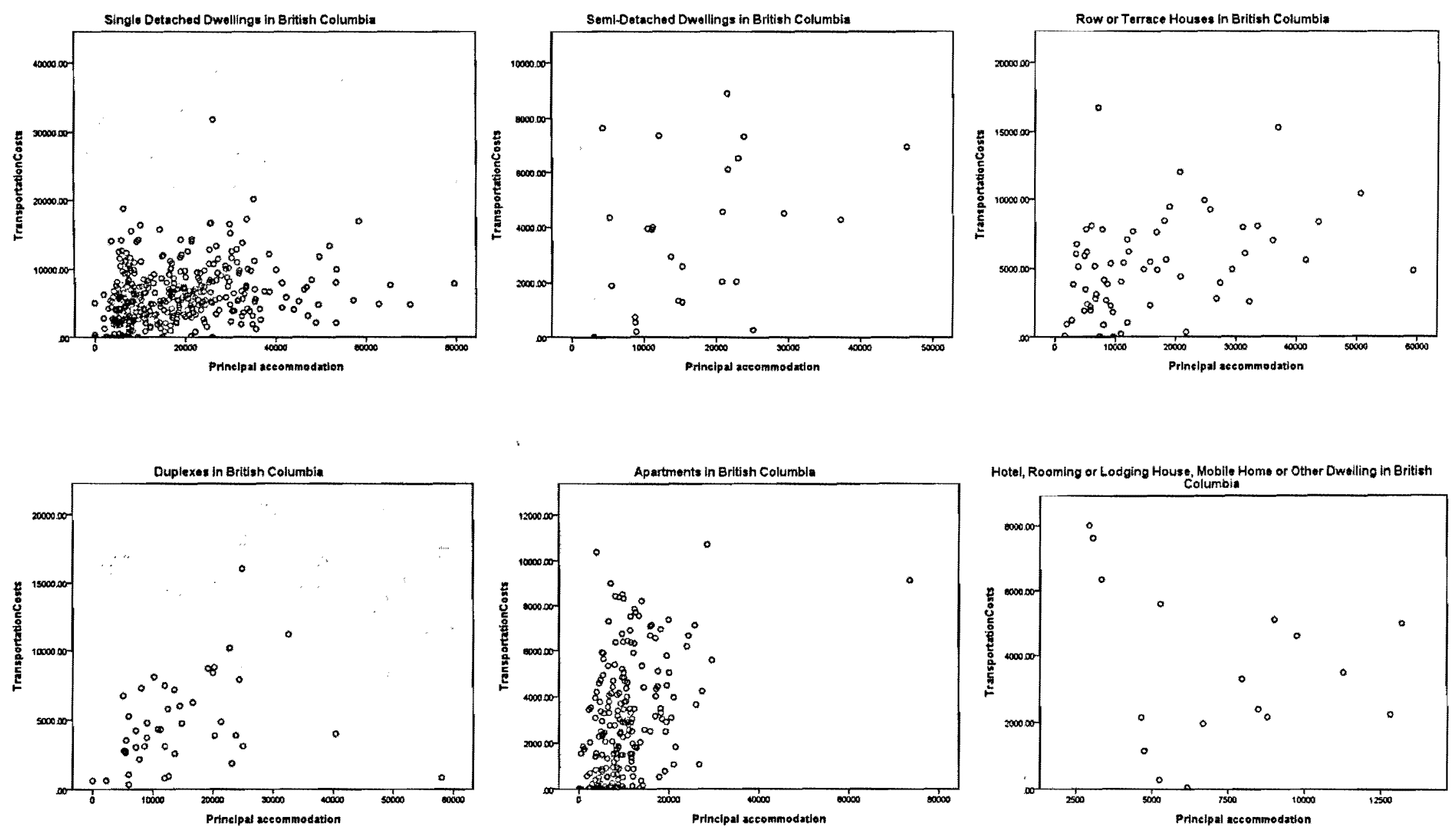
Appendix S Household by Size in British Columbia
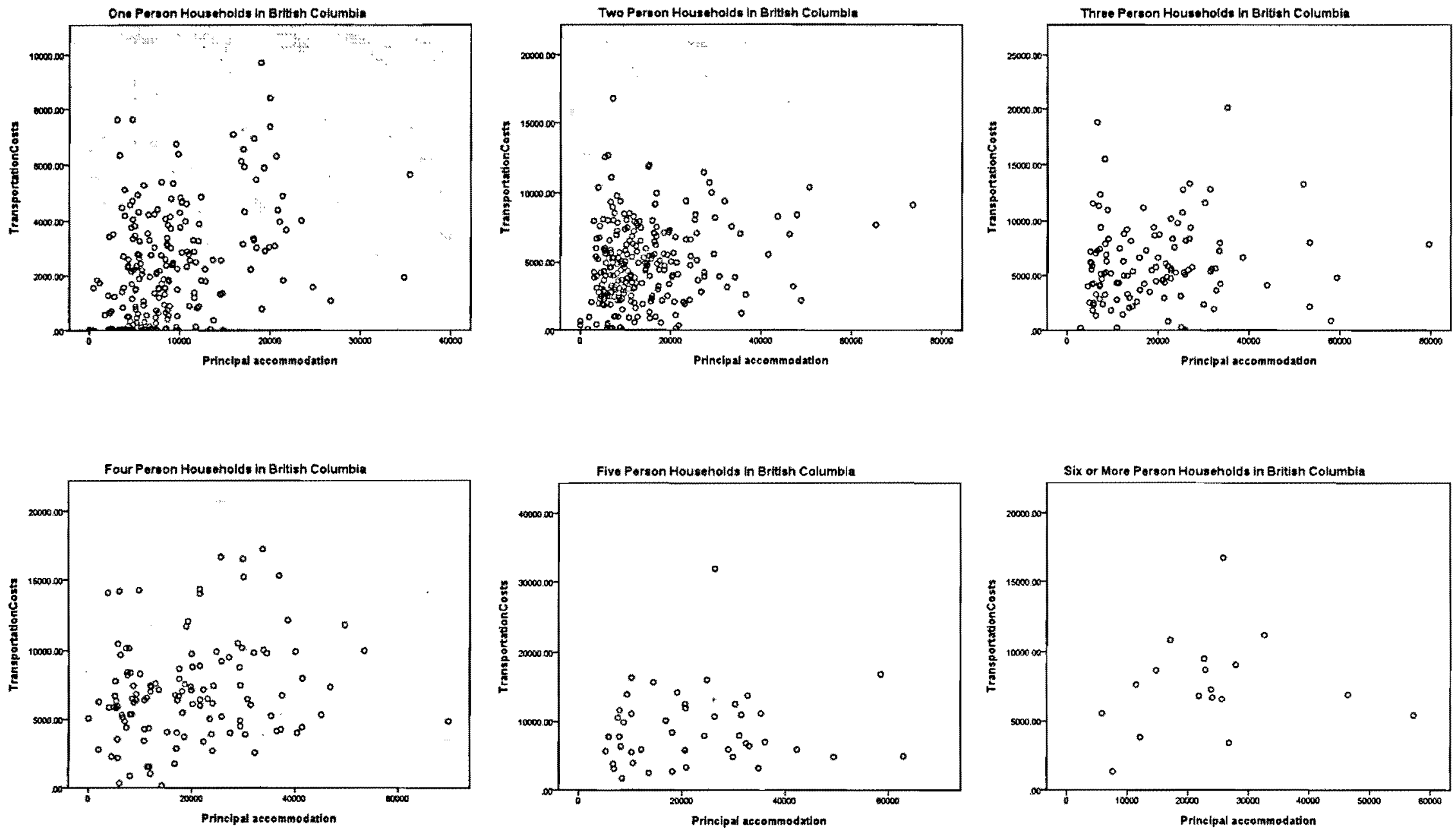
Appendix T Household Types in British Columbia
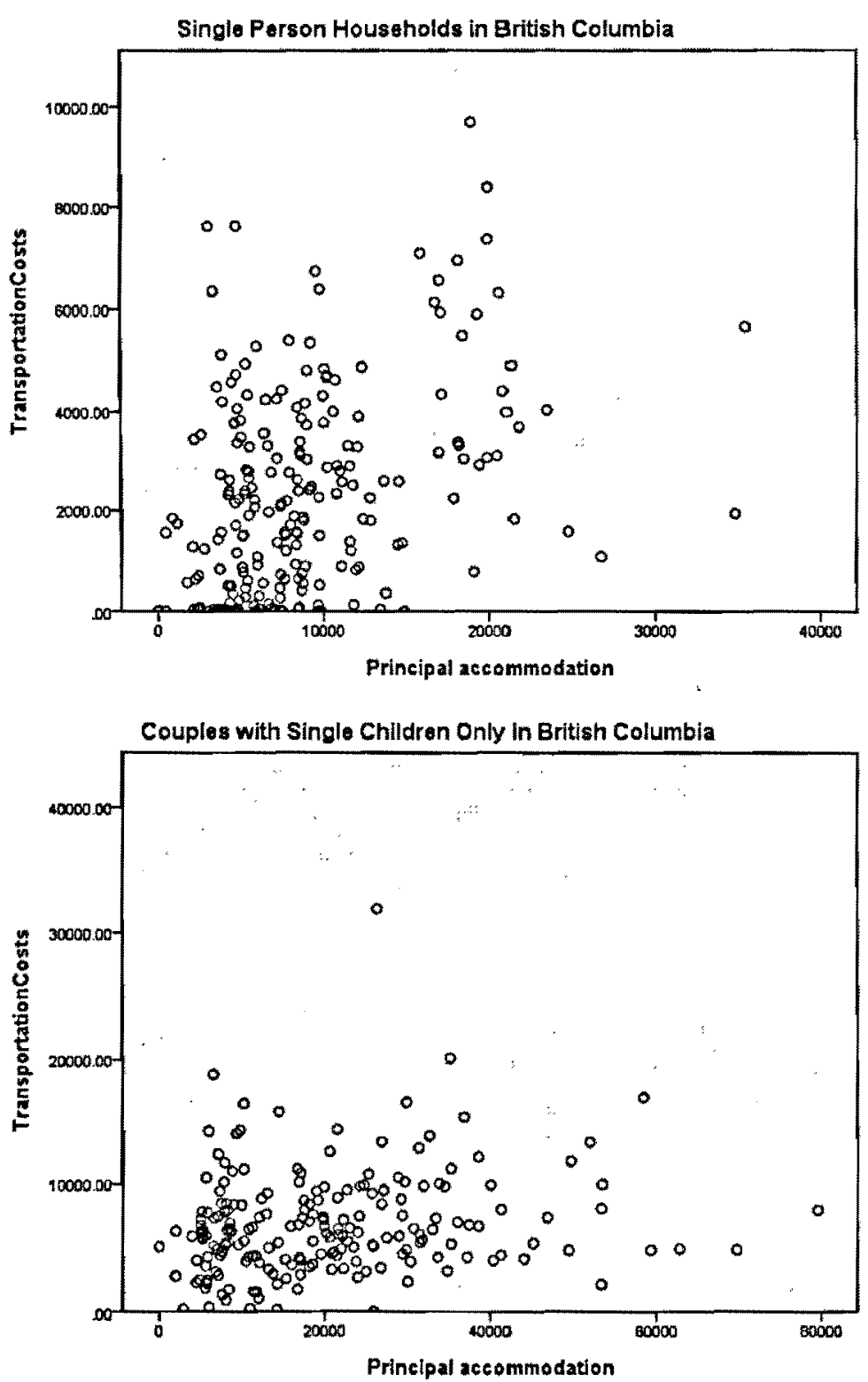
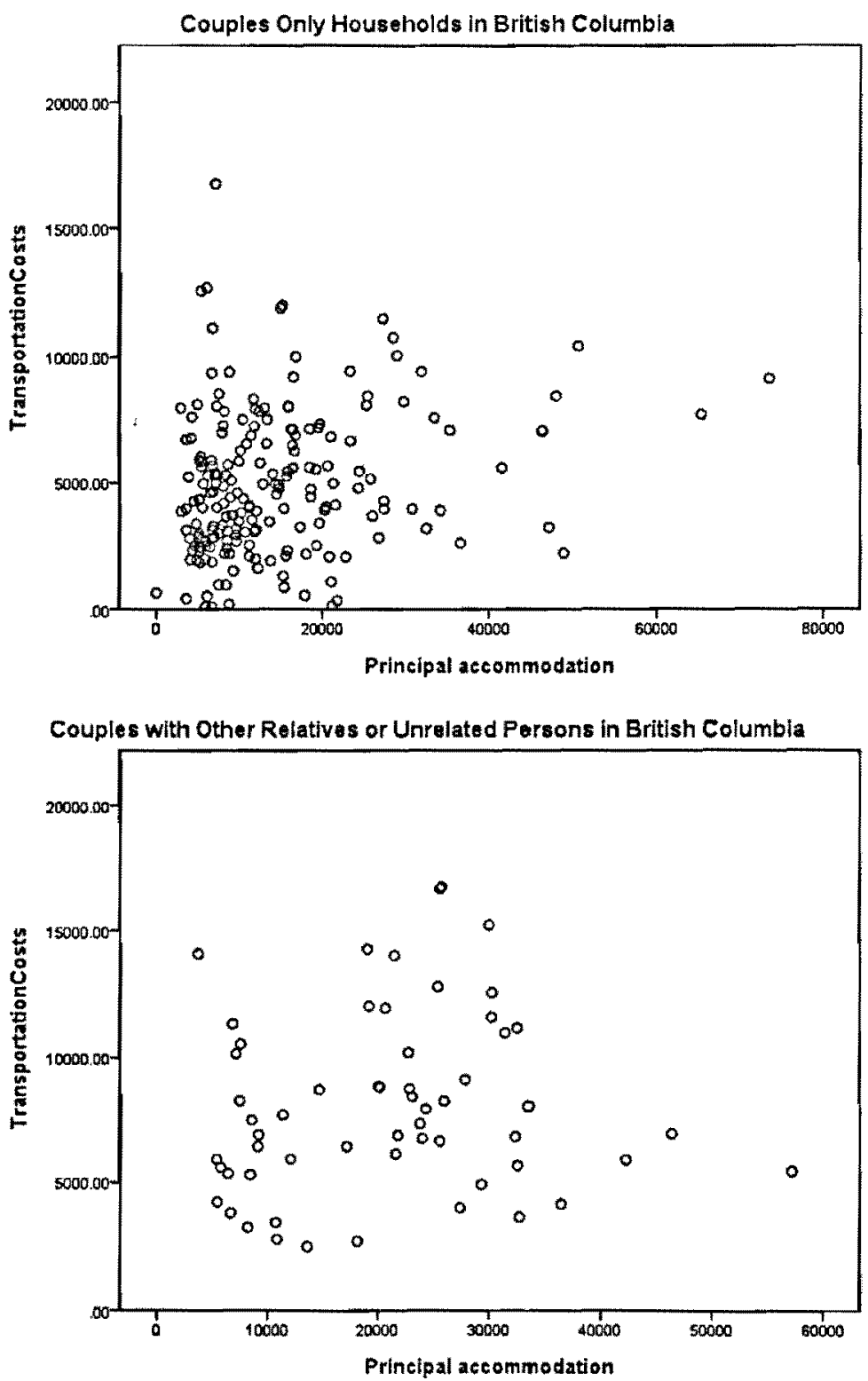

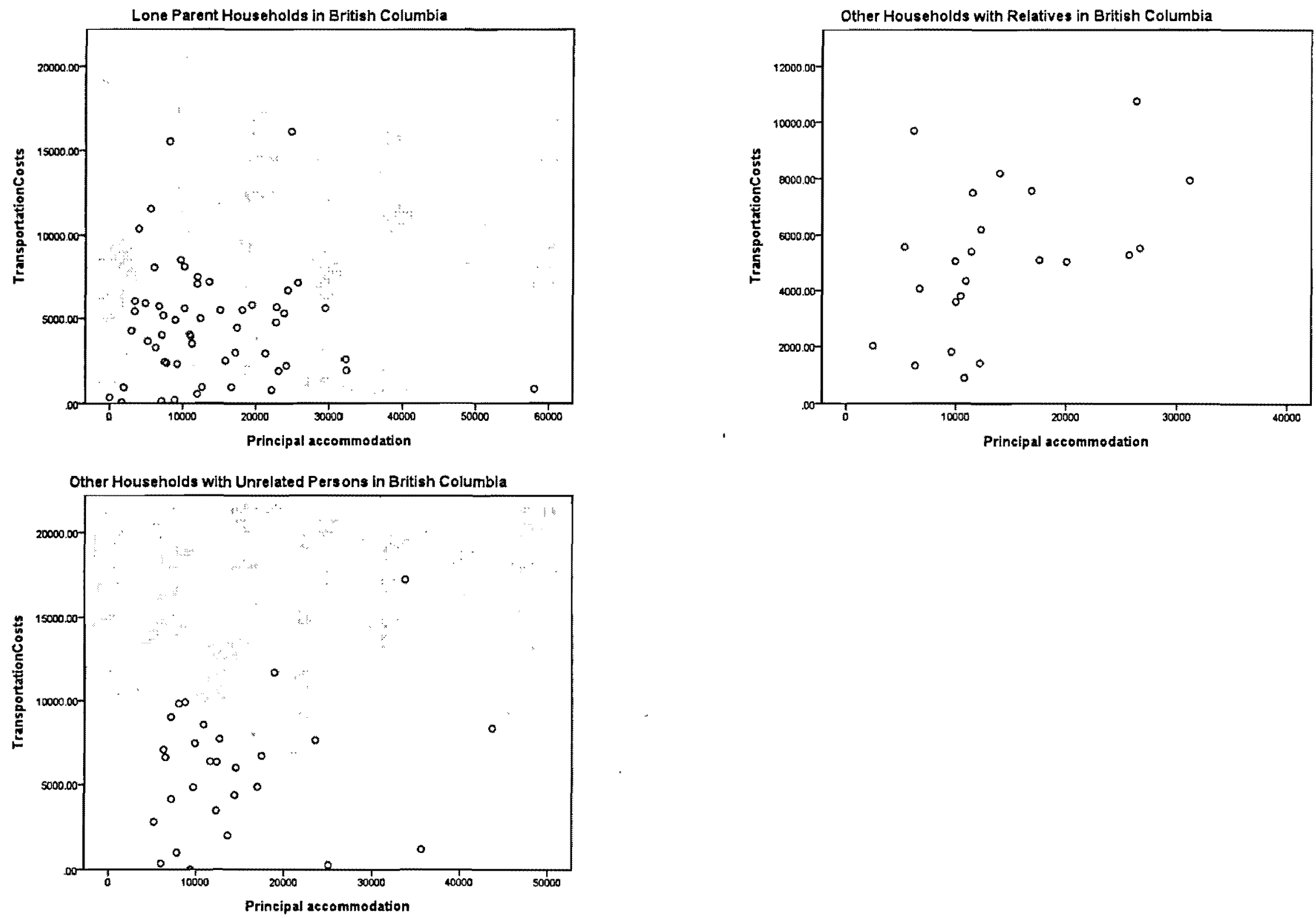


\section{Works Cited}

Blaine, J.C.D. "The Dynamics of Transportation." Transportation Journal (1965): Owned prior, accessed through Brock University, 2008.

Bhat, Chandra R., Sudeshna Sen, and Naveen Eluru. "The impact of demographics, built environment attributes, vehicle characteristics, and gasoline prices on household vehicle holdings and use." Transportation Research: Part B 43.1 (2009): 1-18. Academic Search Premier. EBSCO. Web. 3 Mar. 2011.

Champion, A. G. "A Changing Demographic Regime and Evolving Polycentric Urban Regions: Consequences for the Size, Composition and Distribution of City Populations." Urban Studies (Routledge) 38.4 (2001): 657-677.Academic Search Premier. EBSCO. Web. 3 Mar. 2011. Haas, P, Makarewicz, C, Benedict, A, Sanchez, T, Dawkins, C, Housing and transportation cost trade-offs and burdens of working households in 28 metros, Center for Neighborhood Technology, July, 2006

James E. Chapman, et al. "Stepping towards causation: Do built environments or neighborhood and travel preferences explain physical activity, driving, and obesity?" Social Science \& Medicine 65.9 (2007): 1898-1914.Academic Search Premier. EBSCO. Web. 3 Mar. 2011. Ewert, Ulf Christian, and Alexia Prskawetz. "Can Regional Variations in Demographic Structure Explain Regional Differences in Car Use? A Case Study in Austria." Population \& Environment 23.3 (2002): 315-345. Academic Search Premier. EBSCO. Web. 3 Mar. 2011. Finkel, Ed. "New index Tracks Housing and Transportation Costs." Planning 72.8 (2006): 54. Academic Search Premier. EBSCO. Web. 12 Dec. 2010.

Glazebrook, Garry. "Taking the Con Out of Convenience: The True Cost of Transport Modes in Sydney." Urban Policy \& Research 27.1 (2009): 5-24. Academic Search Premier. EBSCO. Web. 12 Dec. 2010. 
Miller, Eric J., and Amer Shalaby. "Evolution of Personal Travel in Toronto Area and Policy Implications." Journal of Urban Planning \& Development 129.1 (2003): 1. Academic Search Premier. EBSCO. Web. 13 Dec. 2010.

Miller, E.J., M.J. Roorda, M. Haider and A. Mohammadian, "Empirical Analysis of Travel and Housing Costs in the Greater Toronto Area",Transportation Research Record, Journal of the Transportation Research Board, No. 1898, 2004, pp. 191-201.

Shalaby, Amer S. "A simplified approach for the historical analysis of urban person travel." Canadian Journal of Civil Engineering 29.5 (2002): 702-712. Academic Search Premier. EBSCO. Web. 13 Dec. 2010.

Statistics Canada. "Survey of Household Spending in 2008".

Statistics Canada. "Average household expenditures, by province and territory" 2008. http://www40.statcan.ca/101/cst01/famil16a-eng.htm Taylor, Brian D., and Alexandra Tassiello Norton. "Paying for Transportation." Journal of Planning Literature 24.1 (2009): 22-36. Academic Search Premier. EBSCO. Web. 13 Dec. 2010. Van Geenhuizen, Marina, and Peter Nijkamp. "Coping with uncertainty: an expedition into the field of new transport technology." Transportation Planning \& Technology 26.6 (2003): 449467. Academic Search Premier. EBSCO. Web. 13 Dec. 2010.

Weisbrod, G., Ben-Akiva, M. and Lerman, S. (1980) Tradeoffs in residential location decisions: Transportation versus other factors. Transportation Policy and Decision-Making, Vol.1, No.1 